

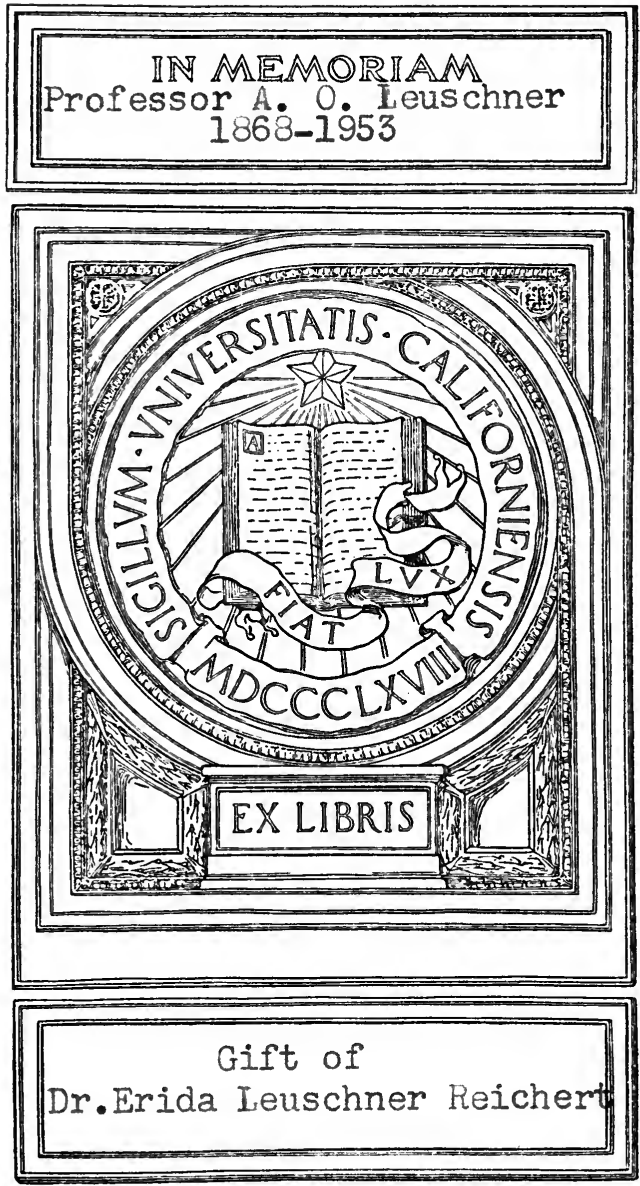
A.tenschnes 



\section{EARTH EVOLUTION AND ITS FACIAL EXPRESSION}


WILLIAM HERBERT HOBBS

Characteristics of Existing Glaciers

Earth Features and Their Meaning

Simple Directions for the Determination of the Common Minerals and Rocks 



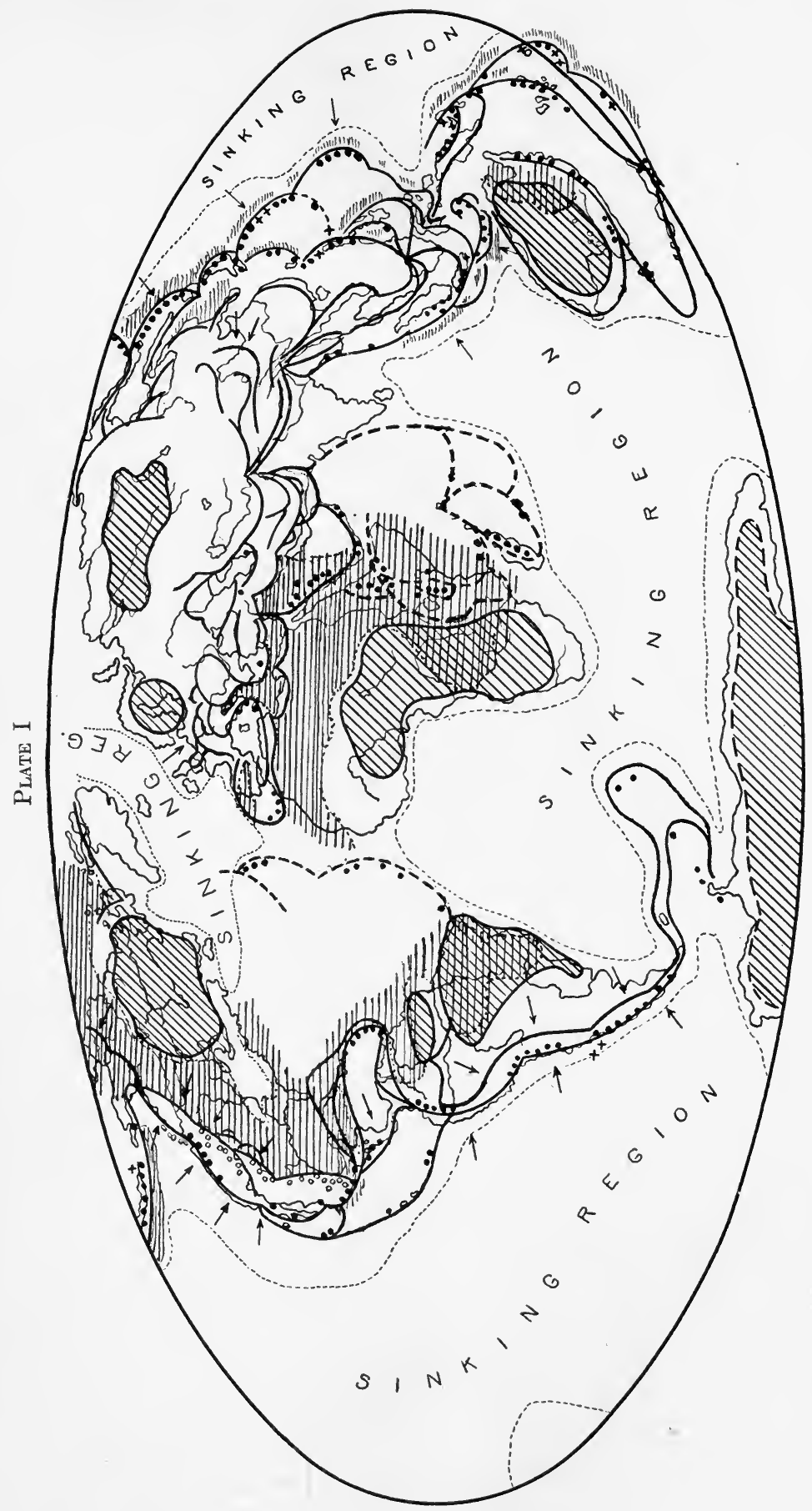

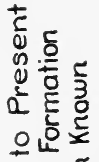

วิ造选

\&으

पू के

는 한

ป造

02

ㄴํำ

iิ ठิ

这文

$(\because \vdots$

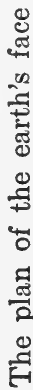

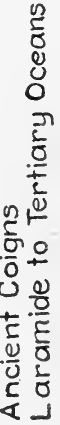

S. 


\section{EARTH EVOLUTION A ND ITS \\ FACIAL EXPRESSION}

BY

\section{WILLIAM HERBERT, HOBBS} Professor of Geology and Director of the Geotogical Laboratory,
University of Michigan

Author of "Earthquakes, an Introduction to Seismic Geology";

"Characteristics of Existing Glaciers"; "Earth F'eatures

and Their Meaning"; "The World War and Its

Consequences"; "Leonard Wood, Ad-

ministrator, Soldier, and

Citizen," etc.

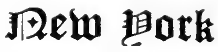 \\ THE MACMILLAN COMPANY \\ 1921}


PRINTED IN THE UNITED STATES OF AMERICA

Coprright, 1921,

BY THE MACMILLAN COMPANY.

Set up and printed. Published October, 1921.

RIP. 6IN. LIB.

ACCESS. NO. $4644-15$

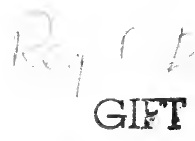

Press of

J. J. Little \& Ives Company

New York, U. S. A. 


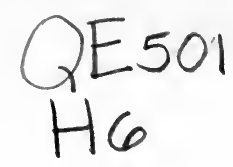

\section{CHASE SALMON OSBORN}

One time Regent of the University of Michigan and Governor of the State, lover of Nature and versed in the secrets of the wild-life of field and forest, discoverer of great iron deposits, world traveller, lion hunter, editor, author and friend, this volume is dedicated by

The Author 



\section{INTRODUCTION}

To the structure of the body of scientific thought the nearest parallel is found in that of a well constructed edifice, with each part so designed as to fit accurately and without intervening space to other parts in its neighborhood, and all reared upon a common foundation. Were our knowledge perfect this ideal might be realized and no harm result, but we are accustomed to erect the superstructure over the accepted fundamental tenets of the science of our time, just as though history did not warn us that on the long upward course of the growth of knowledge the dominant thought of one period has often been abandoned in the next.

A survey of the past will show that the great advances in scientific thought have followed the discovery of new points of view, viewpoints which have offered new outlooks over the field ahead. Such a survey will tell us further that our mistakes in the past have arisen very largely because from each new coign of vantage, as it has been attained, the attempt has been not only to adjust the nearer field, but to sketch in strong lines the hazy distances as well as the nearer landscape. Better than tarrying so long at each station would it have been to advance over the field already mapped so as to secure a better viewpoint and bring up the distant horizon. Our étapes have been both too long and much too infrequent.

If the foundation of our structure is to be removed, it becomes necessary for the superstructure to be taken down, and, before rebuilding, such material as can be used from the old structure must be fitted to the form of the new basement.

Far more than is generally supposed, the recent abanvii 
donment of the nebular hypothesis to account for the origin of the universe, must carry with it a rewriting of our science. This is particularly true of geology for all that concerns seismology, volcanology and the whole subject of the growth of continents and mountains. The present time is therefore an opportune one for supplying to these fields a discussion which can be harmonized with the newer viewpoint and be independent of the abandoned groundwork of the science.

For nearly a score of years the author has concerned himself with certain of the fundamental questions of theoretical geology which are in one way or another connected with the growth of continents and mountains, and these studies moving along different directions were converging upon important results when they were interrupted by the distractions of the World War. Following the war period the studies were resumed, and some of the results have already been communicated in technical papers read at recent meetings of the Geological Society of America, the American Philosophical Society, and the Association of American Geographers. To the non-technical reader with a background of general reading only, the matter of these papers must be presented in somewhat different language, and much must be brought in from those earlier studies which are now scattered through technical journals both in this country and abroad, but which have paved the way for the later conclusions.

The author feels that he has perhaps now reached that age and experience where he is warranted in venturing out. upon a sea never accurately charted, where there have been many shipwrecks, and where there certainly will be many more before the most closely guarded secrets of the universe have been disclosed. He cannot hope to succeed where many others have failed unless he avails himself of the knowledge and experience gained in the past, while refusing to be hampered by any rules which seem to him to be based on 
false premises, however exalted may be the esteem in which . they are generally held.

The views of the evolution of our planet and the expression of its face, as these are set forth in the following pages, s.re in noteworthy degree a result of the independent study and well considered opinion of one who has already for thirty-five years given his attention to many phases of geological study. If they supply a viewpoint which can be made of service in mapping a new area of the great unknown, the object of their publication will have been secured.

Ann Arbor, Michigan, April 4, 1921. 



\section{CONTENTS}

CIIAPTER PAGE

INTRODUCTION . . . . . . . . . . . . . . .

I The Nebular Hypothhis and the Supposed Earth Crust • 1

II The Nature of the Earth's Interior * • • • . • • • 12

III The Source of Volcanic Lava . . . . . . . . . . 28

iV The Origin of Pockets of Molten Rock . . . . • . . . 44

Y The Depth of the Fold Pockets . . . . . . . . . . 63

VI The Vapors and Gases of Lava . • • • • • • • . . 72

ViI The Changes of Figure which the Earth Has Passed

Through . . . . . . . . . . . . . . . 81

ViII The Present Regions of Rapid Change . . . . . . . 95

IX The Contrasted Aspects of the Earth's Face . . . . . 111

X The Migrational Movements of the Surface . . . . . 119

XI The Patterns of the Facial Wrinkles and Their Meaning 135

Xil The Design of the Fracture Marquetry - • . • • . 152

XiII Lava Composition in Relation to Earth Physiognomy • 159

XiV Earth Theories in Retrospect . . . . . . . . . . 174 



\section{LIST OF ILLUSTRATIONS}

I (Frontispiece), Plan of the earth's face . . . . . . . .

II Effects of earth movements upon rails and bridges. 1, Rails buckled in approach to bridge, earthquake of 1891, Japan. 2, Nagara Gawa railroad bridge dropped into river but with all spans still connested, earthquake of 1891, Japan . . .

III Effects of earth movements upon rails. 1, Buckled rails, earthquake of 1888, Charleston, S. C. 2, Buckled rails, earthquake of 1879 , India . . . . . . . . . . . . . . .

IV Effects of earth movements upon rails and bridges. 1, Buckled rails, earthquake of 1906, California. 2, Bridge with girder underridden by abutment, earthquake of 1891, Japan . . .

V Effects of earth movements upon bridges and curbing. 1, Distorted abutment, Salinos river bridge, earthquake of 1906, California. 2, Buckled curbing, earthquake of 1906, California

VI Experiment for producing arcuate wrinkles by underturning of plastic Canada balsam during the contraction of a rubber sheet. 1, The apparatus. 2, The effect on the balsam . .

1 Diagram to illustrate a theory of the constitution of the earth

2 Diagrams to illustrate the different theories concerning the earth's interior . . . . . . . . . . . . . .

3 Structures of meteorites. 1, olivine crystal from the Pallas iron on which the oval areas are the only remnants of the crystal faces; 2 , chondrule with veinlets of rock glass; 3 , chondrules with eccentric spherulitic structure

4. Composite rock diagrams for the main classes of rocks . . 35

5 Sample diagrams to show the composition of lavas . . . . 36

6 Sample diagrams to show the composition of individual shales and slates . . . . . . . . . . . . . . .

7 Maps to indicate how a characteristic petrographic province may develop from local fusions of shale . . . . . . .

8 Diagrams to illustrate the effects of folding and of faulting of different types upon the superficial area of the earth . .

9 Section across a normal fault showing how it may increase the surface area of the earth 
FIGURE

10 Diagrams to show how block faulting may yield a lava chamber . . . . . . . . . • . . • • • . .

11 Model showing the crushing of a shale-like member beneath an anticline of a competent limestone-like formation . . .

12 Diagram to show position of a magma chamber formed under a competent formation in an anticline

13 Successive diagrams showing the manner of contraction of a magma chamber through continuation of the folding process with expulsion of the lava through a conduit . . . .

14 Contrasted views of the origin of laccolites . . . . . . 54

15 Section of the laccolite of the La Plata Mts. (after Holmes) . $\quad 55$

16 Contrasted views concerning the origin of laccolites . . . . 55

17 Map of the laccolites of the Judith Mts., which are formed beneath a competent limestone formation (after Weed and Pirsson)

18 Map of the Black Hills laccolites formed beneath a dome in competent limestone (after Jaggar) . . . . . .

19 Section of the laccolite of the La Sal Mts. with included shale (after Holmes) . . . . . . . . . . . . . .

20 Generalized section across the Andes showing compressed laccolitic domes (after Steinmann)

21 Map of the arcs at the front of the Rocky Mts. with their cores of intrusive igneous material . . . . . . .

22 Manner of formation of a syncline in a marble slab under its own weight alone

23 Anticlines produced by the pressure (shove) of a continental glacier. A, in Queenstown shale on Lake Ontario (Kindle); $\mathrm{B}$, in coal bed in Illinois (Sauer) . . . . . . . . .

24 Sections of tilted coral reefs on islands of the Dutch East Indies (after Verbeek)

25 Successive positions of anticline forming in a rising island arc (after Brouwer)

26 Manner of formation of elevated reef at front and of barrier reef at back of a developing anticline arc . . . . .

27 A tetrahedron with bulging faces and truncated angles to bring out its contrasted antipodal relationships

28 The earth expressed as a departure of the spheroid toward the tetrahedron

29 Series of polyhedrons from the sphere with greatest volume to the tetrahedron with least volume

30 Generalized expression of the earth's figure at the close of the first great era of geological history . . . . . . . 
31 The continents at the end of the Paleozoic era (after Arldt) .

32 Generalized expression of the earth's figure at the end of the second great era of geological history . . . . . . .

33 Generalized expression of the present figure of the earth . . 93

34 Map on Mollweide projection to show the distribution of historic earthquakes for the land areas of the globe (after de Montessus)

35 Map on Mollweide projection to show the distribution of world earthquakes for both the land and water areas of the globe (after Seismol. Comm. Brit. Assoc. Adv. Sci.)

36 Diagrams to show the form of the sections of rising arcs (after Staff)

37 The arcs of eastern Asia with their fore-troughs and their fringes of volcanoes

38 Map of the western hemisphere to show the continental shelves (from Andree's Handatlas)

39 Map of the region about the Arctic Ocean

40 The form of coast terraces . . . . . . . . . . . 103

41 Terraced coasts of recent uplift about the Pacific Ocean . . 104

42 The dated step in a coastal staircase in Alaska (after Tarr and Martin)

43 Diagram to illustrate the relation of a progressive settlement of the ocean floor sector to the elevated Pacific strands .

44 Diagrams to explain the paradoxical compression within rising mountains

45 Comparison of raised terraces, Pacific and Atlantic (from data by Tangier-Smith and Barrell)

46 A sample geological section showing in shading the part removed by erosion

47 Map to show the contrasted aspects of the earth's face within the Eastern Hemisphere (after Suess)

48 Map to show the relation of the Permian mountains of Europe to those of America

49 Earlier (incorrect) and later (correct) methods of representing mountain systems upon maps

50 Map of Java with fore-troughs (after Brouwer but with additional data)

51 Geological section across Java (after Verbeek and Fennema)

52 Sketch map of southern Europe to show the position of the "Bohemian Mass" with reference to the mountain arcs.. 
FIGURE

53 Sketch map of southern Asia to show the position of the "Indian Mass" with reference to the mountain arcs

54 Diagrams to illustrate the contrasted views of Suess and the author concerning the direction of the active thrust in mountain evolution. A, surf; B, Suess view; C, author's view.

55 Contrast of opposing views concerning the origin of arcuate mountains

56 Mountain arcs of the northern hemisphere formed at the close of the Paleozoic era

57 Map of the arcs of the eastern United States with geological sections

58 Geological section across the eastern base of the Andes in northwestern Argentina (after Palmer)

59 Geological sections of the Rocky Mts. facing the Laramide Sea . . . . . . . . . . . . . . . . .

60 Map of the Cretaceous Ocean and the Rocky Mts. which rose about its border . . . . . . . . . . . . .

61 Arcs of the Pacific Coast of the United States as indicated by strike directions

62 Sketch-map of the great depression formed in Pleistocene time, between the Rocky Mts. and the Pacific Coast of the United States, together with sections

63 Contrasted views of Suess and Hobbs concerning the origin of the mountain arcs of the Western United States . . . .

64 Plan of an arc rising in a reëntrant of the coast . . . . . 136

65 Plan of an arc rising off an obtuse salient of the coast . . 136

66 Plans of arcs in two successive stages formed off an acute salient of the coast . . . . . . . . . . . . . . .

67 Sections of rising arcs . . . . . . . . . . . . .

68 Sketch-map of the arcs formed off the eastern front of the Rocky Mts. (based on map by U. S. Geological Survey) .

69 Series of sections through the Bighorn Range showing inward underthrust in the center combined with inward overthrust on the flanks (Darton's sections) . . . . . .

70 Series of sections showing the partly buried arc of the Black Hills with its inward underthrust in the center combined with inward overthrust on the flanks (Darton's sections) .

71 Schematic diagram to show plan of formation of rising arc at the front of a lense of sediments

72 Sketch map to show the arcs of southeastern Asia . . . 147

73 Virgation of the arcs of the Andes at the Peruvian knots (after Karsten's geological map) 
74 Samples of the pattern of the fracture network of the earth. (A), the network itself ; 1 , rectangular system of master joints; 3 . escarpment due to master joints in sub-equally spaced series near Cayuga Lake, N. Y.; 4, joint system with composite groups and a patterned fault system evolved from the joint system by displacement, Norwegian coast; 9 , ground plan of the system with pattern changing its position; 10, fractures produced in block of an elastic substance (moulder's wax) by compression from the ends. (B), Imprint of the fracture pattern in the earth's face; 2 , patterned drainage lines of an area in Connecticut; 5, the gigantic fault-rifts of East Central Africa; 6, the fracture controlled course of a canyon in Swedish Lapland; 7, "Checker-board" drainage of Western Ontario; 8, map of the Batoka Gorge below the Victoria Falls, Rhodesia, controlled by the fracture network; 11, drainage of the "dolomites" of the Tyrol controlled by the fracture pattern . . . . . . : . . . . . .

75 Map showing the fracture network of the Island of Celebes in its relation to the fold lines (after Ahlburg) . . . . .

76 Sketch-map showing the prevailing direction of joint fissures in Southern South America (after Windhausen) . . . . .

77 Schematic diagram to illustrate the relation of the fractures to the growing anticline . . . . . . . . . . . .

78 Comparison of the average composition of Pacific, Predazzic and Atlantic rock types with the average igneous rock . .

79 Comparative composition of andesitic, basaltic and feldspathoidal lavas

80 Section across the arc of the New Hebrides (after Mawson) .

81 Map of the world on Mollweide projection to show the distribution of andesitic and non-andesitic lava types . .

82 Idealized successive sections to illustrate splitting of original Andesitic volcanic magmas into basaltic or feldspathoid types

83 Diagrams to illustrate the average composition of arcuate mountain (fold) lava and fault-block lava in comparison with the average magma

84 Diagram to illustrate a manner of formation of magma chambers by block faulting. 



\section{EARTH EVOLUTION \\ AND ITS \\ FACIAL EXPRESSION}





\section{EARTH EVOLUTION AND ITS FACIAL EXPRESSION}

\section{CHAPTER I \\ THE NEBULAR HYPOTHESIS AND THE SUPPOSED EARTH CRUST}

THE early belief that volcanic lava is the material composing a fused earth interior is to be ascribed to the frequent exudation of lava from the active vents distributed about the Mediterranean region, within which region our civilization developed. The continuation of this doctrine to the philosophies of medieval and modern times is not difficult to understand. It was but natural that primitive peoples face to face with the awe-inspiring phenomena of a volcanic eruption should assume that the liquid lava is issuing through an opening in a solid crust above a liquid reservoir.

As early as 611 B.C. Anaximander assumed the earth and the stars to be made from liquid material, and Heraclitus a century later made fire the original element. About the same time Pythagoras held the earth to be a sphere completing a rotation about central fires once every twenty-four hours. Near the beginning of the Christian era the geographer Strabo accounted for the islands which suddenly appeared in the Mediterranean as raised up by internal fires. Seneca made volcanoes the definite canals which connect the internal fires with the surface of the earth.

The supposed circumscribed limits of the early world gave necessarily an idea of universality to the doctrine of internal heat for the earth, and with the extension of geographical 
exploration the discovery of many new active volcanic vents served only to confirm the earlier impression.

The lands bordering upon the Mediterranean are even more in the realm of earthquakes than they are of volcanoes, and at the time of all heavy earthquakes water spurts up from the ground under pressure to produce fountains, much as would the water which enters the hold of a ship through an opened seam. It is probably this which largely explains the Babylonian conception of waters below as well as above the earth, with the earth floating as a disk upon the waters below. This view, taken over by the Hebrews, seemed naturally to be confirmed when their limited territory was found to be extended outward by the seas. The conception of bodies of water within the earth's crust was a rather general one up to the time of Descartes.

The Cartesian philosophy which forms the basis of our modern doctrines, contains in it the germ of the Nebular Hypothesis, which was later developed by Kant, Laplace, Herschel, and others-an hypothesis which is primarily responsible for fastening upon us not only a false conception of the nature of our planet, but an erroneous notion of the origin of lava as well. Descartes' contribution to the Nebular Hypothesis was his idea of tourbillons or vortices in nebulous matter about the sun and stars, and in his conception of the earth planet he combined the ideas which had grown up from the observation of both earthquakes and volcanoes. To a core of glowing hot matter he added local substrata of water which he believed to be a result of infall attended with local elevation of the earth's crust which was composed of rock. These water substrata thus naturally came to be in the neighborhood of the mountain ranges, within which neighborhood the earthquake fountains are seen.

The three types of matter according to Descartes, who flourished from 1596 to 1650 , were the glowing and hot, the transparent, and the opaque and cold; and in his discussion 
of their relationships the idea of a surface crust above molten nuclei is clearly brought out. The opaque sun spots through enlargement and coming together could form a crust which would extinguish the glowing orb, as he believed had already occurred in the case of the earth; whereas by diminishing they could increase the sum of the sun's luminosity. In his view the extinguished earth had lost its own vortex and been drawn into that of the sun.

The great mathematician Leibnitz (1646-1716), who followed Descartes, like him conceived the earth to have been a glowing mass that had gone out for lack of further combustible materials, leaving a "glass-like" crust enveloped in an original universal ocean derived from condensation of the enveloping vapors, and by an outer envelope of air.

Swedenborg (1688-1772) developed the Cartesian vortices somewhat further in the direction of the later Nebular Hypothesis, through making them break up by withdrawal of matter from the poles into an equatorial ring, within which ring planets and satellites developed.

In the latter half of the eighteenth century was reached the culminating period for theories of the universe. The Nebular Hypothesis now took on the definite form which it has held almost to the present day. Quite independently, it would seem, a great philosopher, Kant; a great mathematical physicist, Laplace; and an astronomer-observer, Sir William Herschel, arrived at similar, even if not identical, conceptions of the universe. Kant, the pioneer of the group, built his theory upon the framework of the Cartesian conception, adopting also some ideas from the atomistic school of Greek philosophers, more especially Democritus and Lucretius, the latter his favorite classical author. To his great contemporary Newton, who it should be remembered conceived of the earth as having a molten interior, Kant owed much; but he built his theory largely upon analogy, going out from the equatorial rings of the planet Saturn. We have here one of those amazing instances so common 
in the evolution of thought, in which the altogether exceptional rather than the common has been taken as a type. To the uniformity of direction of motion of the planets and their satellites within their orbits, at the time believed to be universal, Kant added as the basis of his theory important contributions of his own-he clearly set forth the necessary diminution in the earth's rotational velocity because of the friction of tidal currents, and in 1765 he introduced the idea that the contraction of the sun's mass must develop a high temperature within it.

The development of his theory early in Kant's career and at a time when he had not become known as a great philosopher, explains why its publication brought comparatively little response. Eight years later, in 1763, he introduced into his philosophy a summary of the hypothesis under the title, "The Only Possible Argument for a Demonstration of the Existence of God," in which summary is to be found the best outline of his theory. He conceived of discreet and cold solid particles scattered uniformly in space, which particles under the action of the law of gravitation came together about centers or nuclei to produce rotating vortices. These upon further condensation flattened about the poles of their rotating axes as the velocity of rotation increased, and with further acceleration of the velocity, equatorial rings-like those of Saturn-were thrown off. From these in turn planets were formed which rotated within orbits which had the positions of the earlier rings.

The great French savant Laplace developed the Nebular Hypothesis independently and much more definitely than Kant had done. Instead of being a philosopher he was an astronomer and physicist, and was rated as the greatest of all scientists after Newton. Yet, curiously enough, the famous Laplacian theory of the origin of the universe, which for more than a century has been a foundation stone of modern science, was apparently not a conception carefully 
elaborated and rigorously tested, as were his other studies, but it was thrown off as an undigested afterthought which might perhaps be important. In the fourteen massive tomes which make up Laplace's complete works, his nebular hypothesis takes up only ten pages of a note- "Note VII and Last"- appended to the volume treating the Exposition du Système du Monde.

Looking back over the intervening century in the light of the recent studies which have convincingly proven the fallacies of the Laplacian conception, we are able to see how its success is to be largely ascribed to the fame of the author of the Mécanique Celeste, a work never rivaled in its field, of which indeed it has been said that any one of its twenty-four parts would have made the reputation of a man of science. It is this eminence of Laplace as a scientist which has carried his theory to general acceptance quite regardless of its inherent inadequacy.

Unlike Kant, who thought of the original world stuff as discrete solid particles, really meteoric matter, Laplace conceived space to be filled with a highly heated and extremely tenuous, gaseous nebula; though it may be doubted if he knew of the actual existence of such matter, which his contemporary, Sir William Herschel, was the first to describe. This hot gaseous matter in Laplace's conception extended beyond the orbit of the most remote planet and had the form of a rotating spheroid, its intense heat being accountable for the high rarefaction. Loss of heat through radiation into space brought about continuing refrigeration and resultant contraction with the inevitable effect of an accelerated rotational velocity. This ever increasing velocity produced centrifugal effects which reduced the polar or axial diameter of the gaseous spheroid at the same time that it produced swelling within the equatorial zone. Eventually this centrifugal force would become equal to the centripetal force of gravitation for those portions of the gaseous mass which were most remote from the center, 
and the outer equatorial portion of the spheroid could in consequence contract no further. The concentrated force of gravitation being however for any portion of the mass inversely as the square of the distance from the center, the central core would continue to shrink and so draw away from the outer equatorial belt. This belt would therefore separate from the parent mass as an equatorial ring. Here the analogy with the unique rings of Saturn is apparent.

With continuation of the refrigerating process, other rings would separate in turn, all subject to rotation in the same sense as the residual spheroidal nucleus. Irregularity of distribution of matter within each ring would in time cause a drawing together within the ring about some center so as to form a rotating spheroid or planet whose translational motion would be within the space of the former ring as an orbit, and would have its own rotational velocity in the same clockwise (or counter-clockwise) direction as that of the orbital movement. Further refrigeration would result in the formation of rings and later spheroids (satellites), or rings only as in Saturn, in the rare event of perfect regularity of distribution of density of the nebulous matter.

Thus far the Laplacian theory provides for systems of spheroids of gaseous matter having relative positions and orbital and rotational motions in general similar to those of our solar system. But the earth and its sister planets being solids, at least at the surface, it is necessary to carry the process farther. Continued refrigeration is invoked to produce, first, nuclei of liquid spheroids surrounded by a vaporous envelope; and, still later the refrigeration is further called upon to accomplish the next transformation, namely, that from a liquid to a solid crust-from molten magma to solid rock such as we know under the term igneous rock.

It is at this point that a vitally important step, but one which has been little considered, has been taken in devel- 
oping the conception. At the time Laplace's hypothesis was promulgated it was not known whether solid igneous rock or its liquid equivalent possessed the greater density. That discovery is a very recent one, and in the absence of exact knowledge it is quite evident that analogy determined the form which the hypothesis was to take. This analogy was to be made, not with a general but with an exceptional case, as had already been true of the misleading analogy with Saturn's rings in the matter of the separated equatorial sections of the nebula. It is a fact full of significance that Descartes, Newton, Kant, Laplace and Herschel, all of whom played a part in the building of this "Grandest Conception of the Universe," were residents of northern Europe where water is in the winter season habitually seen to congeal into a surface crust, and they all alike held the view that the earth had a crust of solid rock which floated upon a central core of its liquid equivalent. Of bodies known in both the solid and liquid conditions, water is the one concerning which it was definitely known that the density in the solid form was less than in the liquid. This common and well known substance whose transformation from one state of aggregation to the other had so often been observed that the knowledge had come to be an unconscious acquisition, thus had with them all the force of an axiom.

Had the Nebular Hypothesis been put forth by men who had long been residents of a tropical or sub-tropical country, it is extremely unlikely that this fatal slip would have been made, and it is certain that science would in that event have enormously profited. Of this vitally important subject we shall have more to say in the next chapter. It is pertinent now to consider especially the ways in which the hypothesis as a whole has been found wanting and is being abandoned for another conception. This though still in the realm of hypothesis rather than theory, is at least not open to the serious objections to the Laplacian form of the Nebular Hypothesis, so long accepted on the 
prestige of its sponsor without either serious questioning or scientific testing.

It is hardly necessary for our purpose to here supply the details of the various modifications which the Nebular Hypothesis has since undergone in the hands of Sir William Herschel, Sir George Darwin, and Sir Norman Lockyer. All of them alike followed Kant rather than Laplace in conceiving the cosmic matter out of which the system of the universe has been made, to be in the main not gaseous, but discrete solid particles. It cannot be claimed, however, that any of them in any important way threw discredit upon the idea of a once molten interior of the earth.

It was Chamberlin's recent and elaborate studies in association with the astronomer Moulton which first brought into clear relief the fallacies of a hypothesis which had been supported as much for the grandeur of its conception as by reason of the enormous prestige of its author. First of all, it was to be noted that observational astronomy has shown that the dominant type of nebula is not a ring but a spiral, the analogy of the rings of Saturn having been responsible for this fundamental error in the Nebular Hypothesis. Only a few ring nebulae are known, whereas 120,000 spiral nebulae have already been observed, and the total number must be very much greater. Other considerations are no less cogent as objections to the Kant-Laplace hypothesis.

It is a firmly established law of mechanics that the moment of momentum of any freely rotating or revolving system, when not influenced by outside forces, remains constant without regard to changes which may go on within the system. Starting from this premise, Moulton has shown that if the solar system were converted into a gaseous spheroid large enough to fill all the space within the orbit of the most distant planet, and if this gaseous matter were distributed in density as is required by the known laws of gases; and if, further, the system were given the moment 
of momentum now possessed by the solar system; the gaseous spheroid would not have a velocity of rotation sufficient to detach a ring of matter from its equator, as is required by the Kant-Laplace hypothesis; and, moreover, it could not acquire such a velocity until it had contracted well within the orbit of Mercury and close to the sun. To have detached the ring from which Neptune is conceived to have evolved would have required a moment of momentum 200 times greater than it now possesses, and to have detached the earth ring a moment of momentum 1800 times as great as that available would have been required.

No less striking discrepancies are discovered when the masses of the planets are subjected to scrutiny. The mass of the ring from which Jupiter and its satellites were assumed to have been formed, must have been less than onetenth of one percent of the original nebula, though it must have carried off ninety-five percent of the total moment of momentum. Together, the planets with their satellites contain about one seven-hundredth of the matter of the system, though they possess more than ninety-seven percent of its moment of momentum. The inner planets should, moreover, possess the greater masses, but this is not the case. The sun should have a great velocity with a corresponding eccentricity. As a matter of fact, it rotates very slowly, and its eccentricity is inappreciable. Furthermore, its plane of rotation varies by seven degrees from that of the average rotation plane of its system.

The planetesimal hypothesis which Chamberlin has after long years of study put forward to replace the Kant-Laplace hypothesis of the universe, conceives the material from which the system developed to be innumerable bodies, each having the magnitude of sand or dust, and that these revolve about a central gaseous mass as the planets do today. As far back as the hypothesis carries us, this material was conceived to be kept dispersed by the centrifugal acceleration due to the rotation of the system. The evolution of 
the solar system has been a process of aggregation or assemblage of scattered material. Gases, while not excluded from the hypothesis, play but a subordinate rôle. This hypothesis is today the one which has the most general support among students of earth science, and the KantLaplace hypothesis is already relegated to the category of schemes which, under the rigid test of searching investigations, have been discredited and abandoned.

For our purpose it is chiefly of interest to note that the planetesimal hypothesis, unlike its predecessors, does not call for an originally molten planet and thus provide a ready-made source of volcanic materials-lava, gases, and vapors.

It has been necessary to go over this somewhat extended treatment of the field of cosmogeny in order to clear the decks, as it were, for an untrammeled scientific discussion of the development of continents and mountains. Our concern has been chiefly with those sections of the theories of the universe which relate to the earth planet, but students who are especially interested in the larger problems of the origin of the sun and stars, should not fail to review the Harvard studies upon the age of the stars, and the conclusions which Professor Campbell has formed from them. We are yet far from a complete solution of this grandest of all undiscovered secrets, the origin of the universe, but the efforts to penetrate beyond the veil will go on unceasingly. Galileo said truly: "There are such profound secrets and such lofty conceptions that the night labors and the researches of hundreds and yet hundreds of the keenest minds, in investigations extending over thousands of years, would not penetrate them, and the delight of searching and finding endures forever."

\section{LITERATURE}

KARL von Zittel. History of geology and paleontology to the end of the 19 th century, translated by M. Ogilvie-Gordon, London, 1901, introduction and chapter I. 
Immanuel Kant. Gesammelte Schriften, vol. 1, and vol. 2, div. II, sec. 7 (Cosmogonie).

William Hastie. Kant cosmogeny, etc. Glasgow, 1900, p. 205.

Pierre Simon Laplace. Exposition du Système du Monde, complete works, 6th (French) edition, vol. 6, Note VII and Last, pp. 498-509.

Svante Arrhenius. Die Vorstellung vom Weltgebaüde im Wandel der Zeiten, Das Werden der Welten, Neue Folge, Leipzig, 1900, p. 191.

Sir RoBerT S. BaLl. The earth's beginning, Appleton, New York, 1902, p. 384.

T. C. Chamberlin and R. D. Salisbury. Geology, Holt, New York, 1906, vol. 2, chaps. I-II.

Thomas Chrowder Chamberlin. The Origin of the Earth, University of Chicago Press, 1916, p. 271.

W. W. CAM PBELL. The evolution of the stars and the formation of the earth, Scientific Monthly, vol. 1, 1915, pp. 1-17, 177-194, 238-255.

JosEPH BARRELL. The origin of the earth, chapter I of Lull's, The evolution of the earth and its inhabitants, Yale University press, 1918, pp. 1-44.

T. C. Chamberins. An attempt to test the nebular hypothesis by the relations of masses and momenta, Jour. Geol., vol. 8, 1900, pp. 58-73.

T. C. Chamberlin. Diastrophism and the formative processes, XI, Selective segregation of material in the formation of the earth and its neighbors, ibid., vol. 28, 1920, pp. 126-157. 


\section{CHAPTER II}

\section{THE NATURE OF THE EARTH'S INTERIOR}

Abandonment of the Kant-Laplace hypothesis has, as we have seen, brought release from an error fundamental in our science. The almost blind acceptance of its requirements reacted as much upon the advance of geological science as it did upon astronomy. Now released from the thrall of a scientific dogma, geologists are no longer under the obligation to regard volcanic lava as derived from a fluid earth interior.

While no such blind adherence to the planetesimal hypothesis is to be observed, that hypothesis has been tested insofar as it is possible to apply tests. It is of considerable interest to examine its requirements in respect to the quantity of heat which should be developed in the growing earth and the consequent physical condition of the planet's interior portion.

The theory requires that heat be developed both from impact of the discrete bodies which arrive at the earth's surface, and from increasing compression under the action of gravity so soon as the nucleus has attained considerable proportions. The discrete particles are conceived to be moving in space within elliptical orbits and with orbital velocities measured in the same clockwise direction, and, further, with these orbital velocities varying in different parts of the orbit. Collisions can occur only through one body overtaking another whenever orbits become tangent. The effective velocity of impact must be, therefore, not the sum, but the difference, of the velocities of the two bodies on impact, and at most but a few miles per second.

At the present time the earth planet is shrinking faster 
than it grows, and though an estimated twenty million meteoric bodies reach its surface from space during each year, no less than a billion years would be required to increase the earth's diameter from this source by a single inch. If we assume that one hundred tons of meteoric matter reach the earth's surface daily at an average velocity relative to the earth which may be even as high as twenty miles per second, this material could supply in a year only as much heat as the sun is giving us in one-tenth of a second. These values can, however, be but a fraction of those which were characteristic of the planet during its early stages of relatively rapid growth from the infall of meteoric bodies.

A fact the significance of which seems to have been generally overlooked by students of the subject, is that the meteoric material which now comes to the earth is almost exclusively the less dense stony meteorite, whereas the density of the earth as a whole shows clearly that the greater portion of the centrosphere, or inner core of the earth, must be made up of the dense nickel-iron meteoric matter. The density of the earth as a whole as determined by astronomers is 5.6, and the average density of the known meteorites, predominantly irons, is about the same, that of the analyzed meteorites being 5.57. The meteoric stones, on the other hand, have an average density of about 3.6, which is somewhat higher than that of the earth's outermost shell, which is usually given as 2.67 . This outermost shell of the earth, unlike any lower ones, as we believe, contains a considerable proportion of sediments-shales, sandstones and limestones-which show the reaction with the earth's atmosphere. The proportions of shale, sandstone and limestone have been estimated by Clarke to be respectively as 19, 3, and 1, and the corresponding densities may be assumed to be 2.6, 2.41, and 2.7. With the two former, quartz or silica is the dominating constituent, with a specific gravity of 2.56. Could we secure an average for 
the shell underlying the sedimentary strata-probably less than ten kilometers in thickness-it would undoubtedly be considerably heavier and probably not far from the average value 3.6 determined for meteoric stones.

Nothing that we know concerning the compressibility of rock materials, and especially that of the metals, would warrant us in thinking that the large margin of density of the earth as a whole above that of its surface portion, can be accounted for through compression. The metals are regarded as almost incompressible, and the known density of the meteoric irons and stone-irons makes it easy to account for earth density without recourse to compression. If, in addition, we have in mind the revelations of the spectroscope concerning the unity of the visible universe as regards constituent chemical materials, and, further, that of all the chemical elements known iron, nickel and cobalt are the only ones which possess magnetic properties; the strong earth magnetism is compelling in forcing us to the conclusion that the earth's interior is, like that of its neighboring meteoric bodies, in large part composed of these three elements as they are found associated in meteoric irons.

Students of earth physics have been put to great difficulties to explain this arrangement of denser and lighter matter within the earth without at the same time assuming that the whole mass was once molten and subject to the convectional currents due to differences of gravity within liquids. Chamberlin's explanation, which assumes the existence of radial threads of molten material throughout the mass, is not easy to accept. To the writer it has seemed that an explanation may be looked for in a wholly different direction.

It seems generally to have been overlooked, at least so far as its significance is concerned, that of the total of about 350 known "falls" of meteorites, all but ten have been of meteoric stone. Though only ten meteoric irons have been seen to fall and been collected, yet the larger number of 
specimens gathered in museums are of meteoric irons. This is, of course, for the reason that meteoric stones generally bear such close resemblance to our terrestrial rocks, as to attract little attention and to be distinguishable only by the expert. They are hence little likely to be discovered. Meteoric irons, on the other hand, are unusual in appearance, are heavy and with somewhat remarkable surface features which attract attention, and they moreover are apt to arouse hopes of finding valuable ores of iron in the vicinity. They are thus likely to be collected and submitted to examination by experts. Their predominance in meteorite collections has largely obscured the fact that they have seldom been seen to fall, and we are entitled to suppose that if meteoric stones were as easy to discover as are meteoric irons, our museums instead of containing only 750 known falls and finds would possess about 94,000 of which only about one in 35 would be irons.

The only conclusion possible to draw from the above is that in the earlier stages of earth history the reverse condition has obtained, and that the heavy meteoric bodies having already been swept up to produce the nickel-iron interior of the earth, few of these, but only the lighter masses, remain dispersed in the space which is invaded by our planet.

So soon as we examine into the conditions of collision within the nebula above described, having due regard to the fact that the irons have on the average a density nearly three times that of the stones, we see why such a differentiation as appears to have taken place should have occurred. Collisions can occur only by overtake, as already explained, and there are two significant cases. If an iron meteorite overtakes a stone one, it loses acceleration as it imparts increased acceleration to the stone by a much larger amount than the acceleration of an iron would be increased through collision with a stone following it. Such increases of acceleration in favor of the lighter stones would be sufficient after 
one or more collisions to change the orbits of the lighter bodies from the form of the original ellipse to one of greater eccentricity or to that of the hyperbola, thus bringing about their dispersal.*

Let $v$ and $v^{\prime}$ be the corresponding velocities after impact of the two bodies, and let $\mathrm{m}$ and $\mathrm{m}^{\prime}$, and $\mathrm{u}$ and $\mathrm{u}^{\prime}$ be their masses and velocities respectively before impact occurs. The equations for finding $v$ and $v^{\prime}$ are:

$$
\mathrm{mv}+\mathrm{m}^{\prime} \mathrm{v}^{\prime}=\mathrm{mu}+\mathrm{m}^{\prime} \mathrm{u}^{\prime}
$$

From these we derive

$$
\begin{aligned}
& \mathrm{v}=\frac{\mathrm{u}\left(\mathrm{m}-\mathrm{v}-\mathrm{e} \mathrm{m}^{\prime}\right)}{\mathrm{m}+\mathrm{m}^{\prime}}+\frac{\mathrm{u}\left(\mathrm{u}-\mathrm{u}^{\prime}\right)}{\mathrm{u}^{\prime} \mathrm{m}^{\prime}(1+\mathrm{e})} \\
& \mathrm{mu}(1+\mathrm{e})+\mathrm{u}^{\prime} \mathrm{m}+\mathrm{m}^{\prime} \\
& \left.\mathrm{v}+\mathrm{m}^{\prime}-\mathrm{me}\right) \\
& \mathrm{m}+\mathrm{m}^{\prime}
\end{aligned}
$$

If now, $\mathrm{m}$ be made equal to 1 and $\mathrm{m}^{\prime}$ equal to 3 , the relative masses of meteoric stones and meteoric nickel-iron, we obtain from the above equations :

$$
\begin{aligned}
& \text { (With } \mathrm{e}=0) \\
& (\text { With } \mathrm{e}=1)
\end{aligned} \quad\left\{\begin{array}{c}
\mathrm{v}=\mathrm{v}^{\prime}=\mathrm{u} / 4+3 \mathrm{u}^{\prime} / 4 \\
\mathrm{v}^{\prime}=\mathrm{u} / 2+\mathrm{u} / 2+\mathrm{u}^{\prime} / 2
\end{array}\right.
$$

Now as $u^{\prime}$ is necessarily less than $u, v^{\prime}$ is also less than $u$, i.e., the orbit of $\mathrm{m}^{\prime}$, since it is elliptic would generally remain so.

For the opposite case we will now assume that $\mathrm{m}$ equals 3 and $\mathrm{m}^{\prime}$ equals 1. By a similar process we now derive:

$$
\begin{aligned}
(\text { With } \mathrm{e}=0) & \mathrm{v}=3 \mathrm{u} / 4+\mathrm{u}^{\prime} / 4 \\
(\text { With } \mathrm{e}=1) & \left\{\begin{array}{c}
\mathrm{v}=\mathrm{u} / 2+\mathrm{u}^{\prime} / 2 \\
\mathrm{v}^{\prime}=3 \mathrm{u} / 2-\mathrm{u}^{\prime} / 2
\end{array}\right.
\end{aligned}
$$

In the above $\mathrm{v}^{\prime}$ is greater than $\mathrm{u}$, therefore the orbit of $\mathrm{m}^{\prime}$ will change from the ellipse to the hyperbola either after one or a number of impacts.

The additional case may be considered for the case where the bodies coming into collision are either both of stone or both of iron. Let $\mathrm{m}$ equal 1 and $\mathrm{m}^{\prime}$ equal 1 , we then derive

$$
\begin{array}{ll}
(\text { With } \mathrm{e}=0) & \mathrm{v}=\mathrm{v}^{\prime}=\left(\mathrm{u}+\mathrm{u}^{\prime}\right) / 2 \\
(\text { With } \mathrm{e}=1) & \left\{\begin{aligned}
\mathrm{v} & =\mathrm{u}^{\prime} \\
\mathrm{v}^{\prime} & =\mathrm{u}
\end{aligned}\right.
\end{array}
$$

As a consequence of the above, the order of aggregation of meteoric matter should be: a, material corresponding to

*At my request, Dr. Peter Field, Professor of Mathematics in the College of Engineering of the University of Michigan, has supplied the simple equations which demonstrate these facts. 
the average meteoric matter dispersed in the space which is traversed by the growing planet; $b$, material with an increasingly large proportion of nickel-iron; and, c, meteoric stone derived from that more widely dispersed and traveling either elliptic orbits of high eccentricity or on hyperbolic orbits after the other material has been largely gathered in.

If this has been the history of our planet, it should possess an inner core of only moderate density and elasticity, an intermediate thick shell of maximum density (nickel-iron), and an outer shell of relatively low density and elasticity, which shell is enveloped in a mere skin or rind of relatively light material containing a large proportion of rock sediments.

But we may go somewhat further upon the basis of researches made of velocities of earthquake waves transmitted through the mass of the earth. As early as 1906 Dr. R. D. Oldham brought out the fact that when earthquake waves travel within a central core of the earth which he computed to have a radius two-fifths that of the whole, their observed rate of propagation is noticeably slowed down. Eight years later much more reliable data were published by Gutenberg covering the velocities of the "first" and "second" phases of earthquake waves traversing the earth's mass. The velocities of transmission for these harmonic motions as determined by Gutenberg were as follows:

$\begin{array}{ccc}\begin{array}{c}\text { Depth in } \\ \text { Kilometers }\end{array} & \begin{array}{c}\text { "First" Phase } \\ \text { Km. Sec. }\end{array} & \begin{array}{c}\text { "Second" Phase } \\ \text { Km. Sec. }\end{array} \\ 0 & 7.17 & 4.01 \\ 1200 & 11.80 & 6.59 \\ 1700 & 12.22 & 6.86 \\ 2450 & \{13.29 & 7.32 \\ & 13.15 & 7.20 \\ 2900 & \left\{\begin{array}{r}13.15 \\ 8.50\end{array}\right. \\ 6370 & 11.10 & 7.20 \\ & & 6.72\end{array}$


Gutenberg concludes: "The earth consists, therefore, of a core $(\mathrm{r}=3500 \mathrm{~km})$ and of a mantle whose constitution at three places.undergoes changes, though not abruptly." There thus appears to be strong evidence that matter of a different composition from that which envelops it occupies this inner core. Under our theory of selective dispersion of meteoric matter within the swarm about the growing earth

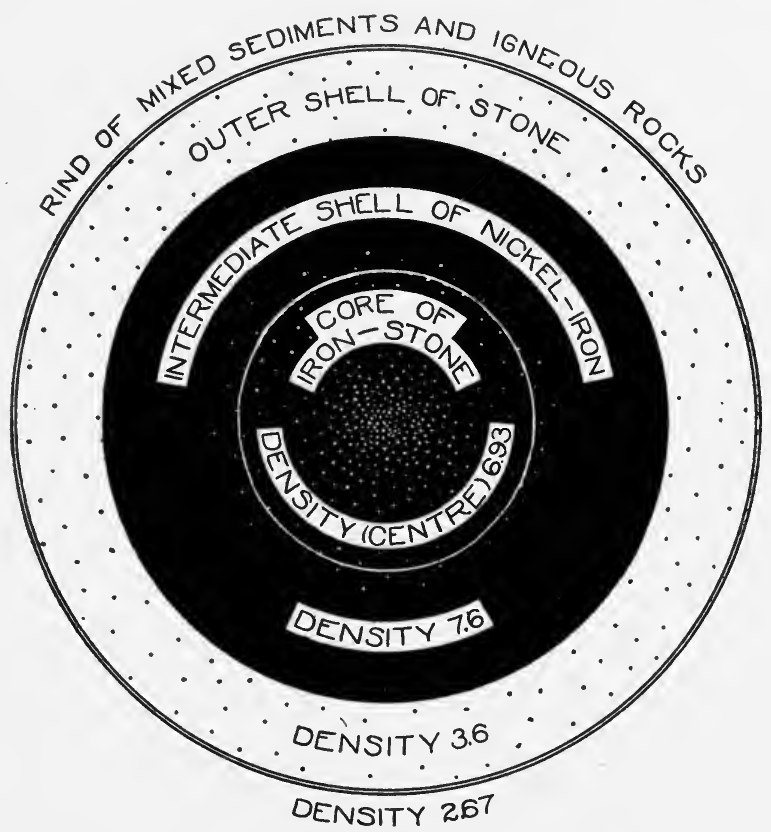

FIg. 1.-Diagram to illustrate a theory of the constitution of the earth

nucleus, there should develop a core of average meteoric material, or meteoric stone-iron; this should be surrounded by a shell of meteoric nickel-iron, the accretion of which took place after the lighter meteoric stone had been largely thrown into elliptic orbits of high eccentricity or into hyperbolic orbits, and an outer shell built up slowly from those meteoric stones which later return from their eccentric elliptical orbits or arrive from other nuclei along hyperbolic orbits. Under this theory the several shells should be ar- 
ranged as in fig. 1, which seems to be entirely in harmony with Gutenberg's observations. If we assume the central core to have a radius of $3500 \mathrm{~km}$. and an average density of 6.9 , the intermediate shell of nickel-iron a thickness of 1700 $\mathrm{km}$. and a density of 7.6, and the outer shell of meteoric stone a thickness of $1200 \mathrm{~km}$. and an average density of 3.6, the whole should have the density of the earth planet, namely 5.6. A survey of the different theories of earth constitution may be obtained from fig. 2 .

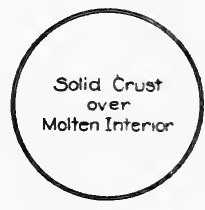

Kant-Loploce $18^{\text {th }}$ Cent.

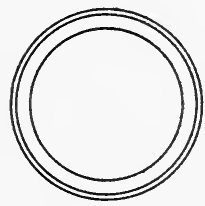

Benndorf 1906

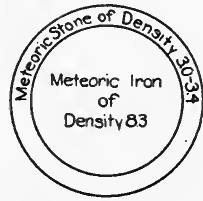

Wiechert 1897

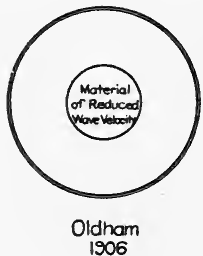

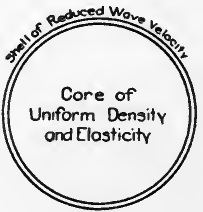

Milne 1903

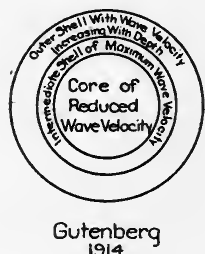

1914

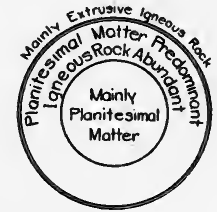

Chamberlin 1905

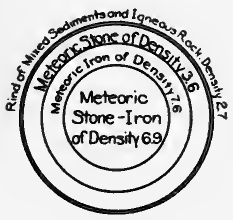

Hobbs

FIg. 2.-Diagrams to illustrate the different theories concerning the earth's interior

That a group of terrestrial rocks of igneous origin which in density approach nearest to the meteoric stones, should also be nearest them in composition and in some of its subdivisions be considered to overlap the series of stony meteorites, is certainly a fact of great importance. No less than five sub-groups of igneous rocks are common to terrestrial and celestial rock series. The presumption that the terrestrial examples of these types have an origin deeper down in the earth's mass than their less basic relatives, and that those of celestial origin belonged to the near-surface portions of the bodies from which they came, seems to be supported by all the facts known to us. The simplest ex- 
planation for the differences which we observe in relatively large meteorites is one that regards them as the detached parts of disrupted planetary bodies, of which the stones represent the surface and near-surface fragments, and the irons the deeper interior portions. Inasmuch as free oxygen has not been found in meteorites, and original water but doubtfully, the bodies from which they came are naturally regarded as much smaller than the earth of the present time -in fact too small to hold an atmosphere. It is probably for this reason that no rocks at all resembling our sedimentary series, such as sandstones, shales, and limestones, have reached us from space.

Even though the meteoric irons reveal no structure to indicate a former fused condition, meteoric stones not infrequently contain rock glass such as is common in our terrestrial igneous rocks of surface origin, and this is generally taken to indicate a rapid congelation from a fused condition. Quite local surface melting from infall of meteoric bodies is quite in harmony with our conception of the mechanics of the process.

More and more since the promulgation of the planetesimal theory of earth evolution, the tendency has been to regard meteoric bodies which reach the earth's surface as constituting "world stuff," though in its larger masses this material probably supplies examples of parts of disrupted bodies which have been themselves aggregated out of planetesimals. In a quite recent paper Chamberlin has stated emphatically: "The masses of meteorites and their methods of infall throw a flood of light on the sizes and modes of infall of the planetesimals, for by this interpretation they are bodies of like origin and like general conditions."

Both in the internal and in the surface structure of meteorites there are found indications of the distinctly limited size of planetesimal bodies. Insofar as the meteorites are not composed of nickel-iron, 90 percent of them 
are possessed of a nodular or chondritic structure, the chondrules being found imbedded in fragmentary material, and the surfaces of these nodules like those of the surrounding fragments generally giving evidence of impact and attrition (a-c, Fig. 3). The large individual crystals of meteoric minerals, such as the olivines in the famous Pallas iron, present a peculiar rounded surface with all crystal angles removed as though by attrition, and with only the central portions of the crystal faces still remaining (at left in fig. 3). The chondrules which are such a dominant feature of the meteoric stones seldom exceed an inch in diameter.

"It does not appear safe," says Professor Chamberlin, "to assume that even the innermost core of the earth took
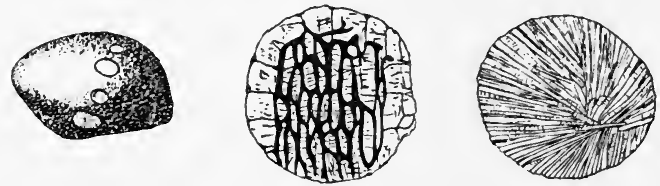

FIG. 3.-Structures of meteorites. Left, olivine crystal from the Pallas iron on which the oval areas are the only remnants of the crystal faces; middle, chondrule with veinlets of rock glass; right, chondrules with eccentric spherulitic structure

on the liquid state, even at the outset, or, if it did, that it long retained that state, however congenial to inherited predilections such an inference may be." In all but the earlier stages the planetesimal bodies would have to plunge through an envelope of satellites and an atmosphere, and today the velocity of meteorites approaching the earth's surface is first counteracted until reduced to zero by air resistance, after which the bodies fall by gravity and attain such moderate velocities only that they are generally but little imbedded in the earth. Cases are upon record where meteorites falling upon thin ice have not even broken it. Chamberlin has assumed that the earth during all stages of its final shaping was an elastic solid of high rigidity.

Since it is not possible to assert positively that the generation of heat from infall of meteorites of large size may 
not in some stages at least of the process of planet growth have been sufficient to fuse the entire mass, it becomes important to consider the problem in what manner congelation would have taken place under such circumstances. Barrell has indeed modified the Chamberlin hypothesis to the extent of assuming the infall of bodies of planetary dimensions, instead of those having a magnitude not much greater than sand or dust; and such infall, he says, would be "sufficient to produce in the growing earth a molten state at least in the outer portions." Against such a conclusion is the fact that the chondrules or largest fragments in meteorites seldom exceed an inch in diameter.

Kelvin, as long ago as 1878, had considered this subject and reached the conclusion that "the heat caused by the collisions, after the earth had grown to be anything approaching its present size, would be far more than sufficient to melt the material falling in."

As was pointed out in the last chapter, the general belief in the formation of a crust over the supposed molten globe is at bottom based upon analogy with the formation of ice upon the surface of water. The first to examine the subject scientifically with a view to determining whether solid igneous rock or its molten equivalent has the greater density was Bischoff, who in 1843 made simple and indecisive experiments which led him to believe that three types of igneous rock-basalt, granite, and trachyte-are on the average about ten percent denser than the corresponding melts. Kelvin, in 1876, in his "Review of Evidence Regarding the Physical Condition of the Earth," wrote, "I may say, with some degree of confidence, that whatever may be the relative densities of rock, solid and melted, at or about the temperature of liquefaction, it is, I think, probable that cold solid rock is denser than hot melted rock," and he adds in another place, speaking of the earth, "As soon as the surface began to freeze, and to freeze in sufficient quantity not to be floated up by mere superficial solidified foam, the 
mass of the rock would fall downwards towards the center. More would then solidify at the surface. This also would fall down, and the same thing would go on again and again."

In an elaborate series of difficult experiments, Barus in 1893 first proved that basalt, the commonest type of volcanic rock, contracts on passing into the solid from the liquid state. These studies had been carried out upon the initiative of Clarence King, who was making a special study of the nature of the earth's interior and its probable age. King's conclusion from his studies was that at present "we have no warrant for extending the earth's age beyond 24 millions of years" and that upon this assumption an originally molten earth would have solidified from the center outward to the crust and become perfectly solid.

The fact that blocks of solid basaltic lava float upon the molten material, not only in the experiments but, apparently, in the open lava lake of Halemaumau (Kilauea) in the Hawaiian Islands, has been responsible for some misapprehension. At Kilauea such phenomena are of frequent occurrence, but careful observation has revealed the fact that these apparently floating rock islands are in reality attached to the walls or to the bottom of the lava lake. The disrupted lava crust founders in the lake.

Wholly apart from the question of what the condition of the earth's interior may have been in the past, we have ample evidence that its condition today is at least as rigid as a ball of steel of the same size, since otherwise it would suffer distortions of large amplitude through the action of the tides produced by the varying attractions of moon and sun. Kelvin, who was the first to demonstrate this, said: "Suppose the earth to consist of a thin shell or crust enclosing or floating on a vast interior of molten matter. The liquid interior would tend to yield freely to the tide-generating influence of the sun and moon. The consequence would be that the exterior crust would be acted on by forces 
which, unless it were of preternaturally rigid material . . . it would be unable to resist. The crust would then be subject to upheavals and depressions taking place in time with the revolutions of the sun and moon. If the crust yielded perfectly, there would be no tides of the sea, no rising and falling relatively to the land at all. The water would go up and down with the land, and there would be no relative movement; and in proportion as the crust is less or more rigid, the tides would be more or less diminished in magnitude."

The earth tide though inappreciable even when measured by what are called precise methods, has none the less been measured by Michelson with the aid of a special device of which his interferometer is an important part. These studies have confirmed Kelvin's statements and shown that the measured and the calculated earth tides are almost identical, and, as Michelson says, are of value "in refuting the old notion that the internal temperature, sufficiently high to melt most of the materials constituting the earth's crust, necessarily involves a fluid or semi-fluid earth supporting a relatively thin solid crust." The coefficients of both viscosity and rigidity, Michelson found to be of the order of, and perhaps exceeding, those of solid steel. Since at the temperatures believed to obtain within the earth's core all substances would be fluid, "it follows," he says, "that pressure increases the rigidity and the viscosity, at least of the substances which form the body of the earth."

Experiments by Bridgman carried out in the Jefferson Physical Laboratory of Harvard University at pressures as high as 30,000 atmospheres, have confirmed this and clearly indicated that the fusing point of bodies is elevated enormously with the increase of pressure, thus adding important confirmation of the now accepted view that the earth's interior is kept rigid, and presumably solid, by the pressure due to the weight of superincumbent material. It follows. of course, that if pressure were to be locally removed in any 
place, that portion of the mass would become fused and produce a local reservoir of molten rock.*

There are two other considerations which confirm the view that the earth's interior is today essentially rigid like steel. The first of these is based upon the fact that the earth continues to spin about its axis of rotation; while the other is based upon the high transmission velocity of vibrations which are carried through the body of the earth at the time of great earthquakes.

Kelvin was accustomed to illustrate the incapacity of a fluid body to spin by attempting to spin both boiled and raw eggs upon the lecture table by twirling them between the palms of the hands. The hard-boiled egg, having an essentially rigid or solid interior, is easily made to spin, though all attempts to spin the raw egg with its essentially liquid interior are unavailing. Internal friction between the different liquid shells stops the motion imparted to the raw egg.

But the spinning earth like the spinning top or the boiled egg, does not maintain its rotating axis in a stationary position. The axis has a leisurely tilting (precessional) rotation as compared with the rotation of the body about its axis, and the earth body is similarly deformed by amounts which are measurable in the precise methods of the astronomer. These are measured in the variations of latitude according to the formula of Euler. The earth was in these studies at first assumed to be perfectly rigid, which would require a Euler period of rotation of ten months. It was only after Newcomb had suggested that a period of four-

\footnotetext{
*The above conclusions apply of course to uniform (hydrostatic) pressure. Pressures which are non-uniform, of the nature of a shear, follow the law that the fusing point is always lowered with increasing pressure, as is well brought out especially by the studies of Johnston and Adams at the Geophysical Laboratory in Washington. It does not seem possible, however, that shearing stresses can ever exceed the elastic limit of the materials, and must therefore be relatively insignificant when compared with the average hydrostatic pressure at great depths below the surface. The effects mentioned by Johnston and Adams refer to a stress system in which there is a discontinuity of the normal component of stress across a surface of separation.
} 
teen months be taken, which would be in correspondence not with perfect rigidity but with that of steel, that the observed data were found to compare well with the computed one. The studies, now confirmed by Michelson's experimental data, gave us the first actual measurement of earth rigidity in terms of solid bodies whose properties are known to us.

When seismographs, or earthquake recording devices, had been so perfected as to register earthquakes from points as remote from the observing station as the antipodes, a means was discovered for measuring the translational velocity of the vibrations which are carried directly through the earth, as well as those which travel along its surface. Now the velocity of such forms of harmonic motion is well known to be a measure of both the density and the elasticity of the medium traversed, and the determined average velocity in excess of ten kilometers per second for compressional waves passing through the earth shows clearly that its interior is not only rigid but has an elasticity at least as great as that of the best tool steel. It can hardly be other than significant that by several different methods the rigidity and elasticity of the earth's core should be found to approximate so closely to that of steel, and it argues strongly for a general identity of the core material with that of the nickel-iron meteorites.

\section{LITERATURE}

Gustav Bischoff. Versuche die Kontraktion zur bestimmen, welche geschmolzene Massen erleiden wenn sie in dem festen Zustande uebergehen und krystallinische Gesteine bilden, etc., Neues Jahrbuch $f$. Min., etc., 1843, pp. 1-54.

LoRd Kelvin. Popular lectures and addresses, vol. 2, Geology and general physics. Macmillan.

Carr Barus. High temperature work in igneous fusion and ebullition, chiefly in relation to pressure, Bull. 103 U. S. Geol. Surv., pp. 1-57 pls. $1-9$, chap. 2 especially.

T. A. JAGGAR, JR. Volcanologic Investigations at Kilauea, Am. Jour. Sci. (4), vol. 44, 1917, pp. 171-172.

Clarence King. The age of the earth, Am. Jour. Sci. (3), vol. 45, 1893, pp. $1-20$.

Chamberlin and Salisbury. Geology, vol. 2, chap. 2. 
JosepH BARRELL. The strength of the earth's crust, reprinted from articles in the Journal of Geology, vols. 22 and 23, 1914-15.

O. C. Farrington. Meteorites, their structure, composition, and terrestrial relations, Chicago, 1913, p. 225.

A. A. Michelson. Preliminary results of measurements of the rigidity of the earth, Jour. Geol., vol. 22, 1914, pp. 97-134.

A. A. Michelson and Henry G. Gale. The rigidity of the earth, Jour. Geol., vol. 27, 1919, pp. 585-601.

T. C. Chamberlin, H. F. Reid, J. F. Hayford, and Frank Schlesinger. The earth; its figure, dimensions, and the constitution of its interior, Proc. Am. Phil. Soc., vol. 54, 1915, pp. 279-308. Reprinted in Smithsonian Report for 1916, pp. 225-254.

Frank D. Adams and ERNEST G. Coker. An investigation into the elastic constants of rocks, more especially with reference to cubic compressibility, Am. Jour. Sci., vol. 22, 1906, pp. 95-123.

R. D. OLdHam. The constitution of the interior of the earth as revealed by earthquakes, Quart. Jour. Geol. Soc., vol. 62, 1906, pp. 456-473.

JoH N JoH Nston and L. H. ADAMs. On the effect of high pressures on the physical and chemical behavior of solids, Am. Jour. Sci., vol. 35, 1913, pp. 205-253.

P. W. Bridgman. The failure of cavities in crystals and rocks under pressure, ibid, vol. 45,1918 , pp. 243-268.

George P. MerRrul. The composition and structure of meteorites compared with that of terrestrial rocks, Smithsonian Report for 1917, 1919, pp. 175-188, pls. 1-9.

T. C. Chamberuin. Diastrophism and the formative processes, XI, Selective segregation of material in the formation of the earth and its neighbors, Jour. Geol., vol. 28, 1920, pp. 126-157.

A. L. Day, R. B. Sosman and J. C. Hostetter. The determination of mineral and rock densities at high temperatures, Am. Jour. Sci. (4), vol. 37, 1914, pp. 1-39.

E. Wiechert. Ueber die Massenvertheilung im Innen der Erde, Nachr. v. d. k. Gessel. d. Wiss. z. Göttingen, 1897, pp. 221-243.

E. Wiechert. Our present knowledge of the earth, Smith. Rept., 1908, 1909, pp. 431-449.

T. C. Chamberlin and R. D. Salisbury. Geology, vol. 2, 1905, pp. 133-138.

B. Gutenderg. Ueber Erdbebenwellen, VIIA, Beobachtungen an Registrierungen von Fernbeben in Göttingen und Folgerungen uber die Konstitution des Erdkörpers, Nach v. d. k. Gessel. d. Wiss. z. Göttingen, 1914, pp. 125-176.

T. C. Chamberins. The self-compression of the earth and related problems, Yearbook No. 19, Carnegie Institute of Washington, 1920, pp. 366-383. 


\section{CHAPTER III}

\section{THE SOURCE OF VOLCANIC LAVA}

Few geologists could be found today who would dissent from the view that, whatever may have been its condition in the past, the interior of the earth, regarded as a whole, is possessed of a rigidity roughly comparable with that of solid steel. Since, however, molten rock accompanied by gases periodically reaches the surface of the earth through volcanic vents, we have no recourse but to conclude that the source of this lava and gas is to be found in pockets, or maculoe, and it seems probable that these are situated relatively near to the surface of the earth.

It is a fundamental conception of geology that the earth has long been and still is losing heat through radiation into the space surrounding it. Though this idea grew up and was fostered by the now abandoned conception of a liquid interior, it does not lack support from observations made in deep mining shafts and in deep borings that have penetrated somewhat further into the lithosphere. Up to the depth to which observations have now been carried, about a mile and a half, the temperature continues to increase; and a composite made from somewhat variant data gives us as perhaps the best value for the rate of increase of temperature with depth-geothermic gradient-1 ${ }^{\circ}$ Fahrenheit for each 60 feet of descent. If this gradient be conceived to continue without change in the direction of the earth's center, a temperature at which all rocks would fuse and even be vaporized under surface conditions would eventually be reached, and a temperature sufficient for fusion would be attained above the depth of twenty miles. Most rocks would fuse at a depth of fifteen miles on the basis of 
dry conditions only. Since fusion is not general it must be explained, as has already been pointed out, by the elevation of the fusing point of the materials with the augmenting pressure upon them. That increase of temperature with depth continues at least to the level necessary for local liquefaction of rock, it is necessary to assume in order to account for the existence of lava at all. Under the influence of the water present, so-called aqueous fusion, depths much less than those above given for dry fusion would be required.

The rate of lowering of the fusion point of rock with respect to the increasing water content is almost startling, and this is augmented rapidly with the percentage of the associated water. It has been shown that amorphous potassium silicate having the composition of $\mathrm{K}_{2} \mathrm{Si}_{2} \mathrm{O}_{5}$ when containing between ten and twenty-five percent of admixed water is at ordinary temperatures a hard glass; whereas with increasing proportions of water it becomes, first, a stiff paste, and, finally, a very viscous solution resembling water glass. When entirely free from water this substance fuses at a temperature of $1015^{\circ} \mathrm{C}$., whereas with only eight percent of admixed water the melting point is lowered to only about one-half that figure, or $500^{\circ} \mathrm{C}$.

The temperature of lava as it exudes at the earth's surface is generally from $800^{\circ}$ to $1500^{\circ} \mathrm{C}$., but the higher temperatures we now know to be in large part due to the elevation of temperature from combination of its occluded gases as they separate from the mass and mingle near the margins on approach to the surface, and, further, to oxidation when they are released into the atmosphere. This intensive union of unstable gases as they separate from magmas has been aptly described as blowpiping, from its close resemblance to the processes which go on in the hot flame of a blowpipe.

Studies of the very siliceous vein-rock which is known as pegmatite and which is usually a marginal phase of granitic magma, have shown that all gradations exist between a true rock melt and a true solution product. With all these 
facts in mind it is not considered unreasonable to suppose that rock may be fused to form magma at depths well within the earth's rind of sediments, and probably not more than six miles below the surface. The depth to which water extends downward into the lithosphere has been the subject of much controversy, but its amount must rapidly decrease below the depth of five or six miles.

With the necessary concessions for the formation of local pockets of lava, there is no good reason to assume that at greater depths the geothermic gradient either increases or diminishes, or that it is not absolutely arrested at some very moderate depth. Of this whole matter we lack knowledge, and the pseudo-scientific estimations of temperature at the earth's center, obtained by multiplying the gradient for the near-surface zone by the length of the earth radius, are of a kind which cannot be defended, but which has been far too common in the history of science. A lesson might here by learned from the experience of the great physicist Helmholtz who averred that the earth's atmosphere could not extend upward from the surface beyond an elevation of 27 or 28 kilometers, upon the ground that the aerothermic gradient within the lower 9 kilometers of the atmosphere -all that had been at that time explored-required that if this gradient continue upward the absolute zero of temperature would be attained at an elevation of 28 kilometers. Subsequent exploration of the air has revealed that in middle latitudes the aerothermic gradient is suddenly arrested and gives place to essentially isothermal conditions at the level of a fairly definite ceiling only about two kilometers beyond the extreme elevation to which soundings had been carried at the time of Helmholtz's statement.

Whenever, from any cause whatever, local relief from the pressure of overlying rock is secured within the lithosphere, provided the rock temperature equals or exceeds that necessary for rock fusion under the reduced pressure, a local chamber of molten rock (magma) may come into 
existence. We shall defer the consideration of the conditions under which such relief of pressure may be obtained, in order to take up first the kind of rock which is likely to undergo fusion and thus produce a magma pocket.

The proper method of attack upon this problem is obviously to examine into the constitution of rocks of molten (so-called igneous) origin, both those which consolidate within the lithosphere (e.g., granite), and those which issue as lava through a vent at the earth's surface (e.g., basalt). It will then be necessary to examine into the composition of the three main types of stratified rocks, rocks which have been formed by the process of sedimentation, and described as sandstones, shales, or limestones. These rocks are made up of the re-deposited and re-cemented débris from the fragmentation of earlier rocks, for whose formation the atmosphere and hydrosphere were indispensable.

The parts of the series of earth sediments are never all present together at any one place, and though when pieced together they would make up a pile on some estimates over sixty miles in thickness, it is probable that they never exceed a tenth of that figure in any one place.

Our first problem is evidently to examine into the constitution of the rocks which have congealed from molten material and are described as igneous. A composite made from practically all of them that have been carefully and completely analyzed, over five thousand in all, is given below in column 1. Recalculated so as to include the eight principal constituents only, we derive the figures of column 2 , opposite which under column 3 are printed the so-called molecular ratios: (See table on page 32.)

Of greatest importance among the constituents are obviously silica and alumina, which together make up nearly two-thirds of the entire rock. The range of content of these constituents in the entire series of igneous rocks is of the greatest interest and significance. If we except perhaps a dozen rare rocks which occur in any considerable quantity, 


\begin{tabular}{|c|c|c|c|}
\hline & $\begin{array}{c}1 \\
\text { Average } \\
\text { igneous rock } \\
\text { (Clarke and } \\
\text { Washington, } \\
\text { 1920) }\end{array}$ & $\begin{array}{l}\text { Recalculated } \\
\text { for Principal } \\
\text { Constituents }\end{array}$ & $\begin{array}{c}\text { Molecular } \\
\text { Ratios }\end{array}$ \\
\hline 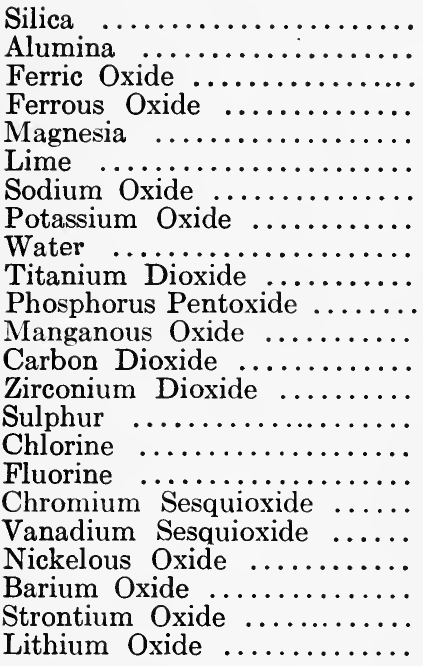 & $\begin{array}{l}59.09 \\
15.35 \\
3.08 \\
3.80 \\
3.49 \\
5.08 \\
3.84 \\
3.13 \\
1.14 \\
1.05 \\
0.30 \\
0.125 \\
0.102 \\
0.039 \\
0.053 \\
0.056 \\
0.078 \\
0.056 \\
0.032 \\
0.025 \\
0.055 \\
0.022 \\
0.007\end{array}$ & $\begin{array}{r}61.02 \\
15.85 \\
3.92 \\
3.48 \\
3.60 \\
5.24 \\
3.96 \\
3.23\end{array}$ & $\begin{array}{r}1.017 \\
.155 \\
.025 \\
.044 \\
.090 \\
.094 \\
.055 \\
0.34\end{array}$ \\
\hline & 100.000 & 100.00 & \\
\hline
\end{tabular}

the silica in no case much exceeds eighty percent or falls much below thirty percent. The alumina, likewise, shows a strictly limited range and is practically always less than twenty-five percent.

Magma pockets may of course be conceived to be located either within the outermost rind of the earth which is composed of a complex of igneous and sedimentary rocks, or in the shell immediately beneath, which we conceive to have originated from the infall of meteoric stone. It has already been shown in the last chapter that as regards chemical composition the lightest of the meteoric stones are essentially identical with the densest of our igneous rocks. Less than five percent of the igneous rocks fall, however, within this category, and we are forced to conclude that, generally speaking, igneous rocks have been largely derived from local fusion of sediments included in the outermost skin or rind 
of the lithosphere. Insofar, however, as they may consist of refused igneous rocks, their composition will probably be but slightly changed in the process of fusion. For such cases the problem is merely carried one step farther back to still earlier rocks out of which these particular igneous rocks were formed.

The study of the composition of sedimentary rocks is, on the other hand, of the utmost interest and significance in this connection. By far the greater number of these rocks appear to have been deposited on the floor of the ocean relatively near shore and where their materials were either brought down suspended in river water or were wrested from the shore itself by storm waves. All the material, whether of one or the other mode of origin has been distributed by the tides and the shore currents over the ocean bottom and there laid down along with the limey remains of marine organisms. Far out from shore beyond the reach of most of the land-derived sediments the deposits are dominantly calcareous, derived from shells and other organic remains, and these when hardened into rock produce limestones. Nearer the shore the finer land-derived sediments are deposited as muds admixed with more or less organic matter, and these when transformed into hard rock are known as shales or slates, by far the most abundant of all the sedimentary rock types. Still nearer the shore where the strong currents raised in connection with the breakers can transport the larger rock fragments, we find the sands which harden into sandstones and often the shingle whose pebbles make up the pudding-stones or conglomerates.

As regards their relative abundance it has been estimated that the shales constitute from sixty to eighty percent of all sedimentary rocks, with the limestones and sandstones each from ten to twenty percent. The continents being surrounded generally by the so-called continental shelves over which the water gradually deepens to about six hun- 
dred feet at the outer margin, it follows that wherever thick deposits of marine sediments have been laid down in continuous process, the shelf which forms the floor of that deposition must have been steadily depressed while the sea advanced over the land, and that the outermost zone where limestone sediments can alone be deposited must have moved progressively landward over that of mud deposition, and the mud-depositing area likewise over the sands of the earlier shore. It is for this reason that shales so generally overlie sandstones, and that limestones so often cap a sedimentary series.

Let us now examine into the average composition of each of these great series of sedimentary rocks. It is evident that the principal constituent of sand, quartz or silica, must dominate in the sandstones, whereas lime and magnesia, together with carbonic oxide will be the chief constituents of the limestones. The shales are of more complex composition and will occupy intermediate positions with a composition bearing a close relation to the main constituent of mud-clay, a substance high in alumina and water.

\section{Average Composition of Sedimentary Rock Types}

\begin{tabular}{|c|c|c|c|c|}
\hline & $\begin{array}{l}\text { Igneous Rocks } \\
\text { (Composite } \\
\text { of 5179) }\end{array}$ & $\begin{array}{c}\text { Shale } \\
\text { (Composite } \\
\text { of } 134^{*} \text { ) }\end{array}$ & $\begin{array}{c}\text { Sandstone } \\
\text { (Composite } \\
\text { of 624) }\end{array}$ & $\begin{array}{l}\text { Limestone } \\
\text { (Composite } \\
\text { of 843) }\end{array}$ \\
\hline $\mathrm{SiO}_{2} \quad \ldots \ldots \ldots \ldots$ & ${ }_{1.017}^{61.02}$ & ${ }_{1.070}^{64.18}$ & ${ }_{1.438}^{86.27}$ & $\begin{array}{l}16.03 \\
0.267\end{array}$ \\
\hline $\mathrm{Al}_{2} \mathrm{O}_{3} \quad \ldots \ldots \ldots$ & 15.85 & 16.91 & 5.58 & 2.13 \\
\hline $\mathrm{Fe}_{2} \mathrm{O}_{3}$ & $\begin{array}{l}0.155 \\
3.92\end{array}$ & $\begin{array}{l}0.165 \\
4.44\end{array}$ & $\begin{array}{c}0.054 \\
1.29\end{array}$ & $\begin{array}{c}0.021 \\
1.10\end{array}$ \\
\hline & 0.025 & 0.027 & 0.008 & 0.007 \\
\hline $\mathrm{FeO} \quad .$. & $\begin{array}{l}3.48 \\
0.044\end{array}$ & $\begin{array}{l}3.05 \\
0.042\end{array}$ & $\begin{array}{l}0.59 \\
0.008\end{array}$ & \\
\hline $\mathrm{MgO}$ & 3.60 & 3.07 & 0.88 & 10.30 \\
\hline $\mathrm{CaO}$ & $\begin{array}{l}0.090 \\
5.24\end{array}$ & $\begin{array}{l}0.077 \\
3.41\end{array}$ & $\begin{array}{l}0.022 \\
3.45\end{array}$ & $\begin{array}{c}0.257 \\
69.13\end{array}$ \\
\hline & 0.094 & 0.060 & 0.061 & 1.234 \\
\hline $\mathrm{Na}_{2} \mathrm{O}$ & 3.96 & 1.39 & 0.65 & $\begin{array}{l}0.56 \\
0.009\end{array}$ \\
\hline \multirow[t]{3}{*}{$\mathrm{K}_{2} \mathrm{O}$} & 3.23 & 3.56 & 1.29 & 0.75 \\
\hline & & 0.038 & 0.014 & 0.008 \\
\hline & 100.00 & 100.00 & 100.00 & 100.00 \\
\hline
\end{tabular}

* Additional analyses here added by the author. 
At the suggestion of Dr. G. K. Gilbert, the average composition of each of the main types of sedimentary rock was some years ago determined in the laboratory of the U. S. Geological Survey at Washington, with results which are
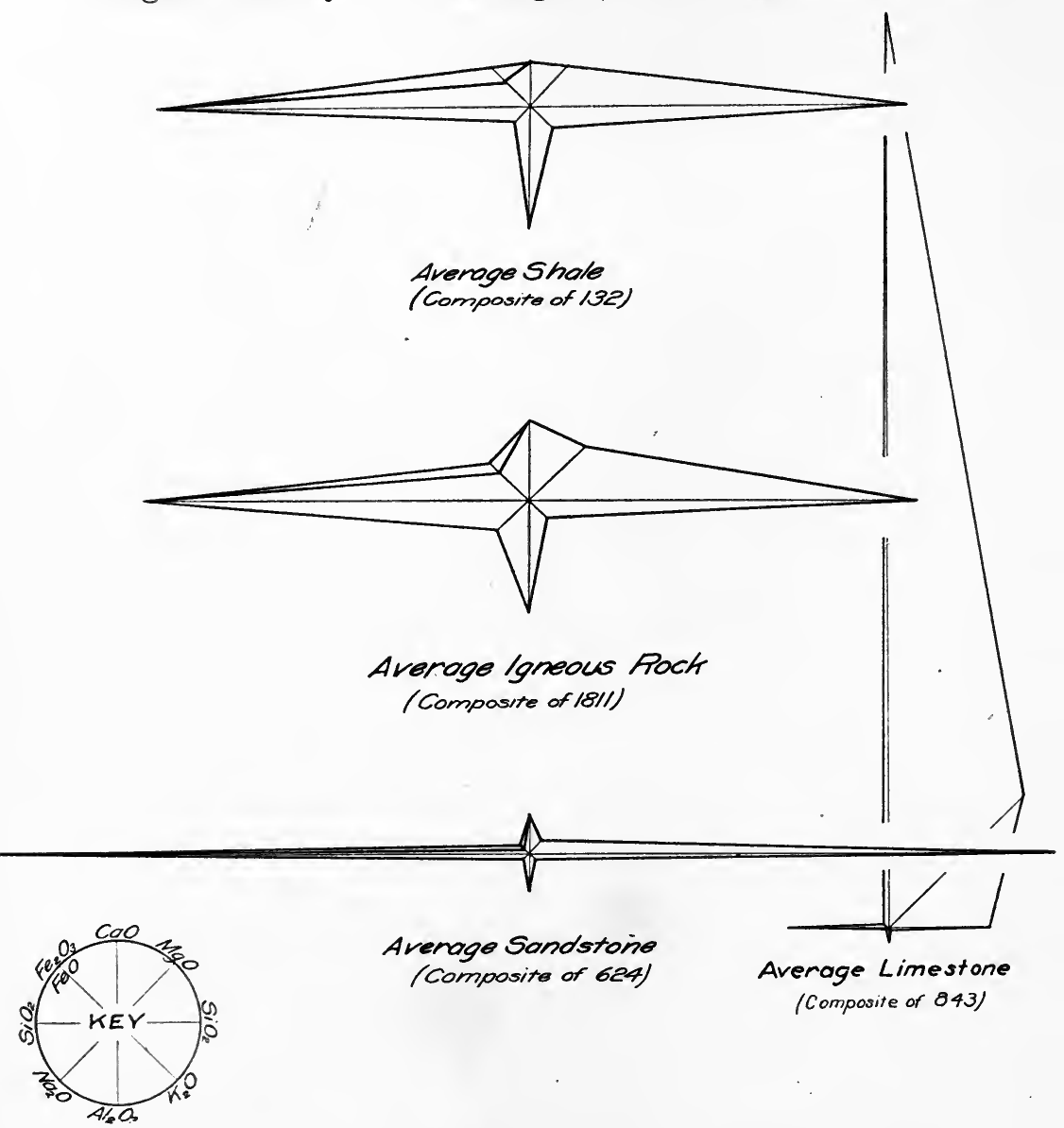

Average Sandstone

(Composite of 624)

(Composite of 043)

FIG. 4-Composite rock diagrams for the main classes of rocks given below in the following table; the less abundant constituents being here for the moment left out of consideration and the analyses recalculated for the eight principal constituents.

The close identity between the analyses of the average 


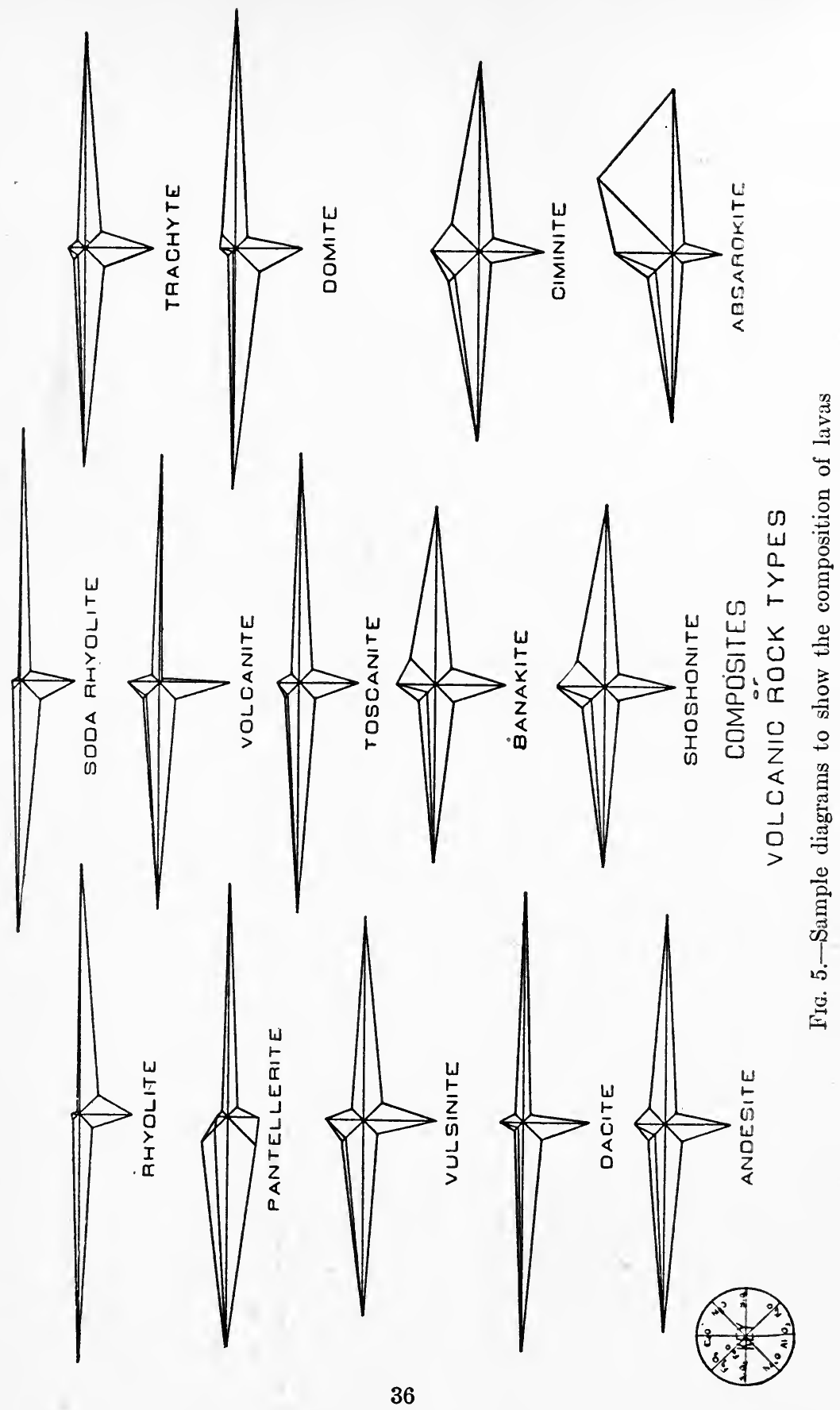




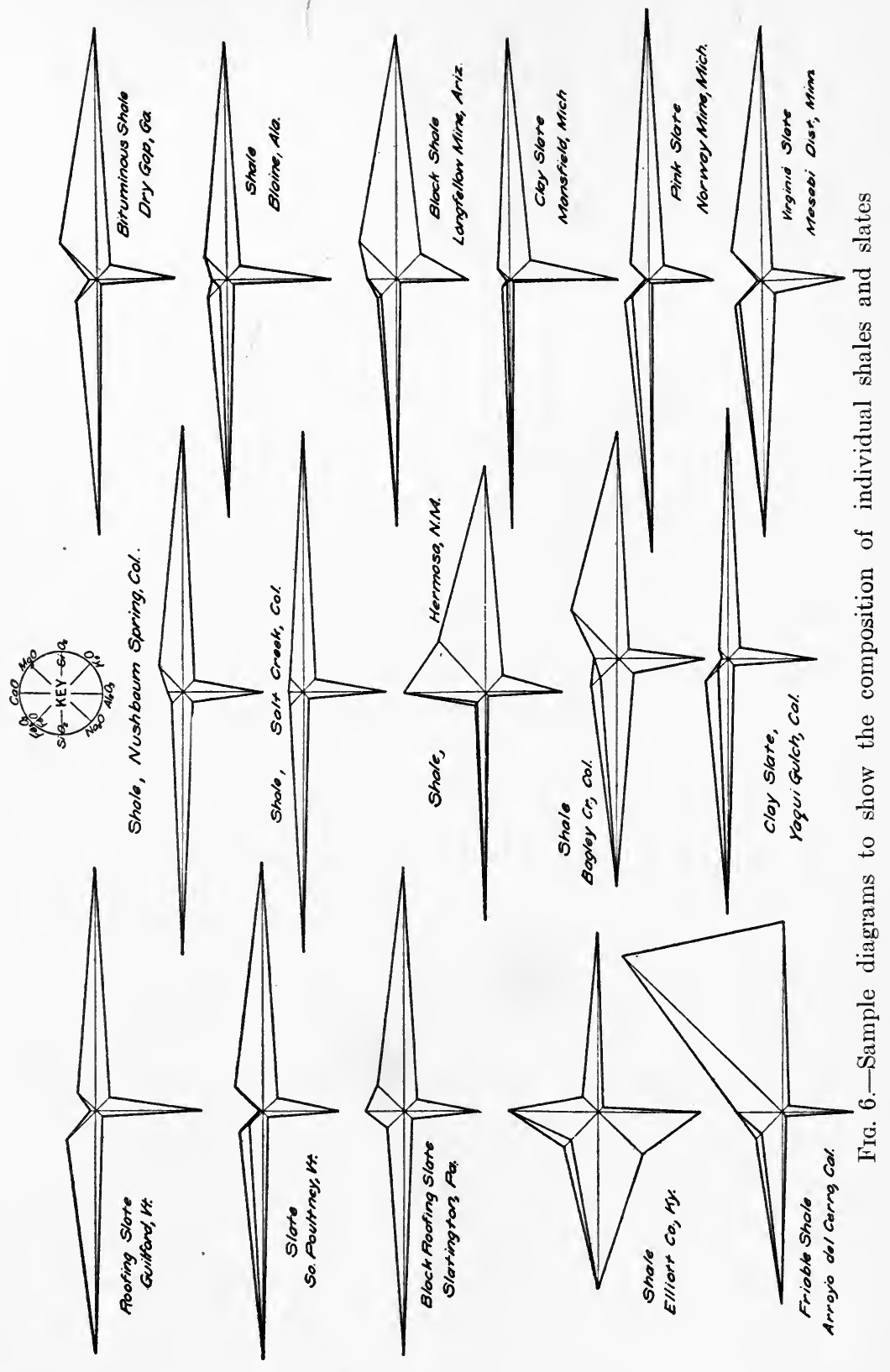


shale and the average igneous rock is certainly remarkable. On the other hand, there is no correspondence whatever between the average igneous rock and the average sandstone or the average limestone. Since the eye notes and retains form characteristics far better than it does mere numerical figures, these relationships appear to better advantage upon the simple diagrams of Fig. 4 in which the key illustrates the method employed for expressing the molecular proportions of the constituents.

It should, however, be pointed out that there is one respect in which the average analysis of igneous rocks does not correctly represent the average chemical composition of the rocks themselves in the proportion in which these are found in the earth's outermost shell. Those rock types which occur in greatest abundance, granite and its close relatives chemically, are so well known to us that there is little occasion to have expensive chemical analyses made from them. It is the exceptional rock type for which it is necessary to prepare chemical analyses, and this is notably true of the alkaline rocks with their lower silica content and their higher percentages of the alkalies and lime. This fact may well in large part account for the lower silica and the higher lime and alkali percentages of the average igneous rock as compared with the average shale; but there are doubtless other reasons also for this difference, some of which will be pointed out.

An investigation carried out by the writer in order to determine whether the relationships revealed by the average rock types applied also to the individuals, has supplied a somewhat striking confirmation which is probably causal in its origin. It was noted, however, that the rarer igneous rock types, the ultra-basic groups of the peridotites and pyroxenites which overlap the celestial and terrestrial rock series, are not represented by any shales that have been analyzed. The diagram of analyses from a selected group of volcanic igneous rocks when compared with those of a group of shales taken almost at random (Figs. 5 and 6) bring out 
the lower silica, lime and soda content of the igneous rocks just as do the composites.

Notwithstanding the rather remarkable approach to identity shown both in the average and in the individual analyses of shales and igneous rocks, there are certain slight divergencies which may or may not have significance. The silica of the average shale analysis is nearly 3 per cent higher than that of the average igneous rock, and the oxides of lime and soda are both slightly higher in the composite igneous rocks, being, namely, in excess by 1.83 and 1.57 per cents respectively. As already explained, this may be wholly due to natural selection in the analyses that were usually made.

It is, further, not difficult to account for these small differences upon the theory advanced, on the ground of the rather small number of analyses which have been combined for an average shale-134; but so far as the oxides of lime and soda are concerned, there is a rather obvious reason why such differences should appear. In the process of ascending to the surface, magma will, after the pressures have become sufficiently reduced, more or less completely, calcine the limestone which it encounters with the result of absorbing the oxide of lime after separation of the carbon dioxide. Similarly from the considerable quantities of common salt which are locked up in certain of the marine sediments, oxide of sodium will be assimilated after separation of the chlorine. The increments of both lime and sodium oxides should in consequence be larger in the effusive igneous rocks than in the deeper seated types. Composites made from plutonic, dike and effusive igneous rock types which were prepared by the author some years ago indicate that this view is not without some warrant, at least as respects the content of lime oxide. The figures obtained are:

Comparison of Calcium and Sodium Oxides in the Plutonic and Effusive

Igneous Rocks

\begin{tabular}{|c|c|c|c|}
\hline & $\begin{array}{l}\text { Plutonic } \\
\text { (Composite } \\
\text { of 1166) }\end{array}$ & $\begin{array}{c}\text { Dike } \\
\text { (Composite } \\
\text { of 119) }\end{array}$ & $\begin{array}{c}\text { Effusive } \\
\text { (Composite } \\
\text { of 1123) }\end{array}$ \\
\hline $\begin{array}{l}\mathrm{CaO} \\
\mathrm{Na}_{2} \mathrm{O}\end{array} \ldots \ldots \ldots$ & $\begin{array}{l}4.39 \\
3.55\end{array}$ & $\begin{array}{l}5.85 \\
4.45\end{array}$ & $\begin{array}{l}6.63 \\
3.69\end{array}$ \\
\hline
\end{tabular}


The question of fusibility is clearly one which has importance in connection with this problem of magma origin, and it may well be of determinative value. Though we are without data concerning the range of fusibility of sandstones, shales, and limestones, we are probably warranted in drawing some conclusions respecting their fusing points from those of the materials which constitute the chief constituent in each.

Quartz, the principal constituent of sandstones, is when pure one of the most difficultly fusible substances which is known, since it melts in the neighborhood of $1700^{\circ} \mathrm{C}$, a value higher by several hundred degrees than any temperature which has been obtained from volcanic lavas. Calcium carbonate, the basis of limestone, according to Boecke fuses at pressures above 110 atmospheres at $1289^{\circ} \mathrm{C}$. Clay, the basis of shale and slate, has so large an importance in the industries that its fusibility properties are pretty well known. The most refractory clays known, which are of course low in fluxing impurities, having fusing temperatures which may equal or exceed that of calcite, but the common types heated under dry conditions begin to fuse at about $1000^{\circ} \mathrm{C}$., and the range of their fusibility is about the same as that of actual lavas which reach the earth's surface. Lava temperatures have been measured in volcanoes and found to range from about $970^{\circ} \mathrm{C}$. to white heat $\left(1500^{\circ} \mathrm{C}\right.$.), but the higher values appear to be, not the temperatures of the lava mass as a whole but those obtained where unstable gases are being liberated into the atmosphere through orifices and producing intense blowpiping effects. It is probable that the mass temperatures of lavas seldom go above $1200^{\circ} \mathrm{C}$.

There is another problem of much importance for which a ready solution is found upon this assumption that magma is produced by the fusion of shale. It has often been pointed out that a close relationship in composition, a socalled "consanguinity," connects the lavas which are 
erupted at localities widely distributed throughout a somewhat broad area. Within a neighboring province similar co-relationships may be established to connect eruptions of lava at its different vents, though with a common marked difference setting them apart from the lavas of the province first mentioned or with those of other areas. Such provinces, within each of which one general type, or related types, of lava, or magma, is encountered, are commonly referred to as petrographic provinces of comagmatic regions.

It has been customary to ascribe the affinities of the lavas within any province to the existence of a common subterranean lava reservoir, and the differences to lateral mag-

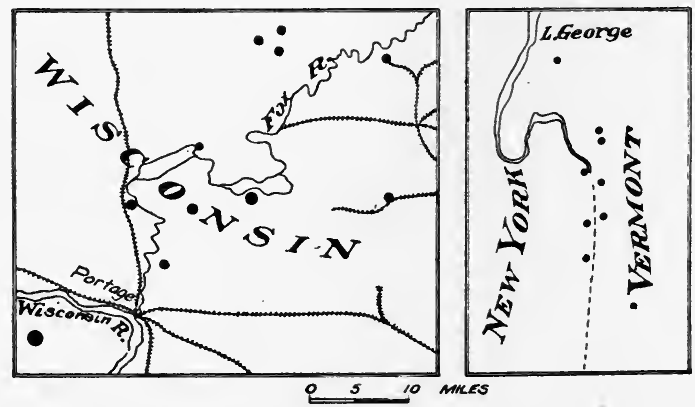

FIG. 7.-Maps to indicate how a characteristic petrographic province may develop from local fusions of shale

matic differentiation subsequent to the formation of the reservoir. Because of the wide extent of such provinces, the assumed magmatic differentiation in a lateral direction, where obviously gravity could play but a small rôle, has made a large demand upon the imagination. So soon as we account for the origin of magmas in the local fusion of shale, it becomes unnecessary to assume a common reservoir extending throughout the province, and the affinities and the differences as well which are observed to characterize the lavas of the different vents, are all alike explainable by the common deposit of muddy sediment from which the shale resulted. The differences have also been introduced by tide and shore current at the time of deposition. 
A petrographic province characterized by soda rhyolites and situated in south central Wisconsin shows the relationships and the differences in composition which are brought out in the first of the following tables. When compared with the set of analyses of slate in the second table representing various localities within the Vermont-New York slate belt, it will appear how natural such relationships of composition would be upon the theory advanced. Upon the same scale the petrographic province and the slate belt are represented in the maps of Fig. 7.

IGNEOUS ROCKS FROM PETROGRAPHIC PROVINCE OF SOUTH CENTRAL WISCONSIN

\begin{tabular}{|c|c|c|c|c|c|c|c|c|c|}
\hline & & $\begin{array}{c}\text { Obser- } \\
\text { vatory } \\
\text { Hill }\end{array}$ & $\begin{array}{r}\text { Mar- } \\
\text { quette }\end{array}$ & $\begin{array}{l}\text { Bara- } \\
\text { boo }\end{array}$ & $\begin{array}{l}\text { En- } \\
\text { deav- } \\
\text { or }\end{array}$ & $\begin{array}{l}\text { Tay- } \\
\text { lor's } \\
\text { Farm }\end{array}$ & $\begin{array}{l}\text { Mar- } \\
\text { cellon }\end{array}$ & Alloa & Utley \\
\hline $\mathrm{SiO}_{2}$ & & 74.46 & 73.09 & 71.24 & 72.80 & 78.23 & 79.03 & 71.14 & 73.09 \\
\hline $\mathrm{Al}_{2} \mathrm{O}_{3}$ & & 15.28 & 15.40 & 12.20 & 15.50 & 11.11 & 13.23 & 19.58 & 13.43 \\
\hline $\mathrm{Fe}_{2} \mathrm{O}_{3}$ & & 1.95 & 0.65 & 1.71 & 2.04 & 1.73 & 0.34 & 1.25 & 2.57 \\
\hline $\mathrm{FeO}$ & & 0.74 & 2.10 & 5.44 & 0.60 & 1.03 & 0.18 & 0.88 & \\
\hline $\mathrm{MgO}$ & & 0.08 & 0.12 & 0.13 & 0.08 & Tr. & 0.7 & 0.37 & 1.03 \\
\hline $\mathrm{CaO}$ & & 0.92 & 1.74 & 0.98 & 0.52 & 0.28 & 0.25 & 2.14 & 2.29 \\
\hline $\mathrm{Na}_{2} \mathrm{O}$ & & 2.57 & 4.57 & 4.29 & 5.70 & 3.44 & 3.95 & 2.34 & 3.85 \\
\hline $\mathrm{K}_{2} \mathrm{O}$ & 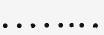 & 3.01 & 2.01 & 1.86 & 2.52 & 4.08 & 2.28 & 2.62 & 1.58 \\
\hline
\end{tabular}

SLATES FROM DIFFERENT LOCALITIES IN THE VERMONTNEW YORK SLATE BELT

Poult-

Castle- Hamp- Gran- Janes- Race-

$\begin{array}{lrrrrrrrrr}\mathrm{SiO}_{2} & \ldots \ldots \ldots & 59.27 & 67.76 & 59.70 & 60.96 & 67.61 & 67.55 & 67.89 & 63.88 \\ \mathrm{Al}_{2} \mathrm{O}_{3} & \ldots \ldots \ldots & 18.81 & 14.12 & 16.98 & 16.15 & 13.20 & 12.59 & 11.03 & 9.77 \\ \mathrm{Fe}_{2} \mathrm{O}_{3} & \ldots \ldots \ldots & 1.12 & 0.81 & 0.52 & 5.16 & 5.36 & 5.61 & 1.47 & 3.86 \\ \mathrm{FeO} & \ldots \ldots \ldots & 6.58 & 4.71 & 4.88 & 2.54 & 1.20 & 1.24 & 3.81 & 1.44 \\ \mathrm{MgO} & \ldots \ldots \ldots & 2.21 & 2.38 & 3.23 & 3.06 & 3.20 & 3.27 & 4.57 & 5.37 \\ \mathrm{CaO} & \ldots \ldots & 0.42 & 0.63 & 1.27 & 0.71 & 0.11 & 0.26 & 1.43 & 3.53 \\ \mathrm{Na}_{2} \mathrm{O} & \ldots \ldots & 1.88 & 1.39 & 1.35 & 1.50 & 0.67 & 0.61 & 0.77 & 0.20 \\ \mathrm{~K}_{2} \mathrm{O} & \ldots \ldots \ldots & 3.75 & 3.52 & 3.77 & 5.01 & 4.45 & 4.13 & 2.82 & 3.45\end{array}$

\section{LITERATURE}

F. W. Clarke. Analyses of rocks from the laboratory of the U. S. Geological Survey, 1880-1903, Bull. U. S. Geol. Surv., no. 228, 1904, pp. 20-21.

H. S. Washington. The distribution of the elements in igneous rocks, Trans. Am. Inst. Min. Eng., 1908, pp. 1-30.

William H. HobBs. Some considerations concerning the place and the origin of lava maculae, Gerland's Beiträge zur Geophysik, vol. 12, 1913, pp. 330-361. 
William H. Hobbs. Variations in composition of pelitic sediments in relation to magmatic differentiation, Comptes Rendus XII Session Congrés Géologique International (Stockholm), 1912, pp. 241-246.

Joseph P. IDDINGS. The problem of volcanism, Yale University Press, 1914, pp. 101-105.

H. S. Washington. The chemical analyses of igneous rocks, Prof. Paper. U. S. Geol. Surv., no. 14, 1903, pp. 495 (revised and expanded as Prof. Paper no. 99, 1917, pp. 1201).

H. S. Washington. The chemistry of the earth's crust, Jour. Frank. Inst., vol. 190,1920 , pp. 757-815.

N. H. Darton. Geothermal data of the United States, including many original determinations of underground temperature, Bull. 701, U. S. Geol. Surv., 1920, p. 97. 


\section{CHAPTER IV}

\section{THE ORIGIN OF POCKETS OF MOLTEN ROCK}

IT has been shown that the rigidity of the earth must be generally maintained today under conditions of internal temperature which locally at least and relatively near to the surface are sufficiently high for at least the aqueous fusion of rock. This rigidity is further assumed to exist in consequence of compression due to load, which compression within the very considerable limits to which tests have been carried raises enormously the melting point of such solids as have been tested.

It follows that though the rock temperature be sufficient to cause fusion under surface conditions of pressure, within the lithosphere rock will melt at those places only at which the load of superincumbent material has in some way been either wholly or partially lifted off- - the load must be at least partially supported without bearing upon the portion of the mass which is to pass into the fused condition. Our problem is, therefore, to examine: (a) the forces present and competent to produce such structures as will lift the load above a shale formation and (b) the nature of the structures which they develop.

It has been customary among geologists to regard the lithosphere as continually losing heat through radiation into the space about it (so-called secular cooling) and in consequence diminishing in volume. The outermost earth shell having long since adjusted itself to the temperatures immediately above it, it is the interior portion of the planet which is now shrinking, and the adjustments of the shell necessary to close in about its shrinking core under the impelling force of gravitation, must induce compressional stresses within the shell. 
The view thus expressed has in recent years been assailed by certain physicists who have set up the claim that sufficient heat is being evolved from emanations of radium to either partially or wholly offset the earth's losses of heat through secular cooling. The geologist can afford to ignore this challenge of the physicist, since whatever may be the computed relative losses and gains in heat energy, there is testimony supplied from the study of earthquakes which is fortunately unequivocal and leaves the geologist no recourse but to conclude that the volume of the earth is today diminishing.

Before taking up this evidence, it seems advisable to first state the case as revealed in vertical sections transverse to the strata. Deformations which take place in the process of mechanical adjustment within that portion of the lithosphere that is open to our inspection are of two kinds: namely, flexuring or folding, and block displacement or faulting. Quite obviously the first mentioned type of adjustment must, in and by itself, supply a proof of shrinking, for the layers which are folded cannot possibly cover as large an area as they did before folding had occurred. This is made clear by Fig. 8, A and B. It has been estimated that in the folding of the Alps the area of sediments involved has been reduced to about one-sixth of its former width.

It now must be considered in how far shrinking of area through flexuring of the strata may be offset by adjustments of block faulting within regions where folding has not taken place. Such adjustments may obviously be of any one of three types, since vertical planes, or those perpendicular to a spherical surface like that of the earth converge downward, and they may be so adjusted that the center of volume of the disturbed region has been moved; a, farther away from the earth's center, b, brought nearer to it, or, c, kept at the same distance as before. Exaggerating grossly the amount of curvature of the earth's surface for the sake of demonstration, these three cases are illustrated by C, D, 
and $\mathrm{E}$ of Fig. 8. It is obvious that they must correspond respectively to a net shrinking, to a net swelling, and to an unaltered volume of the earth during the adjustment, so far at least as the affected region alone is concerned. It should be pointed out, however, that compared to the changes in area which result from complex folding, the measure of these changes in area is relatively small.

Now it is well known that the so-called "normal" type

(A)

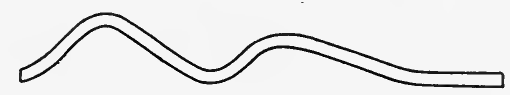

(B)
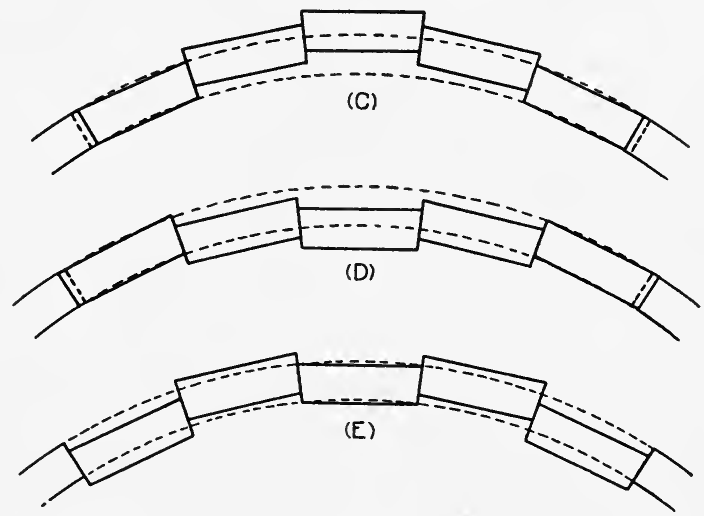

Fig. 8.-Diagrams to illustrate the effects of folding and of faulting of different types upon the superficial area of the earth

of block faulting on other than vertical planes is that represented in Fig. 9, in which the blocks must tend to express an extension of the surface, and without careful quantitative comparisons of the sum total of contraction within folded regions with the total of expansion in block faulted regions - a matter for the distant future, if it may indeed be considered a soluble problem-we are forced to admit that from this angle the solution of the problem is now indeterminate. 
It is the investigation of earthquakes which has supplied us with an answer to the question which fortunately admits of no equivocation. It is today recognized that earthquakes are the manifestations of the frequent sudden adjustments of the earth's surface portions to accumulating stresses within, and with each relief so obtained is brought about a larger or smaller change of form in the surface. The distribution of earthquakes shows that for the land areas earthquakes occur chiefly where mountains are growingrearing their heads-and where the surface is therefore generally considered to be expanding rather than contracting. Now the really surprising observation has been made that after the earthquake the surface has really contracted,

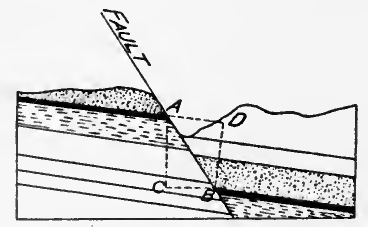

FIG. 9.-Section across a normal fault showing how it may increase the surface area of the earth

other and neighboring portions of the surface having moved in and so permitted the original area to rise.

For the present we shall consider alone the evidence of compression of the rocks, leaving that of the intruding increment of surface to be dealt with in a later chapter. A study carried out by the writer in 1908 of the nature of the damage done to all continuous lines of metal, such as rails, pipes, etc., and the nature of the damage sustained by bridges within regions affected by heavy earthquakes, has yielded the interesting result that these are always such as to indicate a compression of the surface. Rails and pipes are found to be uniformly buckled or, if parted, the displaced ends of the fractured metal are in such positions as to indicate a shortening of the distance. Bridges indicate a reduction, and often a very large one, of the distance 
between abutments, but with no corresponding extension indicated for the approaches upon either side (see plates II-V).

The universality of this observation without regard to direction within the area affected, and the general harmony of the results when tested out for a number of heavy earthquakes affecting widely separated regions, force us to the conclusion that compression is the dominant type of stress within the earth's outer shell, and that this stress is cumulative, as is required by the doctrine of continued secular cooling of the interior of the earth planet.

An important consequence of this constant compressional stress within the earth's shell is that whenever the relief is obtained by a sudden series of displacements with the inevitable result of letting down the potential energy of the system, the stress is again almost instantly renewed and the vise-like compression is again set up before the blocks, thrown beyond their natural positions of equilibrium are able to return to that position. Such return can only be accomplished through numerous later adjustments in alternating directions, which have hence come to be known as earthquake after-shocks.

We may now consider the adjustments which take place under each of the separate heads of block faulting and folding, as a consequence of which may arise areas of local relief from pressure such as are necessary to develop pockets of magma within the lithosphere.

In the case of block faulting the denser massive strata tend to be thrown by the jolting movement beyond their position of equilibrium, just as does a pendulum when released from its extreme position. Within the upthrown blocks any heavy strata in a relatively high position, such as a lava capping or heavy limestone or sandstone members, will tend to separate from weak and relatively light underlying shale members and as a consequence be carried beyond them. The vise of compressive stresses almost 


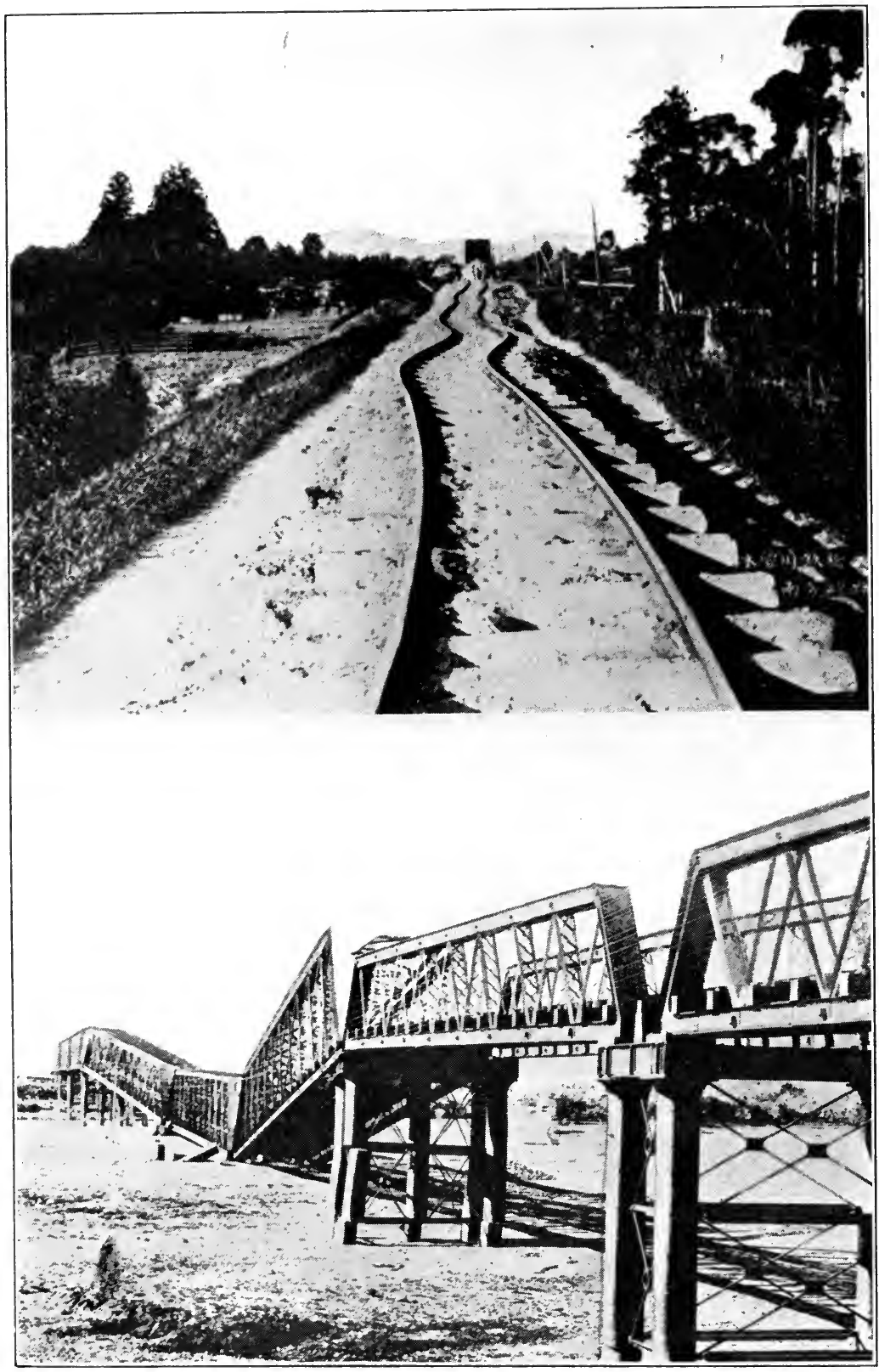

Effects of earth movements upon rails and bridges. 1. Rails buckled in approach to bridge, earthquake of 1891, Japan. 2. Nagara Cowa railroad bridge dropped into river but with all spans still connected, earthquake of 1891, Japan. 

Plate III

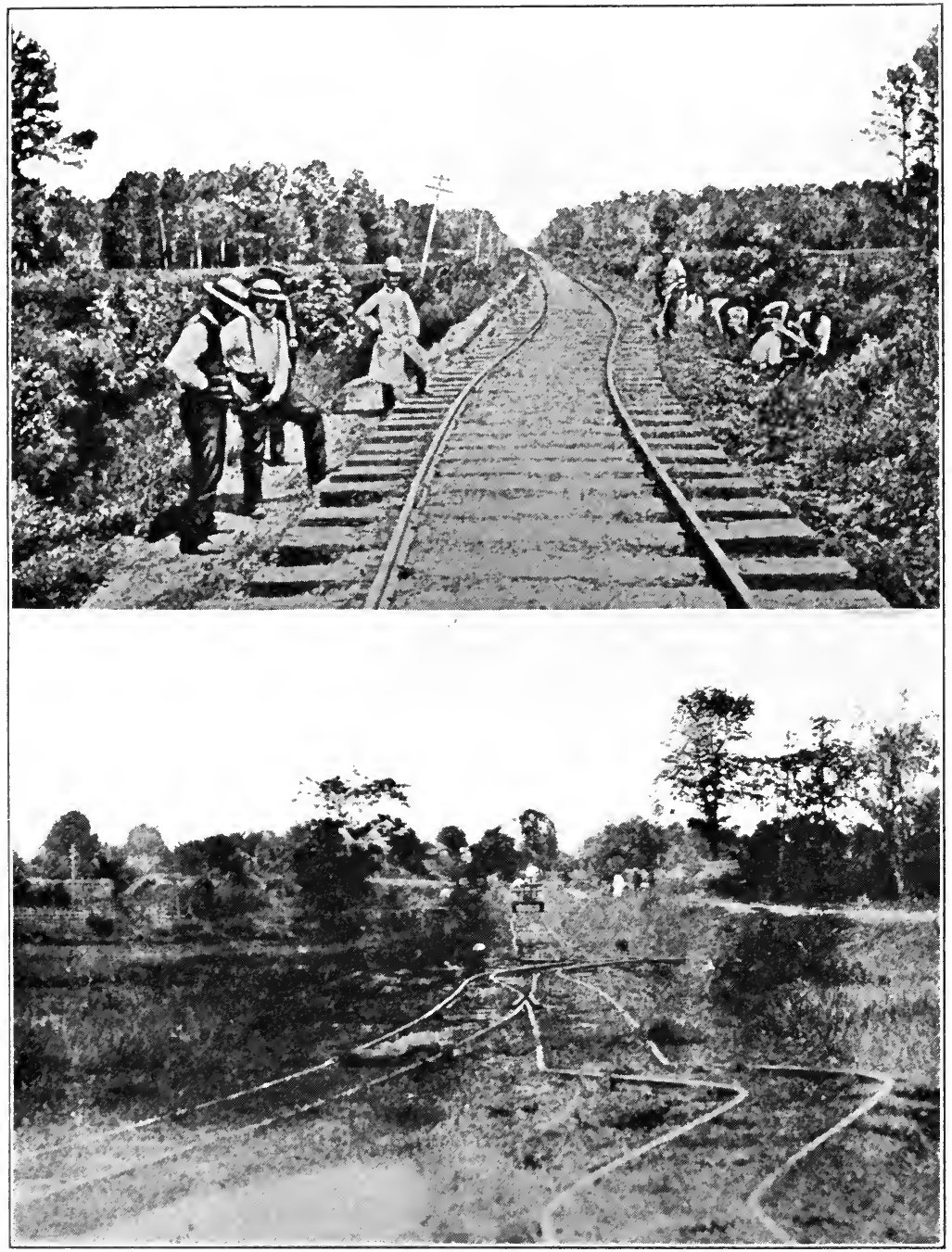

Effects of earth movements upon rails. 1. Buckled rails, earthquake of 1888, Charleston, S. C. 2. Buckled rails, earthquake of 1897 , India. 

Plate IV

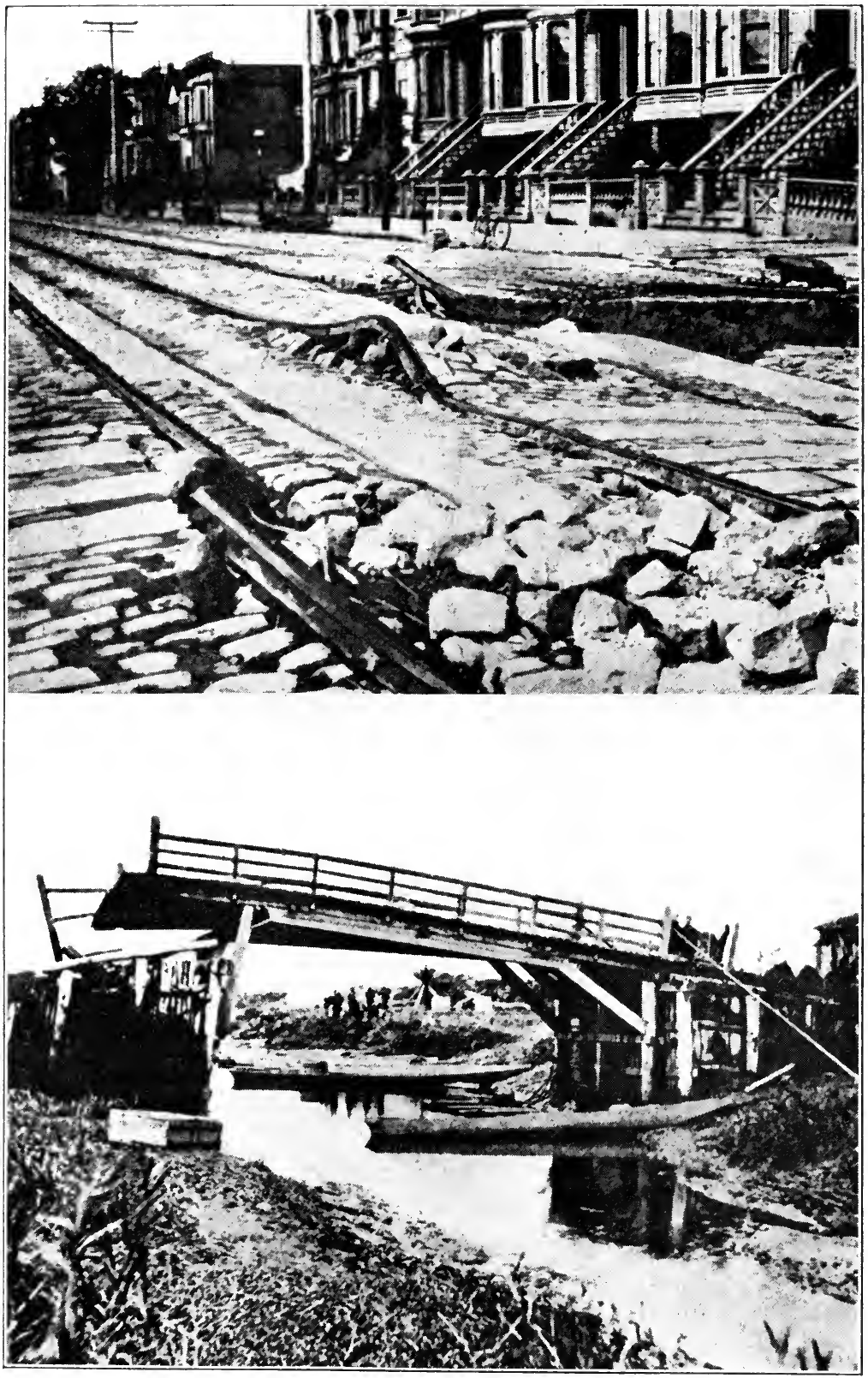

Effects of earth movements upon rails and bridges. 1. Buckled rails, earthquake of 1906, California. 2. Bridge with girder underridden by abutment, earthquake of 1891, Japan. 

Plate V

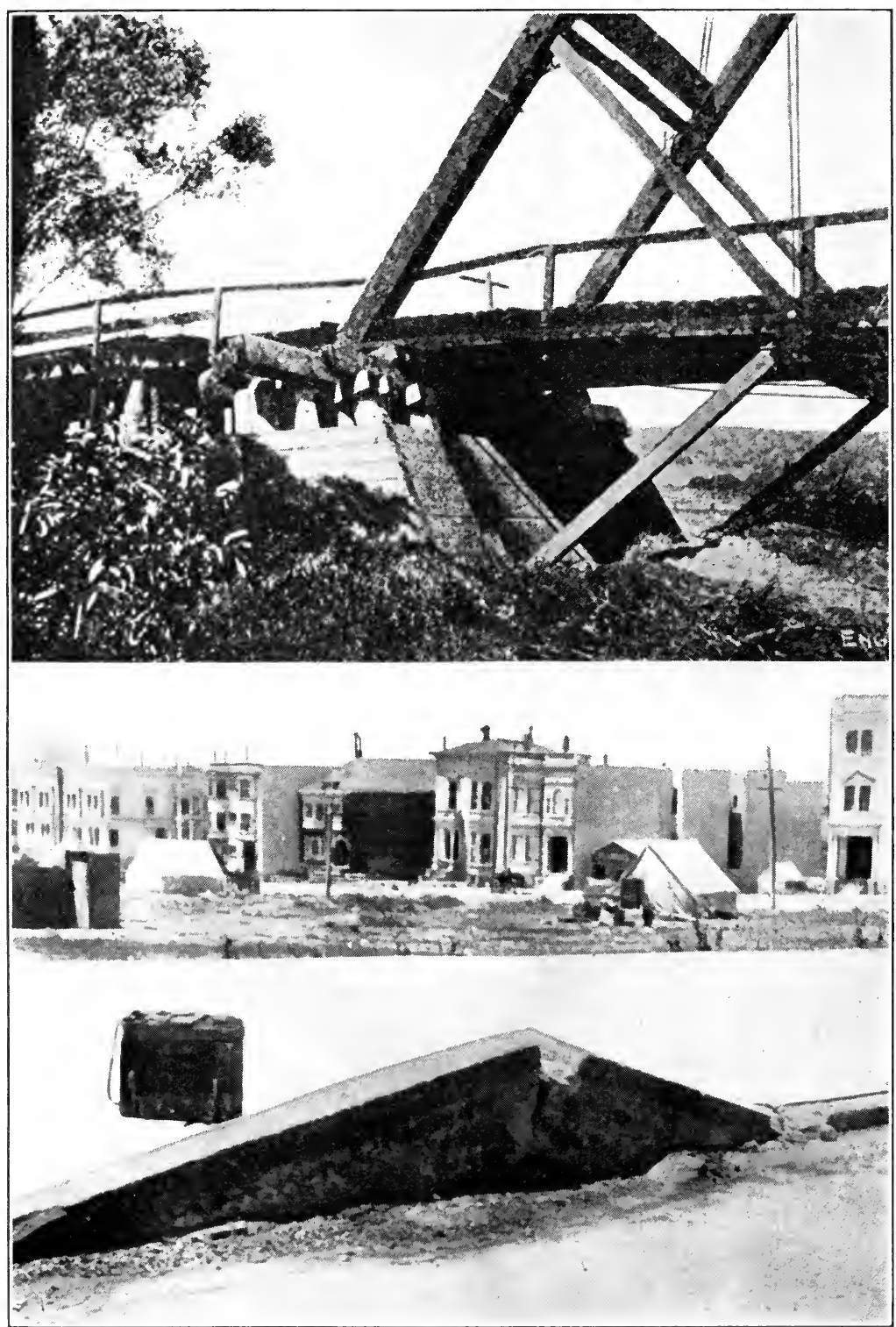

Effects of earth movements upon bridges and curbing. 1. Distorted abutment, Salinos river bridge, earthquake of 1906, California. 2. Buckled curbing, earthquake of 1906, California. 

instantly closing in, however, the massive upper strata may in consequence be largely supported from the sides and so rest but a portion of their weight upon the shale below. Under these conditions fusion of the shale will take place, provided of course the rock temperature and the water con-
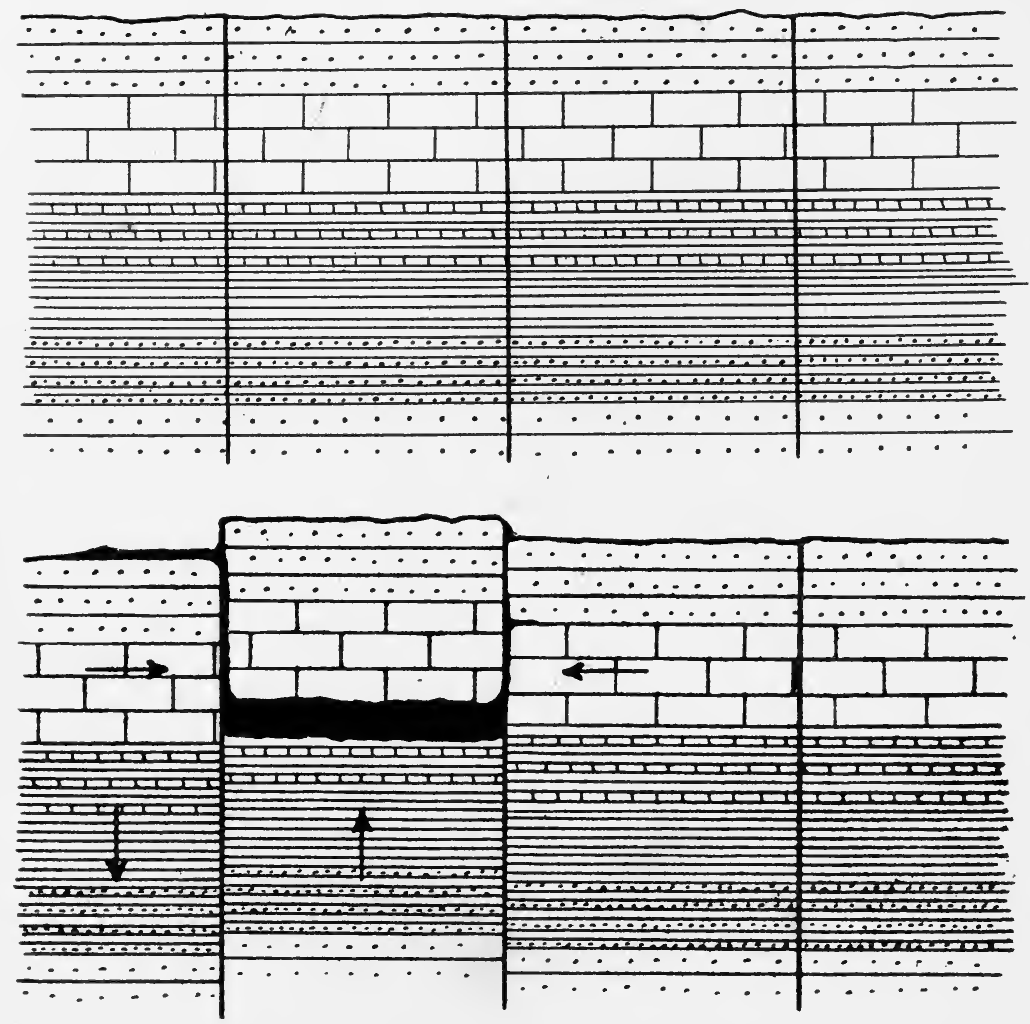

FIG. 10.-Diagrams to show how block faulting may yield a lava chamber tent make this possible under the diminished pressure (Fig. 10).

Either slow subsequent settlement of the upper member or a jolting return at the time of the earthquake after-shock, will account for the pressure from above resting upon the lava reservoir and tending to force its contents out to the surface along one of the marginal faults, where it would of 
course overflow the surface of a neighboring downthrown block (Fig. 10). In Iceland, in the high plateaus of Utah, in the Great Basin of the Western United States, and in the rift valleys of East Central Africa, there are numerous examples of vast outflows of lava which have taken place over downthrown blocks from marginal fissures.

In the process of rock folding there are produced a succession of alternating anticlines, or arch folds, with synclines, or trough folds. The former when composed of strong rocks, possess the preëminent competency of arched engineering structures to support heavy loads, provided the

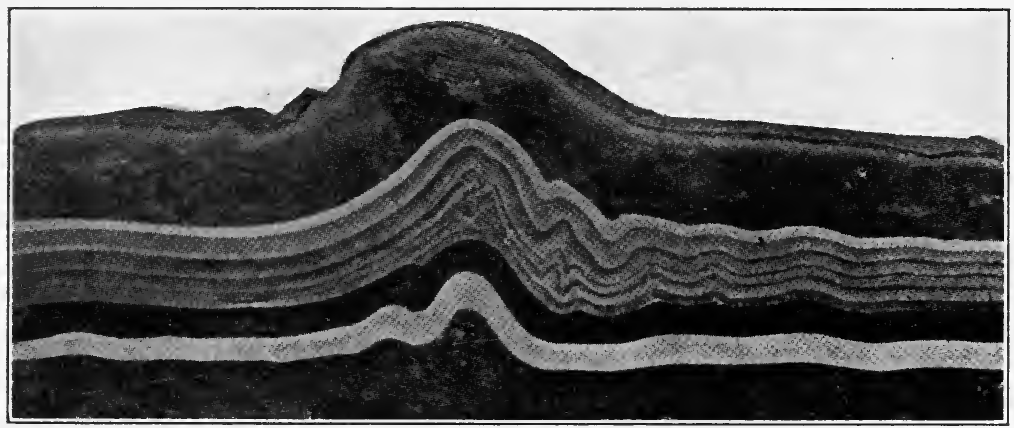

Frg. 11.-Model showing the crushing of a shale-like member beneath an anticline of a competent limestone-like formation

span of the arch is not too broad with reference to its height. To the uninitiated it will seem improbable that bodies normally so rigid as rock should be able to form folds at all, but that under loads in excess of its elastic limit a normally rigid body is susceptible of folding is well established and has been aptly illustrated in the experiments of Willis.

Willis produced compositions from plaster of paris, beeswax and Venice turpentine mixed in varying proportions, and these were shaped into layers of different degrees of rigidity so as to simulate rock strata. Laid along the floor of an iron tank like a series of strata, these layers could be compressed from the end by the use of a piston operated by a screw. Though the layers yielded by fracture when 
compressed under the load of air pressure alone, they underwent folding after the manner of rocks within the lithosphere when subjected to a load of shot equal to but five pounds per square inch.

It was found in the experiments that the stronger layers -those with larger proportions of plaster of paris in their composition-were the ones which alone carried the compressive stresses after the manner of girders, and when the strong members had been placed above the weak onessimulating limestone above shale-the relatively strong members lifted a portion of the load to form anticlines,

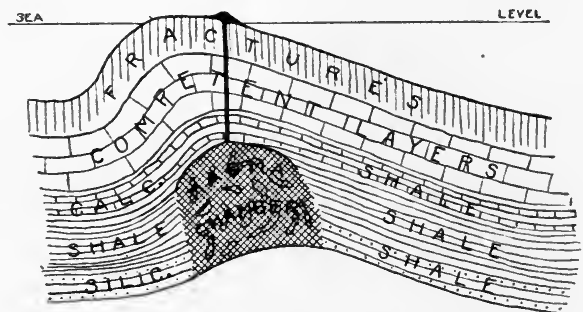

Diagram to show position of Magma Chamber

under competent anticline

FIG. 12.-Diagram to show position of a magma chamber formed under a competent formation in an anticline

whereupon the weaker shale members below the arches, instead of folding, were fractured just as though the load had not been present at all (Fig. 11). At a depth where the water content of the rocks and the rock temperature together supply a combination under which shale is susceptible of fusing at the reduced pressure, the conditions are met for the development of an anticline pocket, or fold pocket, of magma (Fig. 12).

It is characteristic of anticlines that only in the early stages of their growth have they a symmetrical form. With increasing compression the side of the arch which is toward the active compressive force progressively steepens and eventually bends under the other and forms an underturned anticline which tends to close up under the con- 
tinued squeeze. Simultaneously the magma pocket under the continuing compression tends to be reduced in volume, and will be reduced provided any outlet can be found for the magma. (See progressive sections of Fig. 13.)

Discussion of the manner of producing the conduit through which magma rises to the earth's surface will be deferred until after the gases of lavas have been considered. The process of compressing the lava pocket is simulated in the operation of the common form of bulb syringe from which the contents are expelled by compression within the palm of the hand. Thus we see that, as in the case of the already described magma chambers which may arise be-
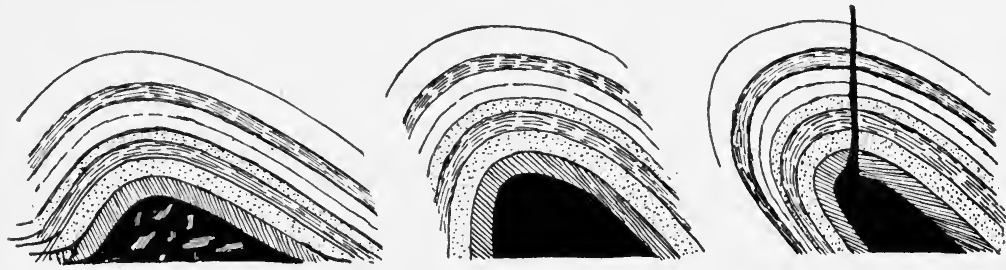

FIG. 13.-Successive diagrams showing the manner of contraction of a magma chamber through continuation of the folding process with expulsion of the lava through a conduit

neath the massive members of upthrown fault blocks, the process of formation and compression of the pocket supplies also a simple solution for that much mooted question of the cause of the rise of lava to the surface of the earth.

It has been said in the foregoing that it is only in the earliest stage of a developing anticline, or arch fold, that its form is symmetrical, and this symmetrical and broadly open arch of the embryonic stage thus represents the initial response of the competent stratum in the direction of flexure by a local elevation of the load resting upon it. It is one of the aims of this treatise to show on the basis of observations that in many, if not in most instances, the initial form of the anticline is not even a symmetrical arched ridge of strata, but rather a linear series of separated broad 
domes which later become merged by growth into an arched ridge.

The above described domes in the strata enveloping a chamber of lava were first described from the Henry Mountains in Utah under the name of laccolites in a now classic monograph by Mr. G. K. Gilbert. This distinguished American geologist believed the laccolites to be the result of intrusions of magma coming up from below through an undiscovered conduit and at a particular level making their way laterally between the strata so as to force the overlying layer into a dome without altering the position of the underlying stratum. The force responsible for the structure was thus made to be the expansive hydrostatic pressure of the intruding magma. Such structures have since been described in considerable numbers from districts within which the laccolites are generally found flanking the higher mountain ranges. Such examples are particularly numerous in the Rocky Mountain region, where they have been described in detail by some of the most competent of American geologists; and especially by Dr. Whitman Cross, who has published an extended monograph upon them.

All geologists, so far as the writer is aware, have held to the original view of Gilbert that the magma chamber of the laccolite represents an intrusion through a conduit underneath, and that the force which elevated the roof was the hydrostatic pressure exerted by the magma itself.

From a somewhat comprehensive study of the literature of laccolites, the writer has been forced to adopt an entirely different viewpoint and to see in laccolites the initial efforts toward flexuring within the more competent strata when these are situated above a stratum of weak shale. Under these conditions the competent stratum rises in domes and the shale migrates inward to be fused into a lava pocket as already pointed out (see Figs. 11 and 12).

It is certainly a fact which calls for explanation on the 
part of those who advocate an intrusive origin for laccolites, that with the remarkable simplicity of the structures and the excellent exposures in section, the supposed conduit feeders have never in a single case been discovered. Certain other considerations of the first importance which follow naturally from the opposed conceptions of laccolite origin, will be easily understood from inspection of Fig. 14.

According to Gilbert and his followers the stress condition within the roof strata, at least during the formation of the laccolite, should be that of tension, due to the expansive
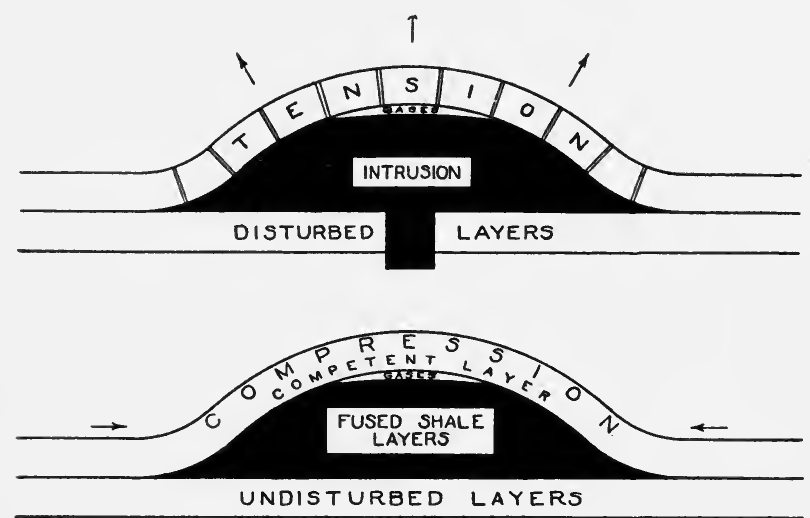

CONTRASTED VIEWS OF ORIGIN OF LACCOLITES

FIg. 14

pressure of the magma which is invoked to explain the structure; and we should therefore expect to see the roof member intersected by dykes and apophyses of magma. Under the view here advanced the condition of stress within the roof of the laccolite, instead of being tensional should be compressional, since the roof is believed to represent the competent structure which carries the earth compression and is responsible for the formation of the laccolite. Furthermore, an intrusion which is conceived to be so vigorous and impelling as to force up the upper series of strata in so remarkable a fashion, could hardly have failed to leave 
some trace of its energy in a disturbed condition of the floor areas. Yet the evidence is in the direction of a generally undisturbed floor, and that keen observer who made so many of the first studies of laccolites, Mr. W. H. Holmes, was

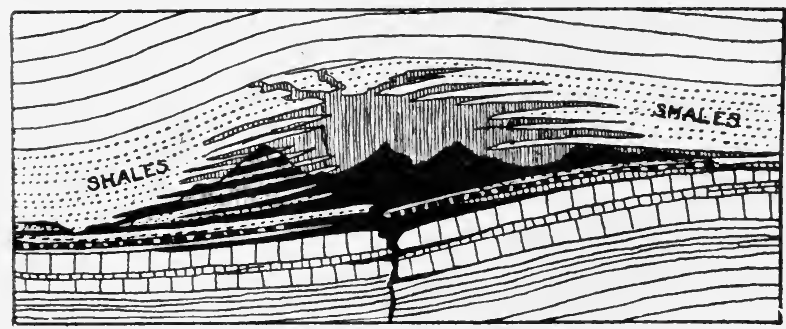

La Plata Mtns.(Holmes)

FIG. 15.-Section of the laccolite of the La Plata Mts. (after Holmes)

evidently greatly puzzled by these indications from his observations. He not only refers to it in his descriptions, but in his beautifully drawn sections he habitually represented the hypothetical feeding conduit as extremely nar-
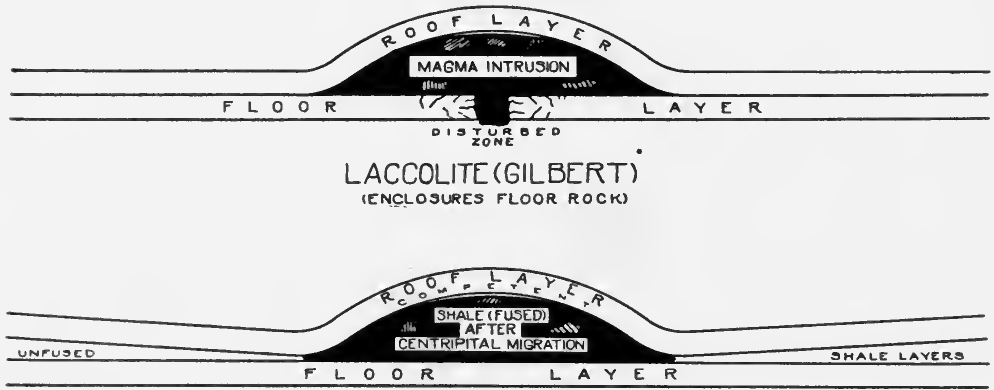

\section{LACCOLITE (HOBBS)}

(ENCLOSURES SHALE)

FIG. 16.-Contrasted views concerning the origin of laccolites

row, possibly in part to account for the fact that he had in no case discovered it (Fig. 15).

Other no less striking differences which characterize the two conceptions of origin, are brought out in the sections of Fig. 16. Upon the Gilbert conception of intrusion, the 
enclosures within the laccolite should be either of floor rock or of materials from still greater depths along the path of the conduit. Upon the author's theory, rock enclosures within the magma should generally be of shale, and must in most cases have migrated centripetally from the sides. It may perhaps be possible to prove by comparative measurements that the shale formation within which the laccolite is formed increases in thickness as one goes out from the

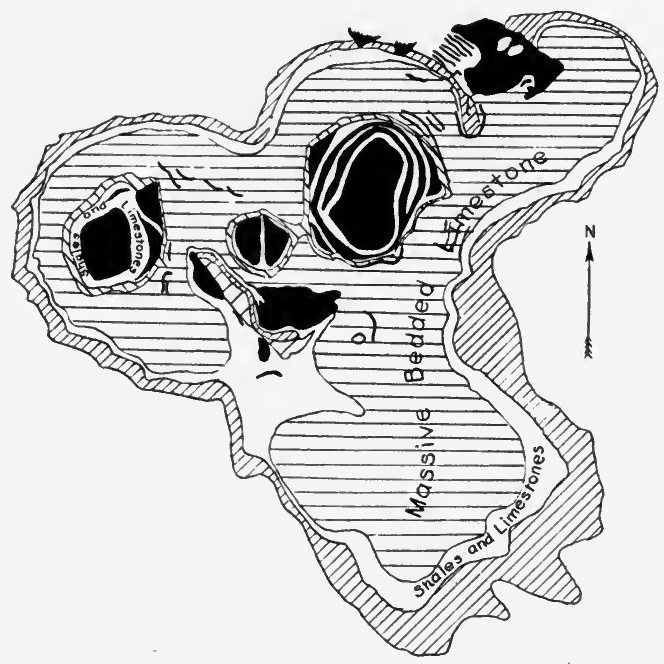

Laccolites of Judith Mts. (Weed and Pirsson)

FIG. 17

laccolite margins. A study of the literature of known laccolites has supplied the remarkable verification for our view of laccolite origin in the fact that they appear only within shale members and quite generally beneath a competent member of limestone or massive sandstone (Figs. 17 and 18). The evidence for this must be left for presentation in another place.

A very striking instance of an apparently early stage of laccolite formation, within which the shale has completed its migration into the dome but has been as yet but slightly fused is supplied by Holmes' section of a laccolite at Sierra 
La Sal in extreme northeastern Utah (Fig. 19). A stage in the process not greatly different from this is apparently illustrated by the Sierra Abaja, some fifty miles east of the Henry Mountains in Utah. Of this occurrence Holmes says: "The shales are still found in all parts of the

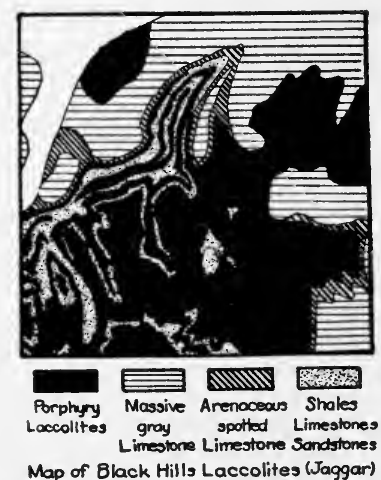

FIG. 18.-Map of the Black Hills laccolites formed beneath a dome in competent limestone (after Jaggar)

group caught up in a manner identical with that observed in el Late and Carriso mountains, and the low saddles between the summits are invariably of these shales."

Cross, in commenting upon Holmes' description, says, "This involves as a physical necessity the assimilation of

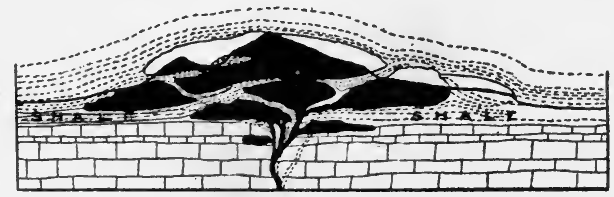

FIg. 19.-Section of the laccolite of the La Sal Mts. with included shale (after Holmes)

shale by the magma, and such is plainly Holmes' meaning, though not explicitly stated in this connection."

The Sierra La Sal of northeastern Utah the writer's preliminary study on the ground has shown to be a composite laccolitic group with the shale mantling over the igneous 
core and capping it in the high peaks. The indications of tension in the roof of sediment called for by the Gilbert theory are conspicuously lacking.

Since laccolites pass by all intermediate gradations into magma layers which are found wedged between layers of sediments, it is obvious that the same theory of origin must to a larger or smaller extent find application to them, but the study has not yet been extended in that direction.

The immense quantities of igneous rock which are found in the cores of recently elevated folded mountain ranges have apparently impressed-amazed, rather-every worker who has studied them. The general observation goes back into the early history of geology and was, in fact, one of the strong supports of the famous "elevation crater" theory of

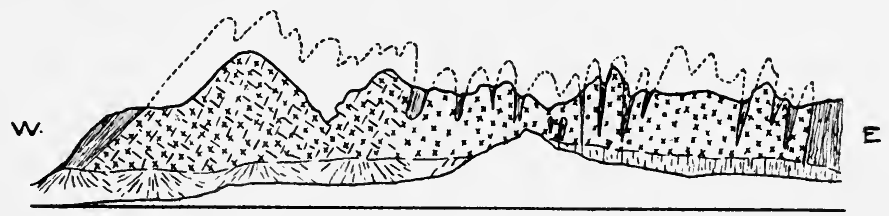

Generalized Section across Andes(Steinmann)

FIG. 20

von Buch and von Humboldt in a day when intrusive and effusive igneous masses were lumped rather indiscriminately together. It will be remembered that according to this theory the mountains were pushed up on the back of the magma much as a blister is raised upon the body, and, like a blister, the mountain was supposed to be a mere skin filled out with liquid under pressure. Everyone will recall the Alps and the Carpathians with their cores of granite, but far more striking examples are supplied by the Rocky Mountains, the Sierra Nevadas and the Coast Ranges of California, and the great Cordilleran system in South America.

Steinmann's generalized section across the Andes with each of the compressed anticlines filled out by a core of granodioritic or andesitic magma is reproduced in Fig. 20. The 
batholites of granodiorite and the laccolites of andesite are alike non-effusive rock, and they come into contact only with the Tithonian limestones and the Neocomian clays. Steinmann's description is illuminating:

"The age of the intrusive rocks is limited backward by the post-Cretaceous folding, forward by the young Tertiary, and it is proper to designate it in general as early or middle Tertiary, hence, younger than the principal period of folding ... the space for the intrusive masses was essentially created by the folding itself. Neither the andesitic laccolites nor the batholitic granodiorites have made a place for themselves by melting it out in the folded range, but they obviously fill previously formed openings, which does not exclude the possibility that it has afterward been somewhat extended."

In the Sierra Nevadas and the Coast Ranges of California, the core of the ranges is occupied by an astounding volume of granitic batholites within the folds to which Lawson has forcibly drawn attention. Speaking of the preCretaceous Mesozoic revolution which produced the ranges, he says, "An essential feature of the revolution was the development of batholitic magmas which invaded the crust, replaced large portions of it, and eventually congealed as plutonic rock of a prevailingly acid character." The development of the batholites, he adds, "followed or accompanied" the uplift.

Describing the granitic cores of the eastern ranges of the Rocky Mountains, these have been rated by Van Hise as pre-Cambrian. Summarizing Hayden's report, he says, "Each of the great ranges of the park are anticlinal axes with massive granite cores and gneissic granites inclining from each side in the form of ridges."

Strangely enough the overlying rock strata generally lack the basal conglomerate which we have every reason to suspect in them. The weakness of the argument that the granite cores of such ranges antedate in age the sediments 


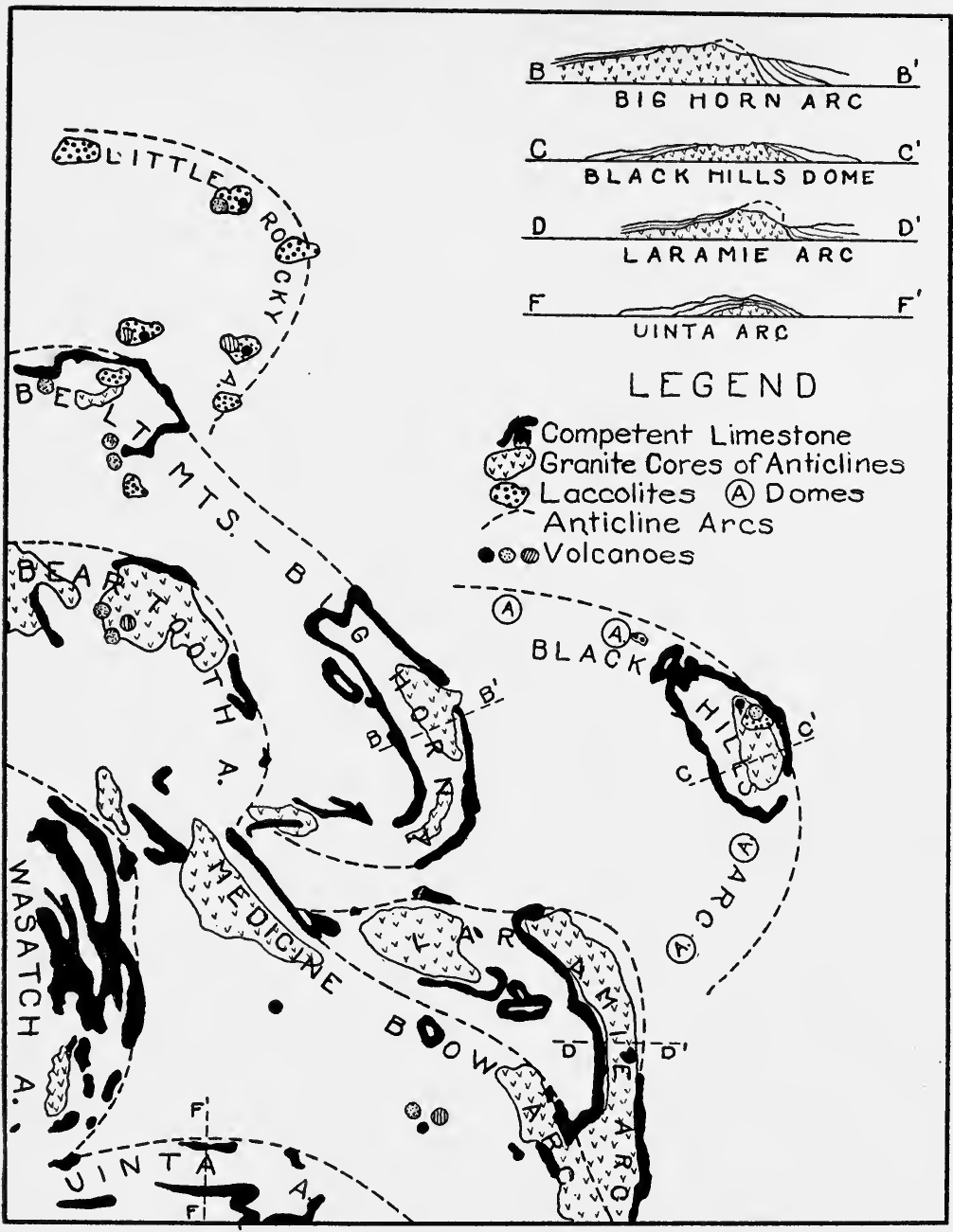

Fig. 21.-Map of the arcs at the front of the Rocky Mts. with their cores of intrusive igneous material

which overlie them, instead of being contemporaneous with the folding of the range, has never been more forcibly put than by Sir Archibald Geikie in discussing the Wasatch Range with its granite core. Writing as long ago as 1880, he said: 
"One would naturally expect that if a mass of strata 30,000 feet thick had been laid down against a steep slope of land, its component beds ought to be full of the fragments of that land. Each marginal belt, representing an old shore line, should be more or less conglomeratic; at least there ought to be occasional zones of conglomerate, just as at the present day we have local gravel beaches on our shore. ... But not only have no pebbles of the Cottonwood granite been recorded as occurring in the overlying Paleozoic rocks, it is admitted that these rocks become metamorphosed as they approach the granite. The natural inference to be drawn from these facts, one might suppose, would be that the granite was later in date than the rocks overlying it."

In the Colorado-Wyoming region there is found a series of rather symmetrical open anticlines, each with its core of massive granite and all alike under a competent arch of the massive Jura-Trias limestone, which arch was elevated in late Cretaceous time (Fig. 21). When the subject of the sequence of these ranges has been considered in a later chapter, it will appear that there are obvious gradations from the laccolites of the Black Hills and Little Belt mountains to the elongated sweeping curves of the granite cores in the Bighorn and Laramie ranges.

A question of considerable interest in connection with this theory of the origin of laccolites and their related bodies of igneous rock, is that of contact effects which ought to be looked for in the enclosing sediments. The theory of origin assigns a common temperature to both the shale which is fused and the sediments which remain unfused about its margins, and except insofar as the separation of gases from the forming magma accomplishes blowpiping effects, there seems to be no good reason why contact effects in the country rock such as belong to true intrusions should be looked for as a necessary condition. 


\section{LITERATURE}

Bailex Wiluss. The mechanics of Appalachian structure, 13th Ann. Rept. U. S. Geol. Surv., 1893, pt. II pp. 217-281, pls. 46-96.

M. P. Rudzki. Physik der Erde, Leipzig, 1911, pp. 118-125.

William Herbert Hobbs. A study of the damage to bridges during earthquakes, Jour. Geol., vol. 16, 1908, pp. 636-653.

G. K. Gilbert. Report on the geology of the Henry Mts., U. S. Geogr. and Geol. Surv. Rocky Mt. Region, 1877, p. 160.

W. H. Holmes. Report on the San Juan district, 9th Ann. Rept. U. S. Geol. and Geogr. Surv. Ter., 1877, pp. 237-276.

Whitman Cross. The laccolitic mountain groups of Colorado, Utah and Arizona, 14th Ann. Rept. U. S. Geol. Surv., 1895, pp. 157-241, pls. 7-16.

G. Sternmann. Gebirgsbildung und Massengesteine in der Kordillere Südamerikas, Geol. Rundsch., vol. 1, 1910, pp. 13-35.

A. C. Lawson. The Cordilleran Mesozoic Revolution, Jour. Geol., vol. 1, 1893, pp. 579-586.

C. R. VAN Hise. Correlation papers, Archean and Algonkian, Bull. 86, U. S. Geol. Surv., 1892, chap. 6, The Cordilleras, pl. 9.

Archibald Geikie. On the Archean rocks of the Wasatch Mts., Am. Jour. Sci. (3), vol. 19, 1880, pp. 363-367.

Waldemar Lindgren. Chap. 6 of Problems of American Geology, Yale Univ. Press, 1915.

Wilson B. Emery. The Igneous Geology of Carriso Mountain, Am. Jour. Sci. (4), vol. 42,1916 , pp. 349-363.

Malcolm Rutherford Thorpe. Structural Features of the Abajo Mountains, Utah, ibid., vol. 48, 1919, pp. 379-389. 


\section{CHAPTER V}

\section{THE DEPTH OF THE FOLD POCKETS}

IT is known to every one that rocks do not under ordinary conditions, those with which we are familiar at the surface of the earth, yield to compressive stresses in excess of their strength by bending or folding, but rather by fracturing, that is, crushing. As long ago as 1878 the distinguished Swiss geologist Heim advanced the idea that the process of rock folding is restricted to a zone within the lithosphere below a depth of 5,000 metres, at which the load of the material above is assumed to close the rock pores and so prevent opening of fractures. It is obviously of prime importance for us to consider what depth, if any, is required for folding to occur and permit the formation of a fold pocket of magma beneath a competent stratum.

The modern theory of a "zone of flow" separated from a higher "zone of fracture" by an intermediate "zone of fracture and flow" was in 1895 elaborated by Van Hise, who declared that even the strongest rocks, the ones which carry the stresses in the folding process, would fold, or "flow," at a depth of 10,000 metres or about 6 miles, though shale might be folded at a depth of only 500 metres. Van Hise's statement was tersely made in the following words, "Rocks under less weight than their ultimate strength are in the zone of fracture, that is, when rocks under such conditions are deformed, they break and crevices small or great separate the broken parts. . . . Rocks buried to such depth that the weight of the superincumbent strata exceeds their ultimate strength are in the zone of plasticity and flowage."

Van Hise failed to realize that, unlike the test pieces which are subjected to crushing stresses in our engineering 
testing laboratories, rocks within the lithosphere are prevented from yielding by lateral expansion when compressed in a single direction, and as a consequence the data which he derived possess small value. With the use of powerful modern hydrostatic presses, Professor Frank D. Adams carried out experiments in 1912 to determine what pressures were necessary to close cavities which had artificially been made in test cylinders of rock, cylinders which in the experiments had been first enclosed in nickel-steel collars and compressed from the ends. His results showed that the crushing strength of granite is under such conditions about seven times the usual figure given for it, and Adams reached the conclusion that "under the conditions of pressure and temperature which are believed to obtain within the earth's crust, empty cavities may exist in granite to a depth of at least 11 miles. These may extend to still greater depths, and if filled with water, gas, or vapor will certainly do so."

King after a study of the data secured by Adams concluded, "It is also shown that as far as hydrostatic pressure in the earth's crust is concerned, a small cavity at ordinary temperatures will remain open provided the depth does not exceed a value between 17.2 and 20.9 miles."

It has however been pointed out by Bridgman that in these earlier experiments of Adams the friction of the sides of the rock cylinders against the walls of the enclosing nickel-steel collars prevents the cavities from closing until a compressive stress has been registered which is too large. Making use of a very ingenious device of his own invention which permits of true hydrostatic conditions of compression, Bridgman obtained values for the crushing strength of rock less than half those which had been obtained by Adams. In addition his studies demonstrated that stresses necessary to produce rupture under these conditions have no connection with any stresses and strains which may be introduced by crystalline structure. 
Bridgman reached the conclusion that pores will exist in rocks under pressures such as should be expected to obtain at a depth of twelve miles below the surface, so that his results are in a general way confirmatory of those of Adams. $\mathrm{He}$ says: "The results of these collapsing tests make it extremely probable, however, that minute crevices, at least large enough for the percolation of liquids, exist in the stronger rocks, at depths corresponding to 6,000 or 7,000 $\mathrm{kg} / \mathrm{cm}^{2}$, and possibly more." His studies show also that the method of collapse of the cavities is by a splintering of their walls and a filling of the cavity with the fragments.

In later studies in this field Adams has shown that cylinders of limestone compressed from the ends and enclosed within a copper casing are able to withstand a pressure of nearly 150 tons to the square inch, whereas when tested in the ordinary way they fail at less than one-tenth or onetwentieth of that value $-11,000$ to 25,000 pounds to the square inch. Moreover, it was found that the tendency to lose rigidity and acquire plasticity is a function of the temperature, and if the experiments with granite may be regarded as a guide, Adams' general figure for limestone should be divided by three if the temperature is taken as $550^{\circ} \mathrm{C}$. or that assumed to obtain at a depth of fifteen miles. At ordinary temperatures limestone and granite give about the same values, but limestone is unsuited to experiments at higher temperatures because of its tendency to lose carbon dioxide even at moderate temperatures.

There are almost insuperable objections in the way of assuming that rocks are susceptible of folding only when at depths of 12 to 15 miles or more within the earth's shell. Every angular unconformity with its lower series of folded rocks separated by an erosional surface from overlying unfolded layers, must upon this hypothesis carry the implication that, subsequent to the deposition of the lower series, it was by a transgression of the sea buried by no less than 12 to 15 miles of sediments, and then by a regression of the 
sea of equal measure raised 12-15 miles before being eroded. Such an assumption is of course too preposterous to be seriously entertained, though it clearly follows if we admit that rock folding can alone take place at depths below 12 to 15 miles.

It must be clear that the factor which has not received due consideration is that of time, which cannot be brought into our experiments. Elasticity and plasticity are in a sense reciprocal terms, since the former property measures the tendency to yield by fracture under excessive loads, whereas the latter measures the tendency to yield by change of figure, as in folding, under the action of the same stresses. The inherent elastic force of a substance by virtue of which it resists any deforming force, diminishes with the time such forces are in operation, and for each substance there is a specific factor to measure this called the relaxation time. For steel and for most strong rocks, which are very elastic, this relaxation time is perhaps measured in centuries. The relaxation time is apparently smaller the greater the force and the higher the temperature. Glass at $300^{\circ} \mathrm{C}$. has a relaxation time of the order of a day.

Any observing and thoughtful person who has strolled through an old graveyard must have been impressed by the illustrations there furnished of the relaxation time of marble. Rectangular slabs of marble may be seen supported in horizontal position by stone posts at the four corners, and it must be clear that when erected these slabs, two inches or thereabouts in thickness, would have supported at their centers without sensible deflection a weight several times their own. Yet, after the lapse of centuries they are found bent under their own weight alone into a distinct trough fold (Fig. 22).

There are, however, not lacking examples of folds which have been produced at or near the surface of the earth through tangential compression induced by a piston-like movement of an advancing glacier front. In such cases the 
involvement of glacial materials within the folds produced, together with other evidence, identifies the agent clearly (Fig. 23, a and b). Also in connection with the process of faulting, a dragging or bending backward of the strata

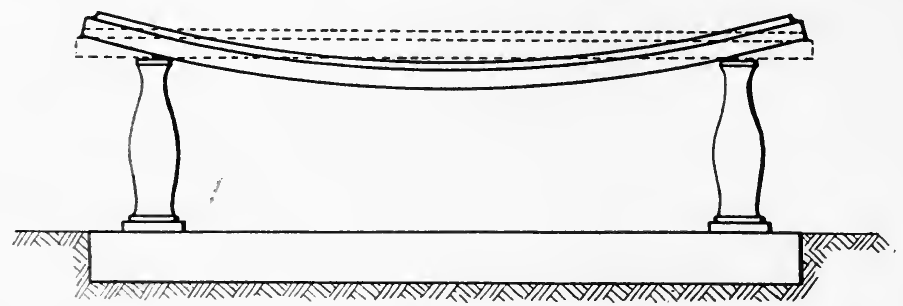

FIG. 22.-Manner of formation of a syncline in a marble slab under its own weight alone

along the fault plane, is not an uncommon observation. At Put-In-Bay on South Bass Island in Lake Erie are found caves which are due to a local elevation of limestone strata to form domes, and subsequent release of the pressure from

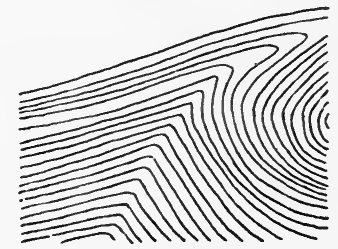

a

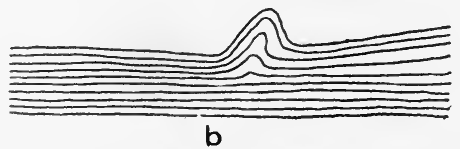

FIG. 23.-Anticlines produced by the pressure (shove) of a continental glacier; $a$, in Queenstown shale on Lake Ontario (Kindle); b, in coal bed in Illinois (Sauer)

below has permitted the lower layers to settle back and leave caves of mushroom form as a result. In the largest of these, Perry's Cave, one of the roof strata is for a portion of the distance still in its earlier domed position, though the 
remaining portion has settled down and again lies horizontally along the floor of the cavern. The late Professor James Geikie described a one inch marble slab enclosed in a sandstone casing in one of the Scottish graveyards, which slab has become so bent that an arm can be inserted behind it. A stone door jamb in the Alhambra of Granada has taken on a strong curvature from load. All these examples, and others that might be mentioned, clearly indicate that bending of rock strata can take place within very moderate time intervals even when the rocks are not sustaining a heavy load.

Who will venture to predict what amount of bending would occur under the loads which rock sustains at the depth of a mile or more within the earth's shell during the same period, or by what factor this should be multiplied to apply to periods measured in thousands, or even millions, of years. Compared with these periods of continued operation of stresses, the times employed by Adams in his experiments are so small as to be almost negligible.

It would lead us too far to assemble here all the reasons why any such figure as a depth of 12 to 15 miles for the upper surface of the zone of folding is untenable. It will be sufficient if we can show that rock folding is going on today at much higher levels and even at the earth's surface itself.

A strong light is thrown upon this problem by the tiltings of reefs in the islands of the coral seas, such as those of Malaysia and Australasia particularly. These recent formations, originally laid down in horizontal position, have since been elevated and simultaneously bent into the forms of folds. In the sections of Fig. 24 the elevated reefs are marked by the letter $\mathrm{k}$, with in some instances the relative age of the reefs brought out by a numerical figure which is the higher the later the formation of the reef.

The eminent group of Dutch geologists who have devoted their attention to a study of the structure within the island 


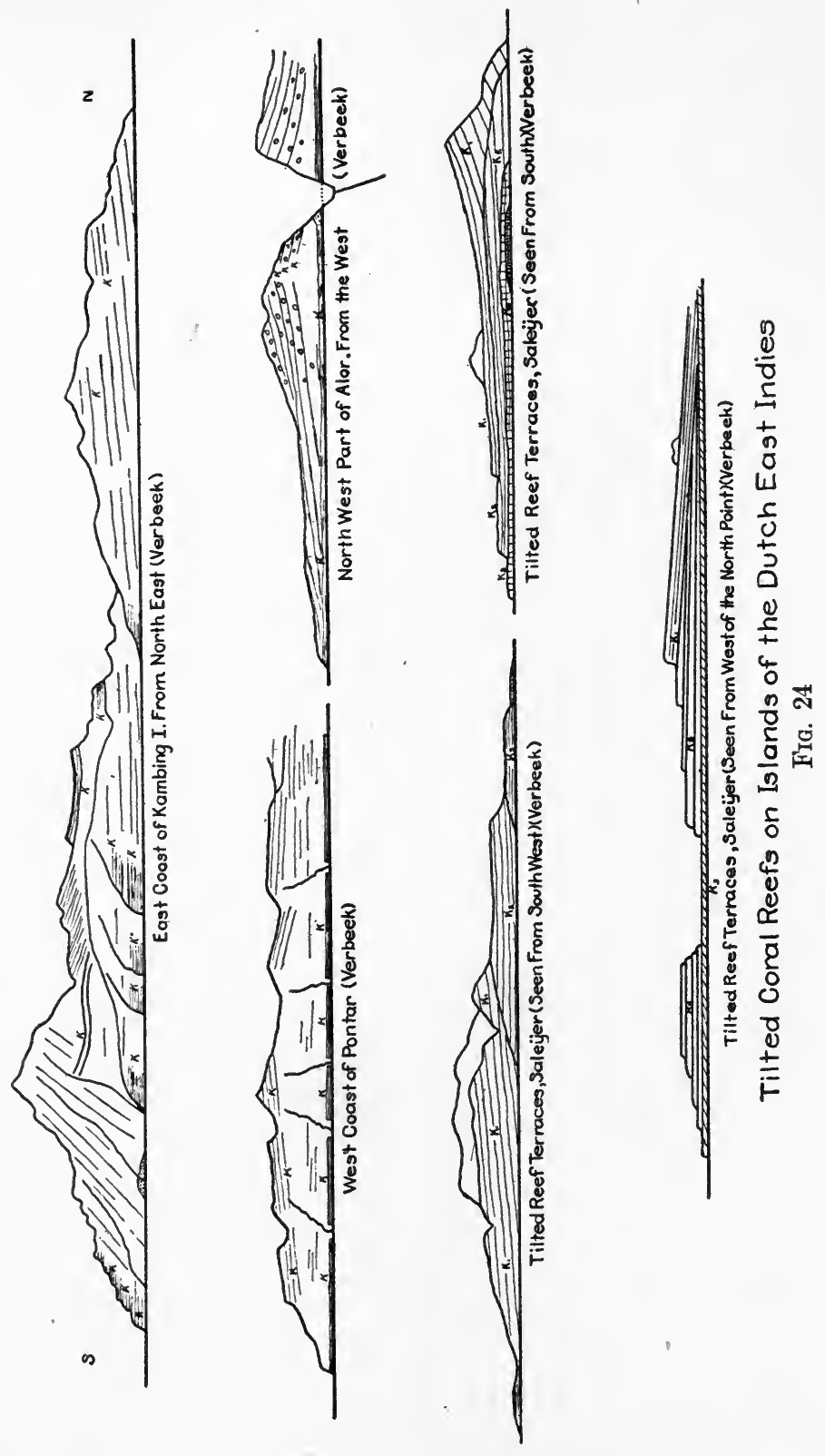


arcs of Malaysia and the Moluccas have made most important contributions to this subject by bringing out the successive steps in the process of anticline formation within the surface rock formations of the islands. Professor H. A. Brouwer has supplied the evidence for large lateral as well as vertical movements of the strata and shown that succes-

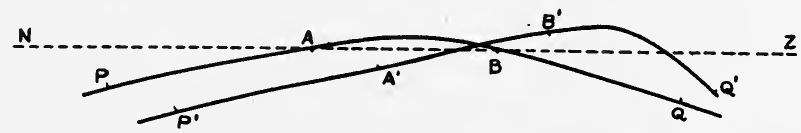

FIG. 25.-Successive positions of anticline forming in a rising island arc (afte Brouwer)

sive positions of the strata during anticline development are represented by PABQ and P'A'B'Q' in Fig. 25, in which $\mathrm{NZ}$ is the level of the sea. The curves represented are just those which correspond to successive stages of growing anticlines on the basis both of field observations in mountain districts and of the results of experiment. To indicate in what manner the coral growths betray such movements, we

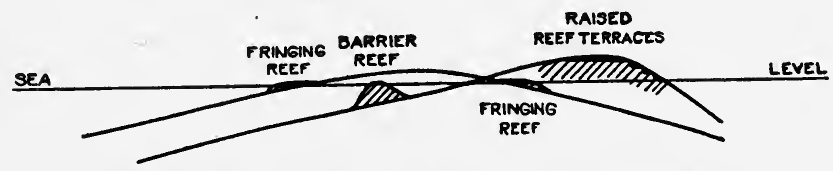

Sections to illustrate the nature and position of the reefs which result from mountain grouth

FIG. 26.-Manner of formation of elevated reef at front and of barrier reef at back of a developing anticline arc

have added the diagrams of Fig. 26. An upward motion of the shore will obviously result in successive elevated reef terraces, whereas a movement in the opposite direction will result under favorable conditions in the formation of barrier reefs or atolls.

Though anticlines develop even at the earth's surface, and doubtless in periods much shorter than those which geologists are accustomed to admit, it none the less seems probable that the process of folding is greatly facilitated at 
greater depths where load must be a factor of importance. Expressed technically, the relaxation time is reduced with depth, and the rock rendered so much the more plastic. In some such sense the basal idea of the zone of flow may perhaps be retained. In any case it can only be at a depth sufficient for rock fusion that pockets of magma could form beneath competent arches in the manner already set forth in preceding chapters.

\section{LITERATURE}

Albrecht Heim. Der Mechanismus der Gebirgsbildung, 1878, p. 31.

C. R. VAN Hise. Principles of North American pre-Cambrian geology, 16th Ann. Rept., U. S. Geol. Surv., pt. I, 1895, pp. 571-603.

C. R. Van Hise. A treatise on metamorphism, Mon. 47, U. S. Geol. Surv., 1904, pp. 186-191.

F. D. ADAms. An experimental contribution to the question of the depth of the zone of flow in the earth's crust, Jour. Geol., vol. 20, 1912, pp. 97-118.

L. V. KING. On the limiting strength of rocks under conditions of stress existing in the earth's interior, ibid., pp. 119-138.

F. D. AdAMs and E. G. Cokre. An experimental investigation into the flow of rocks, First Paper, The Flow of Marble, Am. Jour. Sci., vol. 29,1910 , pp. $465-487$.

JoHn Johnston and L. H. Adams. On the effect of high pressures on the physical and chemical behavior of solids, Am. Jour. Sci., vol. 35, 1913, p. 251.

Frank D. Adams and J. Austin Bancroft. On the amount of internal friction developed in rocks during deformation and on the relative plasticity of different types of rocks, Jour. Geol., vol. 25, 1917, pp. $597-637$.

L. V. KING. On the mathematical theory of internal friction and limiting strength of rocks under conditions of stress existing in the interior of the earth, ibid., pp. 638-658.

P. W. Bridgman. The failure of cavities in crystals and rocks under pressure, Am. Jour. Sci., vol. 45, 1918, pp. 243-268.

P. W. Bridgman. Stress-strain relations in crystalline cylinders, ibid., pp. 269-280.

JAMES Geikie. Proc. Roy. Soc., Edinb., vol. 10, 1880, pp. 525-529.

H. A. Brauer. On reefcaps, K. Akad. Wetensch. Amsterdam, vol. 21, nos. 6-7, pp. 1-10 (reprint).

H. A. Brauer. Fractures and faults near the surface of moving geanticlines, I ibid., vol. 23, No. 4, pp. 1-7 (reprint). 


\section{CHAPTER VI}

\section{THE VAPORS AND GASES OF LAVA}

In practically constant association with the magma that reaches the earth's surface are gases and vapors generally in large volume, and their liberation into the atmosphere with explosive combination and oxidation supply at least most of the energy which serves to make volcanic eruptions among the most awe-inspiring of natural phenomena.

Not all the vapors and gases are released into the air, residual portions being held in the vesicles of the lava; other portions react upon the rock or they collect upon it as solid sublimates. These latter can usually be driven off by strongly heating the rock, by which they often undergo reactions.

The gases and vapors which together issue from an active volcanic crater, have long been believed to be in largest part water, either in the form of superheated gas or of vapor; but with the water is usually associated one or more of the gases hydrogen, carbon monoxide, methane, chlorine, and sulphur dioxide. Recent studies would indicate that relative to the water vapor the admixed gases play a larger rôle than has generally been supposed to be the case.

In the process of release into the atmosphere, those gases which can unite either with their associates or with atmospheric oxygen, do so and thus furnish much of the energy of crater explosions. Hydrogen burns to form water vapor, the carbon monoxide oxidizes to carbon dioxide, and any sulphur to sulphur dioxide and occasionally sulphur trioxide. A portion of the hydrogen may unite with free chlorine giving hydrochloric acid gas.

The "steam" and "smoke" which are so often described 
in connection with every active volcano, even during its periods of relative repose which separate grander eruptions, is now recognized to be a mixture of steam with fine fragments of lava. This "smoke" may be either white, gray, or black, the depth of the shade indicating the proportion of admixed volcanic "ash."

Quite recently Brun has set up the thesis that no water vapor, or at most very little, is present in volcanic emanations; the white color of the cloud above craters being in his belief due, not to aqueous vapor, but to ammonium chloride or other fumes. This challenge of Brun to volcanologists, supported as it has been by extended examinations of active volcanoes and by his own laboratory experiments, has had the effect of bringing out new investigations by both geologists and geophysicists, notably those of Gautier and of Day and Shepherd. As a result of these studies one may now state with all confidence that the statements of Brun must be modified though containing a large measure of truth.

From the surface of the lava lake of Halemaumau in the crater of Kilauea, Day and Shepherd succeeded for the first time in drawing off the escaping vapors and gases through an iron tube and collecting them under such conditions as they believed precluded the possible admixture of atmospheric air. In the first fifteen minutes of the experiment 300 cubic centimeters of water were condensed in the tube. Later analysis showed the water to vary markedly in quantity, namely, from $18 \%$ to $90 \%$ by volume of the entire mixture. Later studies by Shepherd indicated, however, that these data were unreliable because of the admixture with atmospheric air. The conclusion which is reached concerning Kilauea at least, is that little water is present in the fumes over the crater with the exception of what has entered from the atmosphere within the crater itself. Thus those early but keen observers, Green and Brigham, have been confirmed in their opinions. Like many 
others the writer has observed the fume cloud drift away in contact with colder air, but without evidence of condensation such as would be necessary if it contained considerable proportions of steam.

In the emanations from the quiet crater of Vesuvius three months and fifteen months respectively after the eruption of 1906, Gautier found that the proportion of water vapor issuing from crevices (fumaroles) ranged from $62 \%$ to $78 \%$ of all the emanations. These fumarole emanations issued at temperatures varying from $250^{\circ}$ to $300^{\circ} \mathrm{C}$. At the higher temperatures at which gases and vapors are found in association with lava, they must be largely in a dissociated condition, and such condition harmonizes with what we now know of the behavior of these gases. Chief among the dissociations which must take place, is a large one of water vapor into its crmponents hydrogen and oxygen, and in the gases issuing from low temperature fumaroles, such as are found in the craters of volcanoes during the periods between eruptions or at more distant points during an eruption, the content of hydrogen is relatively small or even nothing. It has long been recognized, also, that just as hydrogen, methane, and carbon monoxide are found in the higher temperature emanations from near the molten lava, carbon dioxide is correspondingly abundant in the more distant low temperature emanations.

Water when heated by itself is properly regarded as an exceedingly stable substance and suffers less than $2 \%$ of dissociation at temperatures even up to $2000^{\circ} \mathrm{C}$. Heated in contact with igneous rocks, however, at temperatures at or above red heat, it undergoes large dissociation, particularly, it would seem, whenever substances are present to unite with the nascent oxygen set free. Gautier has shown that iron silicates when heated to redness in a current of steam yield a gas which contains no less than $65 \%$ of hydrogen. It is doubtless because of ready oxidation by the nascent oxygen thus set free by dissociation, that oxygen 
gas is one of the least abundant of those found in volcanic emanations, and that methane and hydrogen sulphide are also sometimes present to indicate a strongly reducing condition within the gaseous mixture.

It is an inheritance from the Kant-Laplace hypothesis and the consequent conception of a still molten interior for the earth, that the gases of lavas, with the exception of water vapor, are so generally believed to be emitted from the molten interior. These gases are assumed to have been absorbed with the condensation of the planet from its vaporous nebula. The great Viennese geologist, Eduard Suess, who held to this view, wrote of it, "Just as molten iron absorbs extremely large quantities of gas, and gives them off again as it cools, so the globe of the earth once absorbed extremely large quantities of gas, which it is now still continuing to emit." He says further, "Just as there is juvenile hydrogen, so there is juvenile chlorine, fluorine, arsenic, carbon, and a series of other elements, all emitted by volcanoes." The name "juvenile" is still widely used for such gases as are assumed to be derived from the original earth interior, though it must be obvious that after discarding the notion of a molten earth core, not only the question of the origin of these gases but that of their liberation must be taken up de novo.

The large volume of water vapor given off at volcanic vents, was for a long time explained by assuming that ocean water in some way finds a passage to the molten magma in the subterranean reservoir, and the localization of volcanic vents either upon islands of the sea or close to its borders has seemed to lend color to this view. As we are to see, this arrangement of the vents finds another explanation more in harmony with our present knowledge of the earth.

It must now be our purpose to see whether the gases and vapors characteristic of lava emanations or occluded in consolidated igneous rock, are satisfactorily accounted for on 
the theory of the origin of lava in the local fusion of shale to form a pocket, and the ascent of the resulting magma to the surface through the superincumbent rock cover.

Omitting the eight principal constituents of shale which have already been considered in their close relation to the corresponding constituents in the average igneous rock, there still remain a number of others present in less amount but yet of large significance. In the analysis made from a composite of 78 shales, an analysis carried out in the laboratory of the United States Geological Survey, the following proportions of these accessory constituents were obtained:

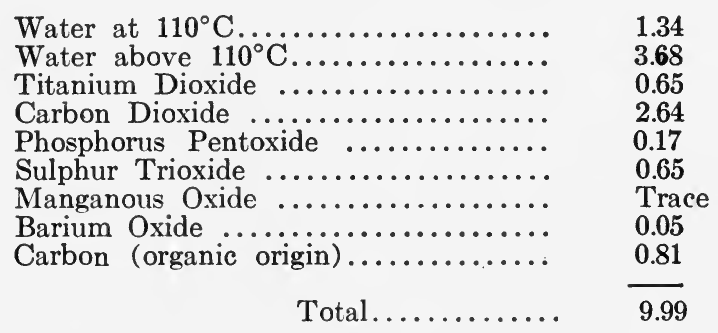

It is not necessary to assume that the sulphur was present in the shale in the form of the oxide, since it is far more probable that this is present in combination with iron as pyrite, iron disulphide.

It has already been pointed out that when in contact with rock at a temperature even as low as red heat, water is to a very large extent (65\%) dissociated into its gaseous components, hydrogen and oxygen. The carbon dioxide at higher temperatures dissociates into carbon monoxide and oxygen. Oxygen from either of these sources in its nascent condition will readily unite as opportunity arises with the organic carbon, with sulphur, and with any sodium which has been set free from sodium chloride.

In its ascent toward the surface with the magma, the volume of $\mathrm{CO}$ and $\mathrm{CO}_{2}$ will be augmented by calcination 
of carbonates in any calcareous sediments which are assimilated, and this will take place particularly under the reduced pressures within the last one thousand feet before reaching the earth's surface. Chlorine will come into the gases through dissociation of any sodium chloride encountered by the magma en route, and the sulphur will be augmented by the breakdown of salts of sulphur such as are admixed with sodium chloride in sea and desert salts. It has already been pointed out in an earlier chapter that a comparison of the composition of rocks which are of relatively deep-seated consolidation within the earth's outer shell, with those which arrived near to or at the surface, shows apparently in the latter group an increase of the bases oxide of lime and oxide of sodium, which would result from such assimilation of carbonates and chlorides as has been described. The combination of free oxygen with sulphur, carbon, sodium and other elements probably explains why oxygen is among the rarest of the gases emitted from lavas and why these have so generally a reducing character. Few geologists have, however, been willing to assume that any considerable assimilation of country rock goes on in connection with the movement of magma, Loewinson-Lessing, Daly and Sederholm being exceptions to the rather general rule.

It is pertinent now to inquire what the observations of geologists tell us concerning the manner of opening up a conduit through which magma contained in a subterranean chamber may be conducted to the earth's surface. It was the belief of Suess that in few cases does this take place through a fissure, but rather after the manner described by Daly, in which the gases issuing from the magma near its upper surface are there permitted to unite and so develop heat after the manner of a blowpipe. He says, "Owing to their high temperature they melt and stope their way through the overlying rocks, and thus force their way up- 
wards." Elsewhere he has described the process as not unlike that by which a red-hot iron makes its way upward through a board.

Barrell and Daly have developed this process of overhead stoping in special studies, and the parallel is drawn with the quarrying process of that name in use by miners. The hot gases fuse and assimilate portions of the roof-rock near pre-existing fissures and eventually quarry away blocks which, once detached from the roof, tend to founder in the magma.

The source of the nitrogen which is generally sparingly present in magmas, though sometimes in large amount, has generally been attributed to admixture of atmospheric air. In cases where air is excluded, its origin must be sought in the air which is held in solution in the underground water of surface origin and involved in the lava during its rise to the surface. Such nitrogen is usually found mixed with argon. Quite surprising was it therefore to find in the gases withdrawn from the lava lake of Kilauea, as first reported by Day and Shepherd, that analysis showed nitrogen quite free from argon comprising from $11 \%$ to $63 \%$ of the whole. Later studies yielded quite different results and ones much more easily explained. Argon is present in all samples which were tested and the nitrogen was found to range from less than $1 \%$ to more than $23 \%$. Professor Jaggar, whose studies carried out through a decade of painstaking observations from his station at Kilauea have yielded such rich results, has shown that air is drawn into the lava column of Halemaumau as though in a furnace, and that it plays a large rôle in supplying the energy of the eruptive forces.

Those gases which are not expelled from the lava at the time of its eruption are locked up in the congealed mass. These are liberated when the rock is heated sufficiently.

The many studies of gases which are driven off at high temperatures from igneous rocks, and notably those which 
were made by $R$. T. Chamberlin, are quite striking in their similarity to those liberated by similar heating of sedimentary rocks and with many which are wholly unconnected with volcanoes. This has led to the conviction that we are here dealing with materials absorbed from the atmosphere and found in a condition dependent chiefly on the process of expulsion.

In summarizing, then, we see that the principal gases of lava-water (gas or vapor) hydrogen, carbon dioxide, carbon monoxide, hydrochloric acid, chlorine, sulphur dioxide, and oxygen - are all to be accounted for either by the materials already present in shale which by fusing may be considered to have produced the lava, or by accessions-largely chlorine and sulphur-which have been secured during the magma's ascent to the earth's surface. It is no doubt significant of this manner of origin for chlorine and sulphur, that of all the gases of lavas chlorine and sulphur in their different. states of combination are the least constant in quantity, both being frequently absent altogether though at other times present in large volume. On Mt. Vesuvius during the waning stages of the great eruption of 1906, Perret detected both hydrochloric and sulphuric acid. It has sometimes occurred after an eruption of Vesuvius that the solution of hydrochloric acid in rain-water has been of such strength as to destroy the vineyards upon the slopes. Sodium chloride in incrustations and in various sublimations are found in the lava, and the iron in the basalt is often responsible for a yellow tinge through the formation of a surface coat of ferrous chloride which the uninitiated believe to be sulphur.

Worcester in his report on the eruption of Taal in the Philippines on the 30th of January, 1911, described a heavy precipitation of mud so strongly charged with sulphuric acid that the bodies of the natives who perished in it were found flayed by the acid. 


\section{LITERATURE}

F. Loewinson-Lessing. Studien ueber die Eruptivgesteine, C. R. VII Sess. Cong. Géol. Intern., St. Petersburg, 1897, 1899, III, Die Magmatische Differentiation, pp. 366-370.

R. T. Chamberlin. The gases in rocks, Doctor's dissertation Univ. of Chicago, Lippincott, 1908 , p. 80.

F. A. Perret. Vesuvius, characteristics and phenomena of the reposeperiod, Am. Jour. Sci., vol. 28, 1909, pp. 422-423.

DeAN C. Worcester. Taal volcano and its recent destructive eruption, Nat. Geogr. Mag., vol. 23, 1912, pp. 350-355.

A. BRUn. Recherches sur l'exhalaison volcanique, Geneva and Paris, 1911, p. 277 , pls. 34 .

William $H$. HobBs. Some considerations concerning the place and the origin of lava maculæ, Gerlands Beiträge zur Geophysik, vol. 12, 1913, pp. 330-361.

A. L. DAY and E. S. Shepherd. Water and volcanic activity, Bull. Geol. Soc. Am., vol. 24, 1913, pp. 573-606, pls. 34.

E. S. SHEPHERD. The composition of the gases of Kilauea, Bull. Hawaiian Volcano Observatory, vol. 7, no. 7, July, 1919, pp. 1-4.

EduARD SuEss. The face of the earth, Translation by Sollas, vol. 4, 1909, pp. 548-559.

R. A. Daly. The mechanics of igneous intrusion, Am. Jour. Sci. (4) vol. 15,1903 , pp. 269-278.

JOSEPH BARRELL. Geology of the Marysville mining district, Montana, Prof. Pap. no. 57, U. S. Geol. Surv., 1907, pp. 151-178.

J. P. IDdings. The problem of volcanism, Yale University Press, 1914, pp. 7-15.

F. W. Clarke. The data of geochemistry, Bull. 616, U. S. Geol. Surv., 1920, chap. 8, pp. 255-285.

J. J. SEDERHOLM. On regional granitization (or anatexis) Comptes Rendus Congrés Géol. Intern. 12me Sers. Canada, 1913, p. 319.

PentTi Escola. On volcanic necks in Lake Jänisjärvi in Eastern Finland, Bull. de la Comm. Géol. de Finlande, no. 55, 1921, pp. 1-13.

T. J. JAGGAR, JR. Volcanologic Investigations at Kilauea, Am. Jour. Sci. (4), vol. 44, 1917, pp. 161-220. 


\section{CHAPTER VII}

\section{THE CHANGES OF FIGURE WHICH THE EARTH HAS PASSED THROUGH}

IT is only to the person looking out over the sea, or upon a vast plain, that an impression of the earth's rotundity is received through the senses, and even under such circumstances it is only the discerning observer who gains any other impression than that of monotonous flatness. The eclipsing of the lower portion of distant objects seen over the bulging surface of the sea, especially ships "hull down" on the horizon, is apt to give us our earliest clear impression of earth sphericity, though an even better demonstration is possible at such times as the profile of the earth is shadowed upon the moon. This latter demonstration makes clear that if the earth's figure departs at all from a perfect sphere, the variation must be by extremely small amounts.

Precise comparative measurements of the length of a degree of latitude along a meridian, made in the equatorial and near polar sectors of the earth, have nevertheless shown that the figure to which the lithosphere and its watery envelope approach is an ellipsoid of revolution or spheroid, whose polar diameter is shorter than its equatorial diameter by about $1 / 299$ th, a difference far too small to be appreciable to the eye upon any demonstration model having the same proportions. This flattening of the spheroid of the earth about its poles, which constitutes its oblateness, though small, must not for that reason be accounted as unimportant. As a matter of fact it is of the utmost significance as indicating that the earth's rotational velocity was once much greater than it is today, for such greater velocity would have increased proportionately the centrifugal force 
and induced bulging in the equatorial region with corresponding contraction at the ends of the axis of rotation.

The departure of the earth's figure from that of a perfect sphere toward an oblate spheroid, is not the only one which it has undergone. Of the same order, and of very nearly the same amount, are other departures from the spherical figure which are revealed by the size, shape and positions of the ocean basins on the one hand, and the continental platforms upon the other. The bottom of the greatest deep of the sea is about twelve miles nearer the earth's center

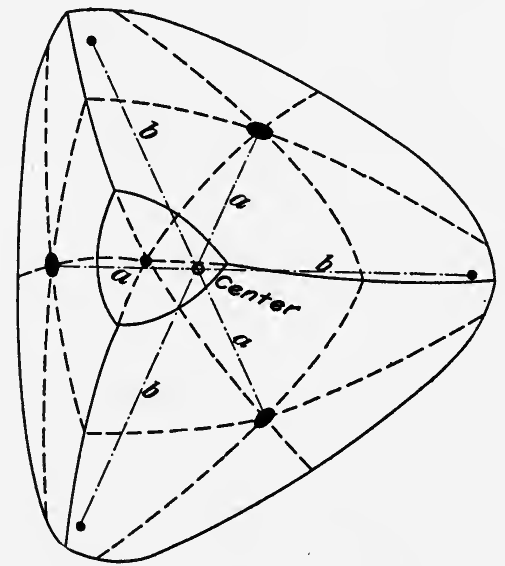

Fra. 27.-A tetrahedron with bulging faces and truncated angles to bring out its contrasted antipodal relationships

than the crest of Mt. Everest, the highest elevation upon the continents, and the geographic poles of the earth as a consequence of oblateness are on the average thirteen and one-half miles nearer the earth's center than the average of points on the equator.

The figure toward which the earth departs from the spheroid, as indicated by the distribution of land and sea, has often been described as a tetrahedron, though the statement is almost grotesque when put in this blunt form. The tetrahedron is a solid body which has four equal plane surfaces, each of which is an equilateral triangle, and four 
"solid" angles in each of which three edges or dihedral angles meet. Such a solid, or polyhedron, has obviously so little resemblance to the spheroid that to show the relationship it is far better to compare a modified tetrahedron with bulging faces and deeply truncated angles. When this is done (Fig. 27), we see that each face of the model represents a portion of the surface which comes nearest to the center of the figure, while opposite to such a face there is always a solid angle representing the part of the figure farthest away from its center of form. The edges in which

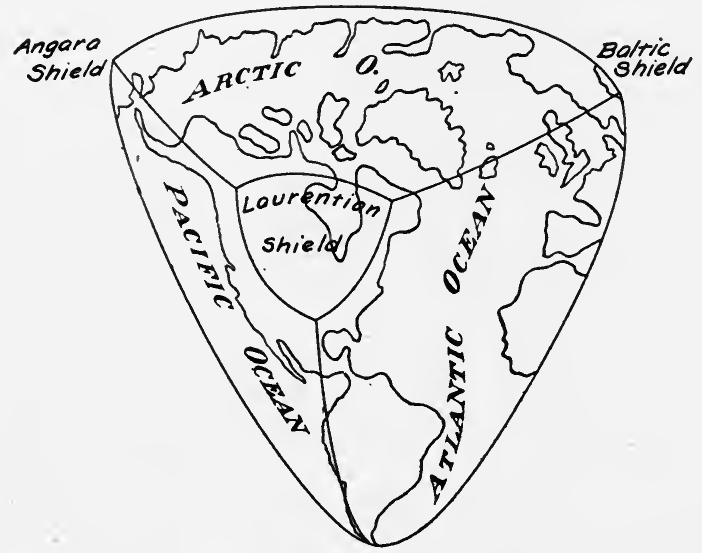

FIG. 28. - The earth expressed as a departure of the spheroid toward the tetrahedron

the bulging faces meet, represent those parts of the surface which are farthest away from the center, excepting only the solid angles themselves in which these edges are united.

If now we stand the model upon one of its truncated solid angles, so as to represent the great protuberance of the Antarctic continent, the opposite (top) face of the model will serve to represent the deep oceanic basin of the Arctic Ocean, with its encircling rim of land in at least partial correspondence with the tetrahedral edges bounding this face of the figure (Fig. 28). The three remaining truncated solid angles all lie within this land rim and fall into rough 
correspondence with three ancient land areas of the globe which have been characterized as its "shields" or "coigns." These coigns are respectively an area surrounding Hudson's Bay known as the "Laurentian or Canadian Shield," one surrounding the Baltic Sea called the "Baltic Shield," and a third in east-central Siberia referred to as the "Angara Shield." These oldest known land areas of our planet constitute the nuclei, to which later marginal land zones have been added in a very complex historical sequence to produce the present continents.

There are several tests which may be applied to the lithosphere to determine whether it may properly be regarded as departing in a significant, even if not in a large, measure from the ideal figure of the spheroid toward the modified tetrahedron. If we include in the continental platforms, as is customary, the shallow sea-floor borders of the continental shelves, these platforms include about one-third of the entire superficial area of the lithosphere, as against about one-half of the area which is included in the relatively deep sea-floor of the oceanic platform, the remaining portion being largely comprised within the continental slopes joining the two platforms. In each medial line of our tetrahedral figure (Fig. 27), the essentially antipodal contrasts characteristic of the figure are displayed. Thus, a, represents a short radius beneath a face of the figure, and $b$, a long radius beneath the opposite angle. For the lithosphere this antipodal relationship is well brought out by the distribution of land and water, or better by the distribution of the continental and ocean platforms. The contrast is greatest along the polar diameter where the basin of the Arctic is opposed to the high continent of the Antarctic. The other coigns of the earth are only less strikingly opposed to the ocean basins, and just as we have the rim of edges to the tetrahedral figure represented by the circuit of land about the Arctic, so we have the continuous zone of oceans, the so-called "south seas," to represent the taper- 
ing figure of the tetrahedron about its southern apex. In general it is true that if the finger be placed upon any portion of the continental platform as represented upon a correct model, a portion of the oceanic platform is found in the antipodal position. Corresponding to the three faces of the tetrahedron which converge toward the southern apex, upon the lithosphere we find the Atlantic, Pacific, and Indian oceans in roughly these positions, and all these oceans broaden progressively in the southerly direction until they unite.

Inasmuch as the force of gravity at any point on the earth's surface has a value inversely proportional to the distance through which it acts, with the earth's mass concentrated at its center of form, the average value for the force of gravity for points within the southern hemisphere should be less than the average value within the northern hemisphere, the Arctic basin excepted. This is a well attested fact demonstrated by investigations carried out with pendulums. The period of vibration of the "seconds" pendulum is a function of the local value of gravity, and when pendulum clocks are transported from the northern to the southern hemisphere, the length of the pendulum must be adjusted if they are to keep accurate time.

We see, therefore, that however grotesque may appear the bald statement that the earth departs in its figure from a spheroid toward a tetrahedron, such an assertion expresses observed fact and not theory only. The absurdity would be to state that its figure is that of a tetrahedron. Its spheroidal form we can easily and naturally account for by its rotation when in a more plastic condition than it is today and rotating more rapidly.

All the planets are similarly spheroidal in figure, with varying degrees of oblateness which are believed to express differences in original rotational velocities. The degree in which oblateness expresses velocity of rotation may be visibly demonstrated by fixing a wooden hoop at one point 
of its rim in the vertical axis of a revolving table and allowing the stiff rod which forms the rotating axis to pass loosely through an aperture at the opposite point of the rim, so as to keep the position of the hoop vertical during its rotation though permitting it to move the free side of its ring upward or downward in obedience to the varying centrifugal force. During rapid rotation the hoop appears as a spheroid and as the table rotates more and more rapidly the oblateness of the spheroid increases, only to fall off correspondingly as the velocity is diminished.

But what is the explanation of the departure of the earth's spheroid toward a tetrahedral figure? The natural explanation is found, and so far as known the only one that has been offered, in a continued reduction of volume of the lithosphere which is believed to be the result of the earth's secular cooling-loss of internal heat to the surrounding space-as has already been pointed out in the previous chapter. The sphere to which the earth's spheroid so closely approximates is of all regular figures the one which has the smallest superficial area for a given volume. Now the outer shell of the lithosphere must early have acquired an essentially stable temperature, whereas the interior portion, protected by its poorly conducting shell, lagged behind in the cooling process, and has apparently continued to lose heat throughout the geological ages continuing to the present time. The shell having thus acquired a fixed superficial area, has been compelled to undergo changes of figure in closing in upon its ever smaller core under the impelling force of gravitation.

Now it is true that regular geometric figures have smaller volume for any given surface in proportion as they have few plane surfaces or faces, and the tetrahedron with its four faces represents the lower limit to this series, as the sphere with its infinite number of faces does the upper, for the reason that a lesser number of plane surfaces than four could not be made to enclose space. The solid series repre- 
sented in sequence in fig. 29 from the sphere through bodies having respectively $48,24,12$, and 8 faces to the limiting tetrahedron of 4 faces, will help to make this clear, though it must on no account be assumed that the earth has passed to its present tetrahedral tendency by the route represented.

Experiments carried out with hollow spheres made from thin and flexible metal have demonstrated that these bodies deform toward a tetrahedron when reduction of their volume is brought about through exhaustion of the contained air. It is therefore no more unnatural to account for the departure of the earth's figure toward a tetrahedron as a result of reduction of volume through secular cooling, than it is to explain the departure of the sphere toward the spheroidal figure by almost exactly the same amount due
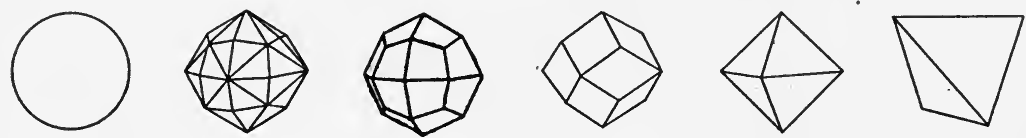

FIG. 29.-Series of polyhedrons from the sphere with greatest volume to the tetrahedron with least volume

to an earlier higher temperature and higher rotational velocity.

We might, perhaps, carry the subject of departures of the geoid from the spheroid of tetrahedral tendency, so as to take account of the fact that the disproportionate size of the Pacific involves a certain flattening of the spheroid in one plane parallel to its polar axis and give it somewhat the form of a potato, but the cause of this departure is still obscure, at least to the geologist.

It is not, of course, to be assumed that the earth spheroid, or geoid, underwent transformation toward the tetrahedron through any such series of figures as are represented in the progression of Fig. 29. To learn in outline what the intermediate stages of earth physiognomy have been, we must consult the past history of the earth as revealed in the rocks themselves, the essential documents of geological history. 
Geological thought, and indeed especially American geological thought, has in respect to theories of continental evolution undergone great transformations within recent years. Throughout the first third of the nineteenth century the ideas of the so-called "catastrophists" dominated the field, their view being that geological history had been punctuated by great catastrophes in which a seemingly quiet condition of earth forces permitting plant and animal life, had been suddenly interrupted by a world cataclysm in which great surface changes were brought about and all forms of life destroyed, after which plants and animals of new forms were created. The period in which these ideas prevailed was one in which the Church dominated scientific thought, and a literal interpretation of the first chapter of Genesis formed the basis of earth history. In all Christian countries geologists labored diligently to bring their observations into literal harmony with the Scriptures, and those who dared openly to express opposing views suffered persecution for their independence.

The appearance in the thirties of the last century of that masterpiece of geological writing, Sir Charles Lyell's Principles of Geology, marked the opening of a new era in which was brought about an entire transformation of geological thought. The fundamentally new conception at the basis of Lyell's work was that the cataclysm which had been supposed to end the geological periods with destruction of life and creation of new forms, had no existence; but that the conditions of the present are a key to the past as well. Such a change involved the principle of evolution of life as opposed to the idea of relatively sudden recreations of life following upon its destruction, and this new trend in geological thought antedated by some years the great period of change in the biological field marked by the appearance of Darwin's Origin of Species.

It was only natural that the pendulum of thought, swinging away from a revealed error, should be carried past the 
correct norm to the very opposite side of the arc as a result of the rather extravagant claims for the slowness of geological processes, as opposed to the long approved suddenness of geological change. It will be pointed out in the succeeding chapter that different sections of the earth's surface now differ most widely in the rate at which geological change is taking place, and that in the British Isles such change is today very near to the minimum. It is therefore in no way surprising that Sir Charles Lyell, and his followers even to the present day, have continued to make drafts upon the bank of time for which to the writer there seems to be little warrant.

The idea of a minimum of physical change in combination with a prodigious length of geological time was bolstered in America by the foremost American geologist of his time, Professor James D. Dana, who set up a theory that the ocean basins throughout geological history have maintained essentially the positions they have today, a doctrine widely known and accepted as a fundamental tenet of the science, under the name "permanence of the ocean basins."

It was not until a half century after the appearance of Lyell's masterpiece, which is generally regarded as giving date to the modern era in geological thinking, that the appearance of a work of the same dominating quality marked the beginning of the returning swing of the pendulum, not indeed back to the ideas of the catastrophists, but away from that of slow and moderate geological changes in the earth's surface, which had been the essential element in Lyell's "uniformitarianism." This masterpiece was entitled Das Antlitz der Erde, The Face of the Earth, and was the work of Professor Eduard Suess of Vienna. In it he brought out arguments for the most profound transformations of the ocean basins and the continental platforms. Against the idea that the positions originally taken by the ocean basins had been maintained throughout geological history, 
it was shown on the basis of the now known development and distribution of life, faunal and floral geography, that across where today are great ocean basins there once stretched vast continents larger than any that exist today. The second largest of our oceans, the Atlantic, and the third largest, the Indian, were in middle geological time in large part continents. Professor Suess's broad generalization concerning the main lines in earth physiognomy of the past as well as the present, will continue to stand out among the landmarks in the history of geological science.

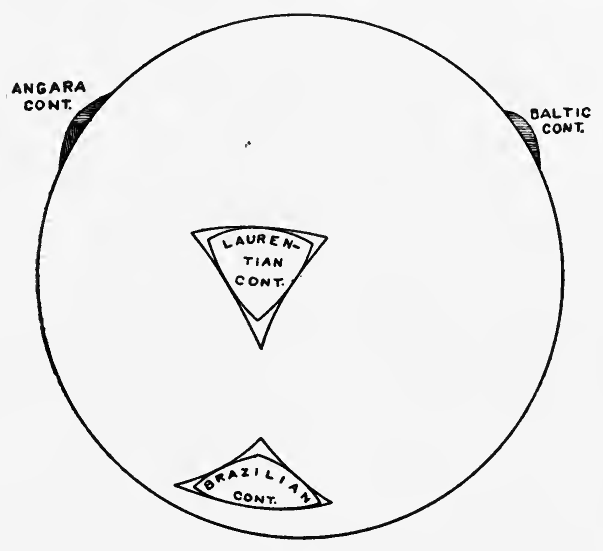

\section{AT END of EOZOIC ERA}

FIG. 30.-Generalized expression of the earth's figure at the close of the first great era of geological history

In the field of the biological sciences, the modifications of Darwin's theory in the direction of recognition of mutations, sudden changes in the evolution of species, has likewise tended to the ascribing of somewhat less importance to the earlier view concerning the extreme slowness of development of the new species of plants and animals.

With this general introduction we shall now pass to a discussion of the outline of evolution in earth physiognomy in an attempt to determine through what transformations the spheroid of earlier planetary history has passed in arriving at its present tetrahedral leanings. Attention has 
already been drawn to the three ancient continents of the northern hemisphere which have been described as coigns or shields-the Laurentian, Baltic, and Angara shields. In their earlier history they existed without the enveloping portions of the present-day continental platforms. Somewhat less clearly defined, perhaps in part because of the less advanced state of geological knowledge for the southern hemisphere, three ancient shields have been recognized to the southward of the equator, the Brazilian, African and Australian shields. In a broad way these southern shields took position similar to the northern ones in being some-

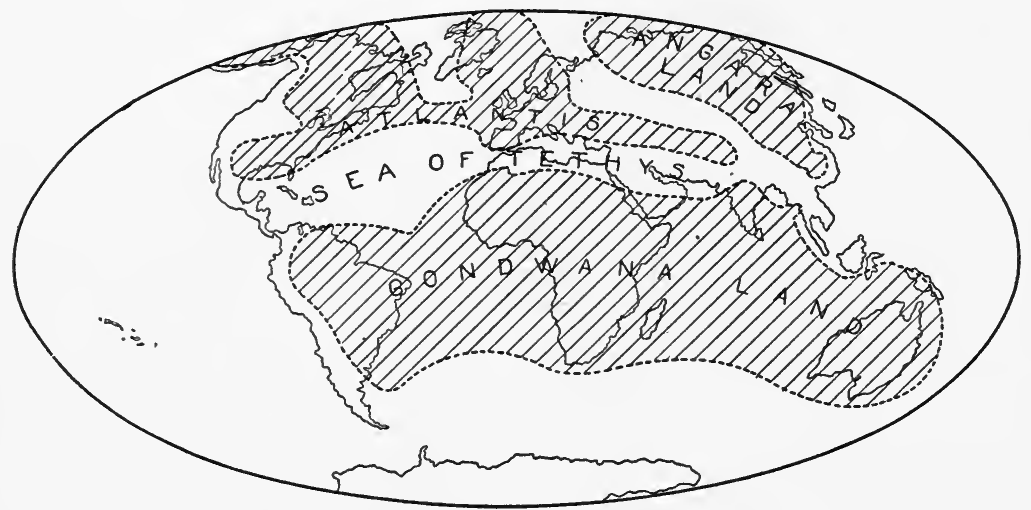

FIG. 31.-The continents at the end of the Paleozoic era (after Arldt).

what evenly spaced in respect to longitude and in rough alignment as respects the northern and southern coigns. Thus at the conclusion of the first great geological era, the Eozoic, the earth physiognomy was, we have reason to believe, comparatively simple and somewhat as represented by figure 30 .

Subsequent to the Eozoic era the coigns became enlarged by marginal growth, and after a series of changes which cannot be here followed in detail, there came about a distribution of land and water which was in striking contrast both with that of the earlier era and with that of the present time. 
Today the continents and the oceans may be described as elongated on north and south lines, if we have regard to the Caspian depression as an interrupted continuation of the basin of the Indian Ocean. Quite otherwise was the distribution at the close of the second great era of geological history, the Paleozoic, when the distribution was more on east and west lines. In the southern hemisphere a great continent which has been called Gondwana Land, stretched from South America eastward across Africa to Australia

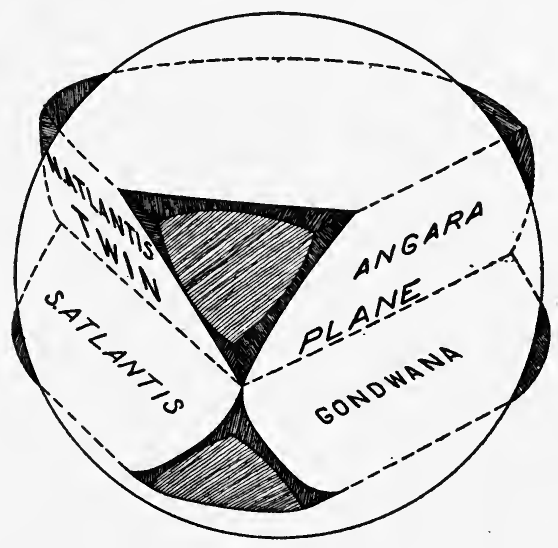

\section{AT ENO OF PALEOZOIC ERA}

FIG. 32.-Generalized expression of the earth's figure at the end of the second great era of geological history

taking in the intervening ocean basins. Somewhat less continuously, apparently, the North Atlantic Ocean was bridged by land to form a real, as opposed to the mythical "Atlantis," which may be referred to as AppalachiaArmorica; and between the northern and southern continents lay a dividing sea which has been named by Professor Suess the Sea of Tethys, the consort of oceans (Fig. 31).

To express this aspect of the earth physiognomy as an intermediate stage toward the present tetrahedral leanings, we arrive at the form represented in figure 32. Such a 
figure with its reëntrant equatorial girdle suggests the well known twin plane of a compound crystal, and it has therefore been denominated the twin plane.

During the next geological era, the Mesozoic, there came about those profound changes which resulted in the foundering of all parts of the Gondwana continent except those which now remain in South America, Africa, Hindu-

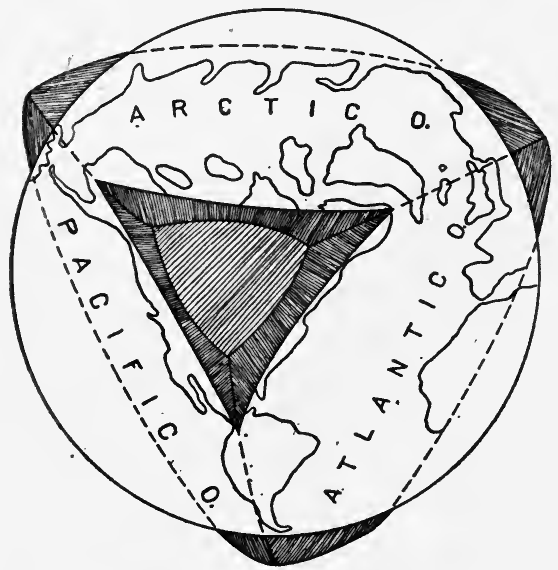

The paesent

Fig. 33.-Generalized expression of the present figure of the earth

stan and Australia. Farther north the portions of Appalachia-Armorica, which separate North America from Europe, foundered to form the North Atlantic Ocean; and to the eastward of the Mediterranean the Mesozoic geosyncline was elevated to form a great belt of mountains so lofty as to be referred to as the "roof of the world." Thus was ushered in the earth of present-day aspect, the physiognomy of which is broadly outlined in Fig. 33 .

\section{LITERATURE}

Sir Charles Lyell. Principles of geology, 2 vols., 11th ed., 1872.

JoH W. Judd. The coming of evolution, Cambridge manuals of science and literature, Camb. Univ. Press, 1910, p. 171.

Eduard Sunss. The face of the earth, English translation by Sollas, 5 vols., Clarendon Press, 1904. 
W. Lowthian Green. Vestiges of a molten globe, as exhibited in the figure of the earth's volcanic action and physiography, pt. 1, London, 1875; part 2, Honolulu, 1887.

JoHn W. Gregory. The plan of the earth and its causes, Geogr. Jour., vol. 13, 1899, pp. 225-251.

B. K. Emmrson. The tetrahedral earth and the zone of the intercontinental seas, Presidential Address, Bull. Geol. Soc. Am., vol. 11, 1900, pp. 61-96, pls. 9-14.

Theodor ARLDT. Die Entwicklung der Kontinente und ihrer Lebewelt, Leipzig, 1907, p. 729, pls 23.

WrLliam H. HobBs. Earth features and their meaning, Macmillan, 1912, chap. 2, The figure of the earth. 


\section{CHAPTER VIII}

\section{THE PRESENT REGIONS OF RAPID CHANGE}

We have seen that the earth's figure as shown by the changing distribution of land and sea has more than once undergone profound changes during the geologic past, and that in the transformation from one figure to another the strains must obviously have been greatest within certain belts or zones which separate the sinking from the rising sectors. If such large-scale deformations have not altogether ceased, a question of absorbing interest is concerned with the place of their operation today. Now movements of the earth's surface shell do not take place uniformly through a slow continuous warping only of the shell, as was so long believed; but stresses which tend to produce movement are resisted until they have accumulated sufficiently to overcome the resistance, whereupon partial relief may be obtained through a jolting displacement and subsequent readjustments, which successive joltings are manifested to us as earthquakes and their "after-shocks."

In the distribution of earthquakes is to be found the locus of most pronounced earth movement today-the zones of present maximum change in figure of the straining lithosphere. For the continental areas we have long knowr the position of the earthquake districts. Such visitations are too destructive of life and property not to have been mapped out on the basis of historical data, at least for the more thickly settled portions of the earth. As assembled by de Montessus de Ballore, these are given in the Mollweide projection in figure 34. It is quite as important that we know the part of the sea-floor in these movements, hidden though it is beneath the hydrosphere. It is only 
during the present generation that methods have been perfected for exploring the bottom of the sea for earthquake adjustments, though some indication of the more mobile zones are supplied us in the location of earthquake seawaves, long erroneously referred to as "tidal waves." Modern seismographs, or earthquake-registering instruments, set up in a coördinated system of earthquake stations properly distributed over the surface of the planet, now regularly record all sudden major movements of the litho-

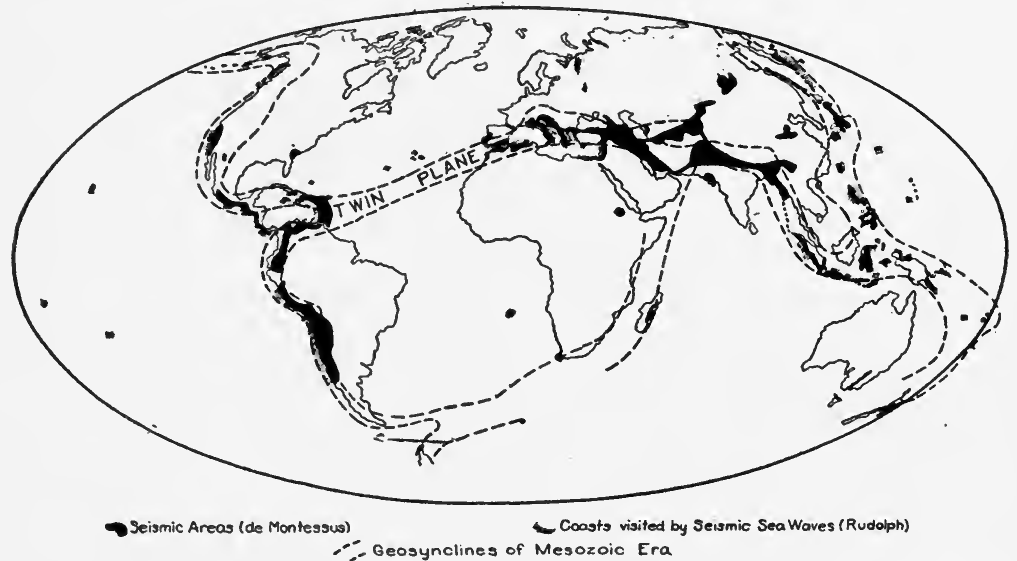

FIG. 34--Map on Mollweide projection to show the distribution of historic earthquakes for the land areas of the globe (after de Montessus)

sphere surface, quite independent of whether these occur at the bottom of the sea or upon a continent or island.

The recorded centers of disturbed areas-the so-called "epicenters" or "origins"-assembled for a period of ten years (1899-1910) by Professor Milne are entered as the spots upon the map of Fig. 35. While furnishing a striking confirmation of the accuracy of the map derived from observations made on the ground within the earthquake districts of the continents, this map tells us further that the continental earthquake districts are extended outward for some distance upon the floor of the neighboring ocean, and that the measure of the disturbances is greater for the 
undersea portion of the zone and for the belts of festooned archipelagos southeast of the Eurasian continent.

If now we examine a modern atlas upon which the sea depths are indicated, it is at once discovered that the disturbed near-shore zones of the sea-bottom are characterized by generally narrow trough-like depressions with steep walls and with the shoreward wall generally continuous with the precipitous rising shore of the neighboring continent or island (Fig. 36). A section across trough-deep and rising-

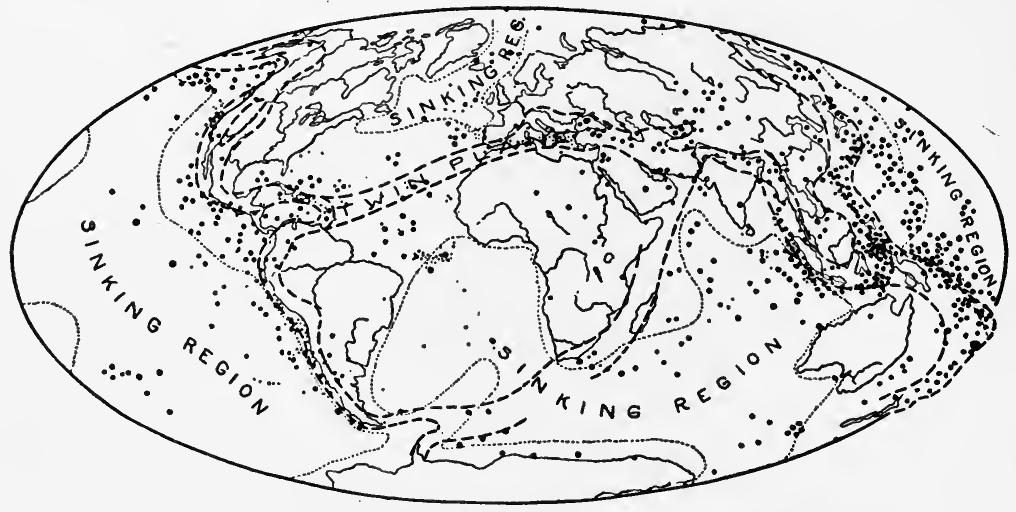

LEGEND

$\therefore$ Epicenters of Earthquakes 1899-1910(Milne) ...-Geosynclines of Mesozoic era

Approximate boundaries of areas which have sunk since late Mesozoic time.

FIG. 35.-Map on Mollweide projection to show the distribution of world earthquakes for both the land and water areas of the globe (after Seismol. Comm. Brit. Assoc. Adv. Sci.)

shore together, and extended to include the rising mountain range which borders the shore, will generally be similar to one of those represented in Fig. 36.

It will hardly escape the reader who has followed the discussion through the preceding chapters, that the nature of the adjustments which are represented in these sections is exactly that developed in folding, and that the elongated trough or "fore-deep" represents a syncline, while the rising mountain range presents the associated anticline. That the development of the anticline is responsible for the formation of a pocket of magma beneath a competent 
stratum at some proper depth is attested by the fringe of active volcanoes which almost invariably follows the back of the anticlinal ridges throughout the extent of these zones. For a portion of the belt these coördinated relationships are brought out in Fig. 37, but a good modern atlas, such, for example, as Andree's, will supply confirmation for the zones throughout.
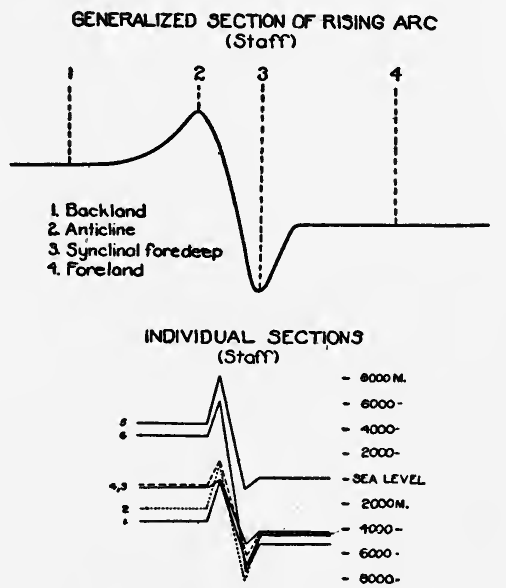

1. Bering Sea-Aleution Arc-Aleution Foredeep-Pacific 2. Japan Sea-Japan A rc-Japan Fonedeep-Pacific 3 East China Sea-RiukiuArc-RiukiuForedeep-Pacific 4 Java Sea-Java-Java Foredeeps-Indian Ocean

5. Thibet-Himalaya Arc-Ganges Foredeep-Hindustan

6. TiticacaPlateau-Western Cordillera-Atacamoforedeep-Facific

Fra. 36.-Diagrams to show the form of the sections of rising arcs (after Staff)

A study of the distribution of sedimentary rocks with reference to their age, tells us further that the belts of exceptional disturbance of the earth-of the present-day zones of folding-are situated just where there were narrow seas throughout the long preceding era of the Mesozoic, and where in consequence sedimentation was practically continuous throughout. Thus we see that the seas of deposition, or the geosynclines, of one era become the great mountain systems of the next, and that these in turn are worn down by erosional processes to supply the sediments for a 
later geosyncline. Thus is found a doubtless unintentional meaning for the scriptural language, "Eviery valley shall be exalted and every mountain and hill shall be brought low."

It will now be in line with the development of our subject, if we examine the shores which are being elevated into anticlines opposite the synclinal fore-deeps of the neighboring sea. To do this intelligently we must first take ac-

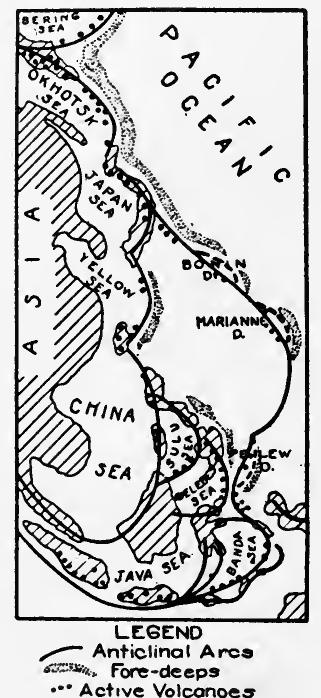

FIG. 37.-The arcs of eastern Asia with their fore-deeps and their fringes of volcanoes

count of the way in which the shores are being shaped by the action of the sea itself. The sea exerts its influence directly upon the land areas adjacent chiefly at the times of the great storms; and so much greater is the measure of its attack at the time of an exceptional tempest that by comparison all others pale into insignificance. At such times its energy is expended in drilling, battering, and prying away the rock from any steeply rising shore as far upward from its quiet level as it is able to throw its mass. Undercut at the base, the overhanging rock falls in blocks 
which are themselves generally moved about and eventually broken up to form the sand of the neighboring beaches in the lee of the exposed headlands, or else it is transported by the powerful undertow to build seaward the gently sloping floor which is steadily invading the continent under the relentless attack of the waves.

Though the size and corresponding power of waves depend both upon the intensity of the storm and, up to a certain limit, upon the expanse of sea over which the waves advance toward the shore, yet so broad are the larger oceans with respect to the diameter of storm areas, that it is doubtful if either shore of the continent has very greatly the advantage of the other in this respect. We may therefore consider that the rate of formation of a planed off-shore surface of marine erosion is about the same for the Atlantic as for the Pacific.

Such surfaces of marine degradation surrounding the continents are referred to as the continental shelves, and with a stationary position of the shore as regards uplift they should be of their greatest width. The depth of the outer margin of a marine platform of degradation closely approximates to 200 metres (100 fathoms), which is about the length of the greatest storm waves of the ocean except within the southern seas. This wave length fixes the depth of the outer margin of the shelf, and it is therefore not surprising that on the borders of the Antarctic continent the waves of the southern seas have graded the continental shelf to a considerably greater depth.

When we now compare the opposite coasts of the American continent, we find that they are strikingly different. On the map of Fig. 38 the submarine contours for the special depths of 200 meters and 2000 meters are represented, and together they show that the continental shelves which border the Atlantic coast of the continent are relatively wide, averaging not far from one hundred miles in breadth, whereas those of the Pacific coast are by contrast 
extremely narrow. We may interpret the Atlantic shelves to indicate a relatively stationary position of the continent near this coast, thus confirming the observations assembled

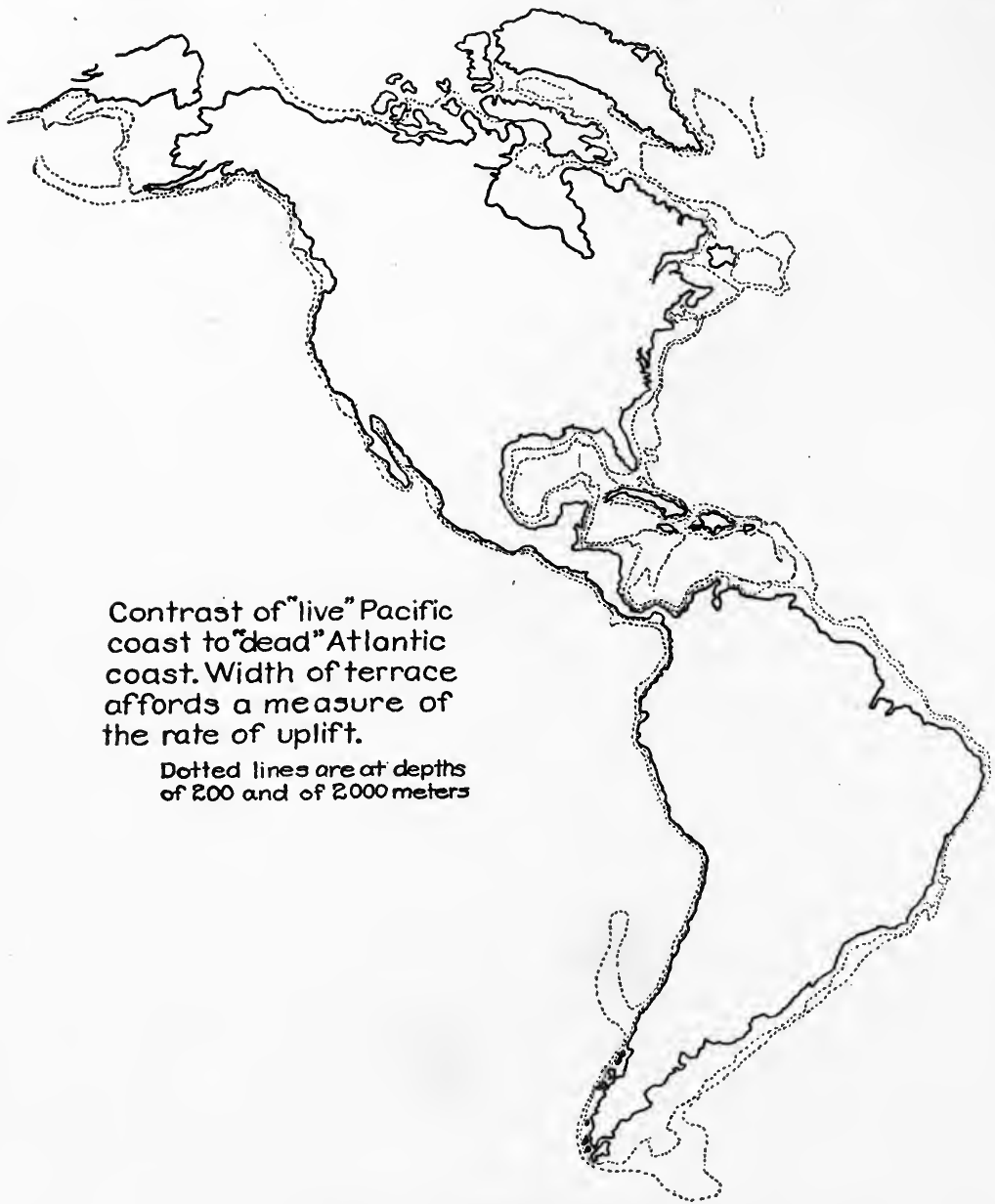

FIG. 38.-Map of the western hemisphere to show the continental shelves (from Andree's Handatlas)

for earthquakes and set forth in Figs. 34 and 35 . The coasts about the Arctic ocean are bordered by broad shelves, and are likewise to be interpreted as indicating that the continental areas where they border this ocean are also rela- 


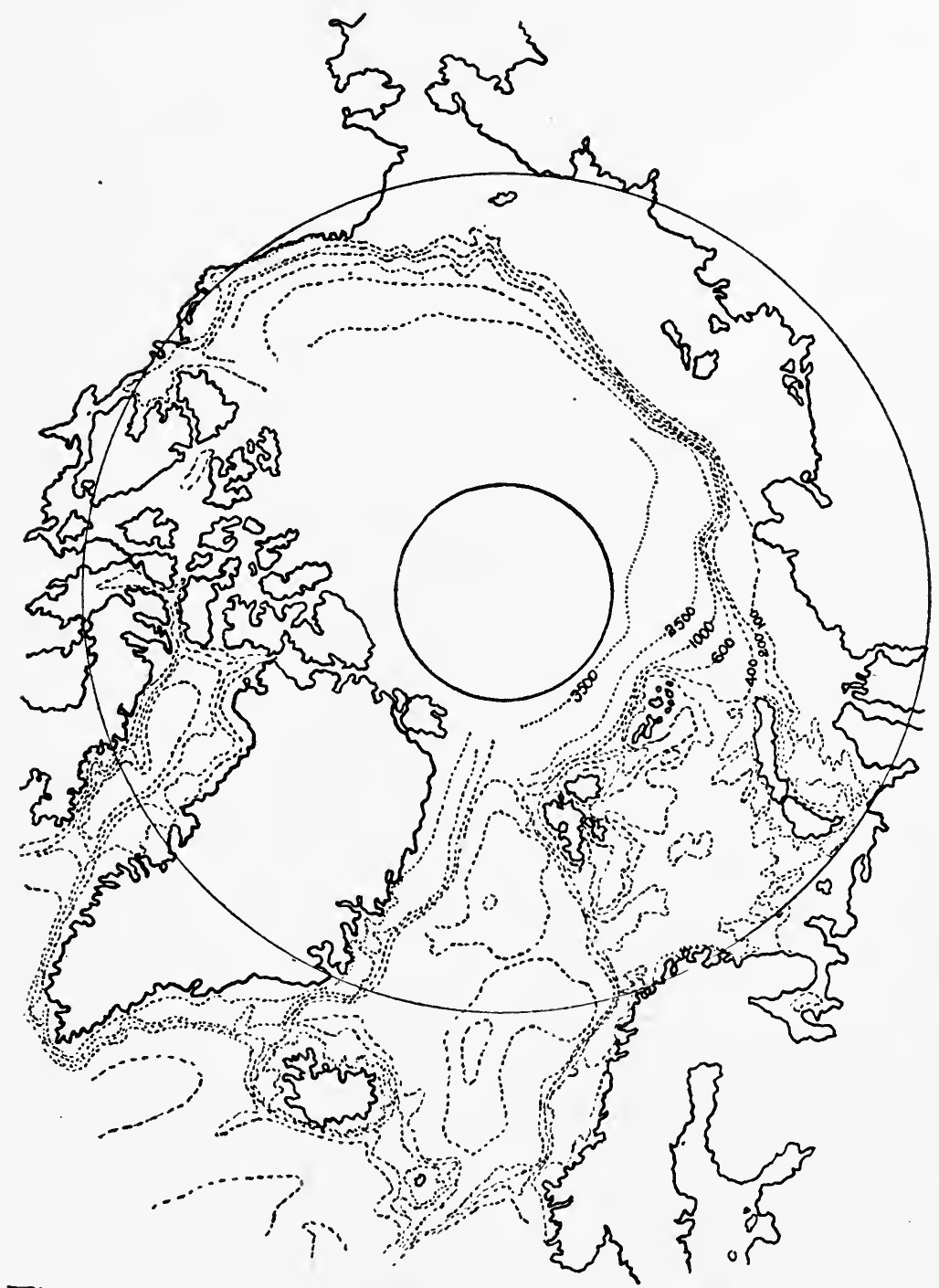

The Continental Shelf about the Arctic Ocean (Nansen) 
tively immobile (Fig. 39), a fact confirmed by the earthquake map.

Yet the sea waves have probably been doing their work quite as effectively on the Pacific coast as upon the Atlantic. What then has become of the surface planed by wave erosion? The examination of almost any section of coast bordering the Pacific supplies the answer to this question. Sections of this surface have clearly been suddenly lifted out of the reach of the waves, where they may now be seen in a long succession in the form of a gigantic staircase (fig. 40). To make this more impressive, a few examples out of many have been brought together in fig. 41 .

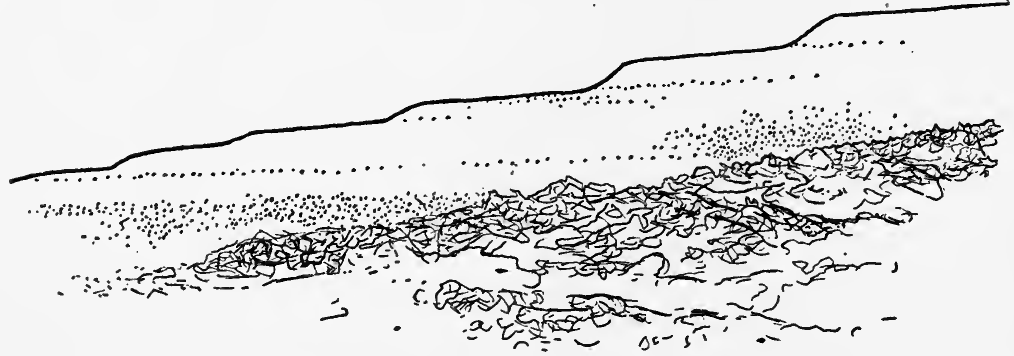

FIG. 40.-The form of coast terraces

Each of the cliffs, or risers, in the coastal staircase measures the amount of the uplift of the coast either during one or a succession of earthquakes, although in but few cases can we as yet affix the exact date of this adjustment. Exceptionally such terraces can be dated, as in the case of one raised on the shore of Alaska during the earthquake of 1899 (Fig. 42).

Such coast terraces as have been described for the borders of the Pacific Ocean reveal the fact that portions of the sea-floor are being pushed up onto the continent, the testimony of the abrasion surfaces which make the treads of the staircase being indubitable. This implies that a thrust from the sea-floor toward the continent is continually operating, but becomes effective only at intervals when the 
potential energy of the system is let down at the time of an earthquake. This force would be adequately explained if the floor of the sea within a large area opposite the rising shore were settling downward and in consequence becoming reduced in area, as is required by the theory of secular cooling of the earth (Fig. 43).

If now we inquire whether there is evidence that any

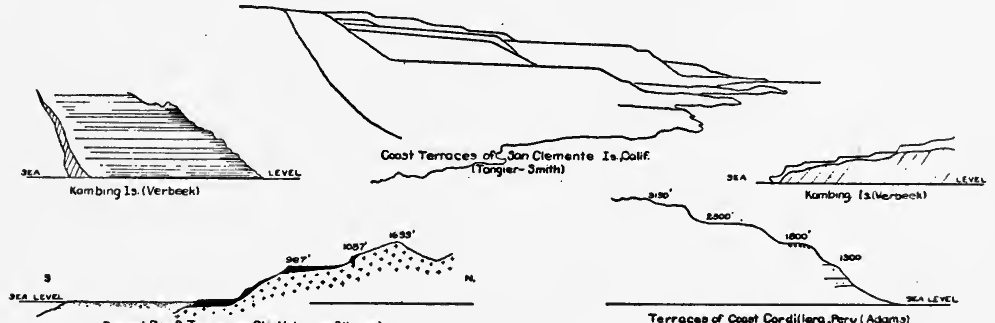

Terraces of Coost Cordillera, Reru (Adams)
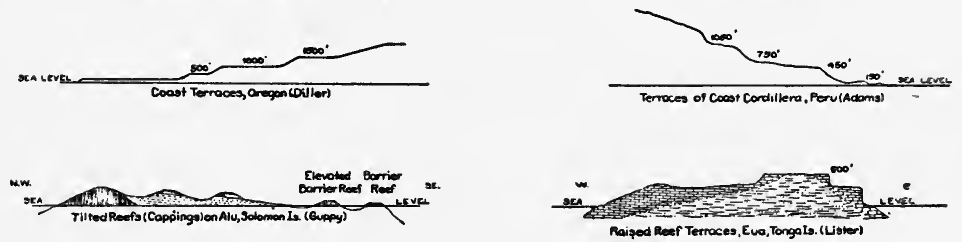

Raised lleef Ternaces, Eva, Tongals. (Lister)

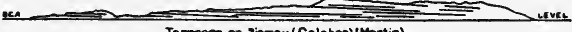

Terroces on Siompu (Celebes) (Martin)

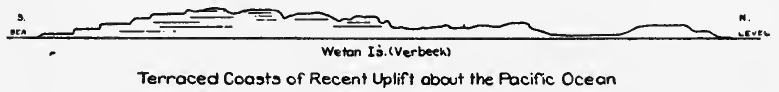

Fig. 41

large portion of the Pacific sea-floor has been settling since the elevation of the mountains began on its borders, an answer is supplied for a large area by the study of the Polynesian islands and their coral reefs and atolls. Quite independently, Charles Darwin and James D. Dana, on the basis of extended personal examination offered the explanation of the low atolls within the Pacific, as a result of settlement by slow increments of former volcanic mountains. These at first emerged from the waves with fring- 
ing reefs about them, but with progressive settlement became bordered by barrier reefs and, eventually, when the volcanic island had become entirely submerged, by the upwardly extended reef alone-the atoll-enclosing a lagoon. This view of the origin of coral islands has been assailed by several biologists, notably by Sir John Murray and Alexander Agassiz, who have offered a different explanation, but one which has not commended itself strongly to geologists; though an alternative theory has been brought forward by Daly and drawn a considerable number of geologists to its support. The original theory of Darwin

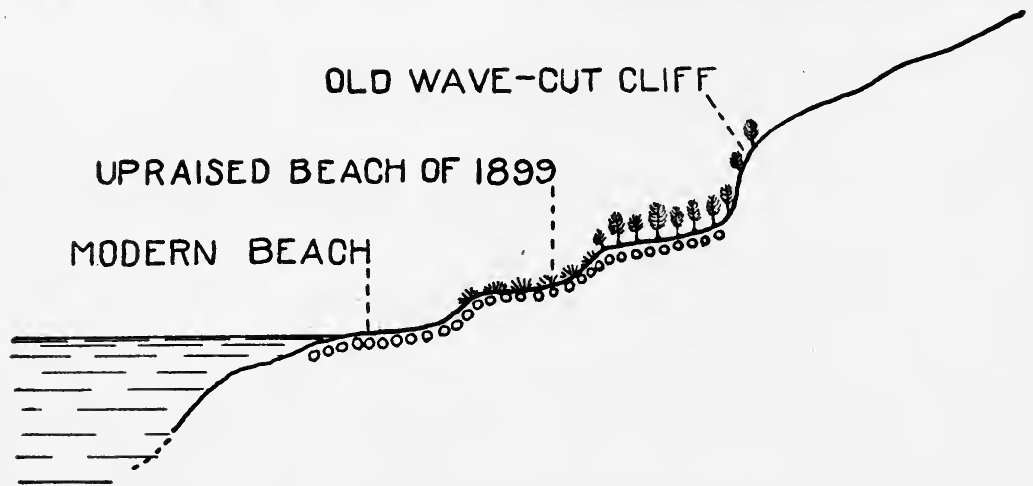

FIG. 42.-The dated step in a coastal staircase in Alaska (after Tarr and Martin)

has recently received strong support in an extended series of studies by Professor W. M. Davis, and insofar as the question of subsidence is concerned it is also supported by Vaughan. Outside the zone of the tropical seas within which corals can grow, we are without direct evidence for subsidence or elevation, but the landward direction of the outward thrust from the sea-floors seems in itself to offer us a proof of a reduction of surface within some neighboring region of the ocean floor.

But, it will be said, the elevations of the mountains above the borders of the Pacific must just as clearly afford an indication of extension of the earth's surface wherever the 
mountains are rising, as does the settlement of areas of sea-floor of surface contraction within those areas. There can be no denying the fact that the elevation of any belt on the earth's surface with respect to any relatively fixed datum like the sea level, must, in and by itself, imply an expansion of the original surface, as indicated by the upper diagram of Fig. 44. Such an expansion should be displayed through an extension of every continuous line of metal which crosses the district; such, for example, as rails, pipe lines, etc. The effect will also be shown in the behavior of bridges, particularly railroad bridges, which are parts of a continuous metal line. Now, as has already been pointed out in an earlier chapter, the behavior of such struc-

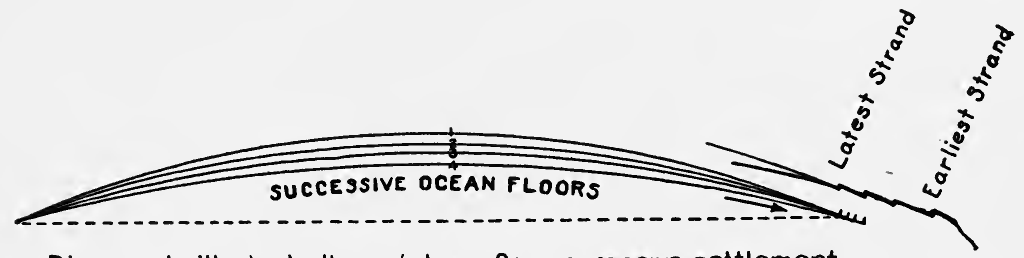

Diagram to illustrate the reiation of a progressive settlement

of the ocean floor sector to the elevated Pacific strands

FIg. 43

tures at the time of earthquakes has offered us the surprising result that, instead of being pulled apart, they are squeezed together and variously buckled. This can only be interpreted to mean that the area of the sea-floor which has been pushed up upon the continent and is in full view in the coastal staircase upon the ocean side of the mountains, has been more than sufficient in area to compensate for the necessary expansion of the zone by mountain elevation. The behavior of the rails and bridges indicates that with each uplift to the accompaniment of earthquakes the thrust from the sea renews its vise-like compression, and operating through a certain distance gains momentum which is effective in producing still greater compression (lower diagram of Fig. 44). 
Only recently has it been pointed out that on the Atlantic coast of the United States there exist elevated coast terraces, but of a character so different from those of the Pacific, that they have heretofore been overlooked. The reason for this appears in part to be that they have been so much longer above the sea and hence have been so profoundly changed by the erosive processes that they can be recognized only upon the basis of precise measurements and elaborate synthetical studies. Credit is due to the late
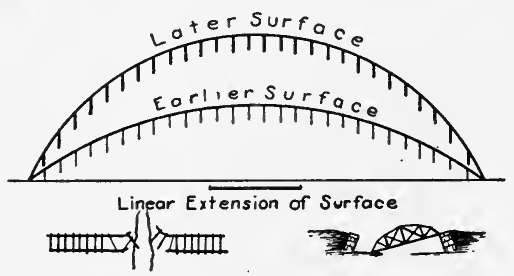

MOUNTAIN GROWTH(THEORY)
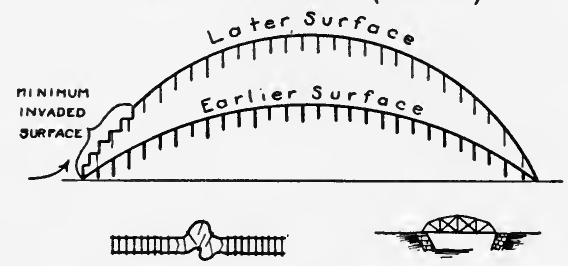

MOUNTAIN GROWTH(ACTUAL)

FIg. 44.-Diagrams to explain the paradoxical compression within rising mountains

Professor Barrell for having recognized this condition within the New England district, and his results, which were nearly ready for publication at the time of his death, have appeared in a series of posthumous articles. The terraces which border the Atlantic coast are also less easy to perceive for the reason that the height of the risers is so small in comparison with the breadth of the treads. The contrast which has already been pointed out between the breadth of the eastern and western continental shelves of the continent, is thus shown to be continued upward in the uplifted sections of the earlier shelf; and these latter 
afford an even better measure of the comparative rates of uplift of the coasts, than has already been foreshadowed in the earthquake maps.

From Fig. 45, in which up to a level of about 1800 feet above tide the Atlantic terraces in New England and the Pacific terraces of San Clemente Island, California, are brought into comparison; it may be seen that while the Pacific coast was being elevated to this height of about a third of a mile, the waves were able to cut inland a distance of only about three miles, whereas on the Atlantic coast the corresponding elevation of the coast was accomplished only after the waves had cut back the shore a distance of some fifty miles.

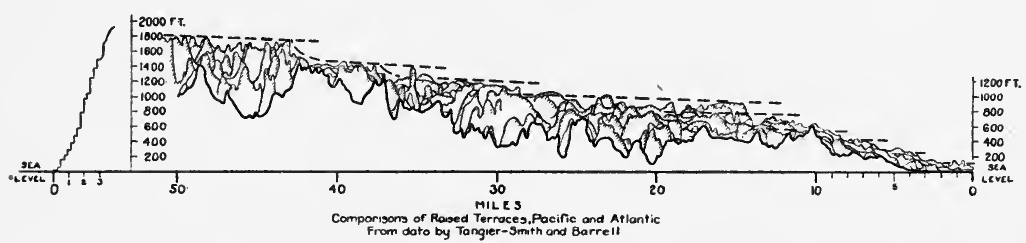

Fig. 45.-Comparison of raised terraces, Pacific and Atlantic (from data by Tangier-Smith and Barrell)

To extend the comparison so as to include the entire uplift upon the Pacific coast, it might be necessary to employ the painstaking synthetical methods of Barrell within the higher levels in which erosion has in part effaced the characteristic terrace contours. However, our comparison of the two sets of terraces has sufficed to confirm the clear indication of the earthquake maps that the zones of the earth which are now undergoing greatest change of position -where the surface shell of the lithosphere is relatively active-is the great border zone of the Pacific and a second great-circle zone which traverses the Mediterranean Sea of both America and Europe and is continued eastward along the course of the former Sea of Tethys - the twin plane of the earlier lithosphere. The maximum of surface mobility 
of our planet is to be found at the intersection of these two zones in the Moluccas of the Dutch East Indies (see Fig. 35).

It would thus appear that when Sir Charles Lyell succeeded in overthrowing the then accepted doctrine of catastrophism-calling for sudden and rapid geological changes-and supplanting it in the science by his own doctrine of uniformitarianism-supposed to demand almost incredibly slow and gradual geological changes-he failed to appreciate what vast differences in these very respects characterize different portions of the earth's surface. Lyell's famous slogan, "The present is the key to the past" has come to mean "The present in Great Britain, an area of extremely slow change, is the key to the past." The present rate of change in the region of the southern Andes or in New Zealand, but most of all in the archipelago of the Moluccas, has a very different meaning. Though Lyell had been a great traveller and had brought to public attention the facts concerning a great earthquake in New Zealand, yet he was not impressed by it sufficiently to modify materially the form of his doctrine, modelled as it was upon conditions in Great Britain.

\section{LITERATURE}

Charles Darwin. The structure and distribution of coral reefs, 1874, p. 278.

JAMES D. DaNA. Corals and coral islands, 1872, pp. 398.

R. S. TARr and L. MARTin. Recent changes of level in Yakutat Bay region, Alaska, Bull. Geol. Soc. Am., vol. 17, 1906, pp. 29-64, pls. 10-23.

F. DE Montessus DE BalloRe. Les tremblements de terre, Géographie Seismologique, Paris, 1906, p. 475, maps 1-2.

Hans v. StafF. Zum Problem der Entstehung der Umrissform von Celebes, Zeitsch. d. deutsch. Geol. Ges., vol. 63, 1911, pp. 180-86.

H. H. TURNER and others, 20th Rept. of the Seismological Committee, Rept. Brit. Assoc. Adv. Sci., Manchester meeting (1915), 1916, pp. $52-79$, pl. 1.

W. M. DAvIS. Subsidence of reef-encircled islands, Bull. Geol. Soc. Am., vol. 29,1918 , pp. $489-574$.

JOSEPH BARRELL. The Piedmont terraces of the northern Appalachians, Am. Jour. Sci. (4), vol. 49, 1920, pp. 227-258, 327-362, 407-428, pls. 5-6.

W. S. T. SMITH. A geological sketch of San Clemente Island, 18th Ann. Rept. U. S. Geol. Surv., pt. II, 1898, pp. 459-496, pls. 84-96. 


\section{EARTH EVOLUTION AND ITS FACIAL EXPRESSION}

E. Rudolph. Ueber die geographische Verteilung der Epizentralgebiete von Weltbeben und ihre Beziehung zum Baue der Erdrinde, C. R. 11th Sess. Congr. Géol. Intern., Stockholm, 1910, 1912, pp. 837-848, map.

A. Agassiz. The coral reefs of the tropical Pacific, Mem. Mus. Comp. Zool., vol. 28, 1903.

R. A. DaLY. The glacial-control theory of coral reefs, Proc. Am. Acad., vol. 51, 1915, pp. 155-251.

T. W. Vaughan. Fossil corals from Central America, Cuba, and Porto Rico: with an account of the American Tertiary, Pleistocene and Recent Coral Reefs, Bull. 103, U. S. Natl. Mus., 1919, pp. 238-332. 


\section{CHAPTER IX}

\section{THE CONTRASTED ASPECTS OF THE EARTH'S FACE}

IN an early period of geological science before accurate maps had been prepared and before observational methods of study had been generally introduced, it was natural that the theories set up should have borne but small relation to the facts they were supposed to interpret. Thus in the first half of the nineteenth century Leopold von Buch in Germany and Élie de Beaumont in France attempted to fix the age of mountain systems upon the basis of their directions or trends. Since it was no easy matter in the absence of observations to disprove the claims which they set up, and as both were men of great intellectual power and aggressive in leadership, their theories, wholly unsupported by fact as they were, dominated the field of thought of their time. With the passing from the stage of these dominating personalities, their theories came almost at once into discredit, and it is a direct result that attention was withdrawn from the plan of the earth and became concentrated upon perpendicular sections through the earth's outer shell (Fig. 46).

Such sections were constructed largely upon the basis of the observed attitudes of the hard rock strata at the various points where these emerge from beneath the unconsolidated materials generally forming the surface; and being thus connected up with actual observations, sections contained a larger measure of truth than had the crude theoretical maps. This profound change in the direction of effort toward increasing observation, proved a most salutary one for the time, and it was responsible for putting upon record a 


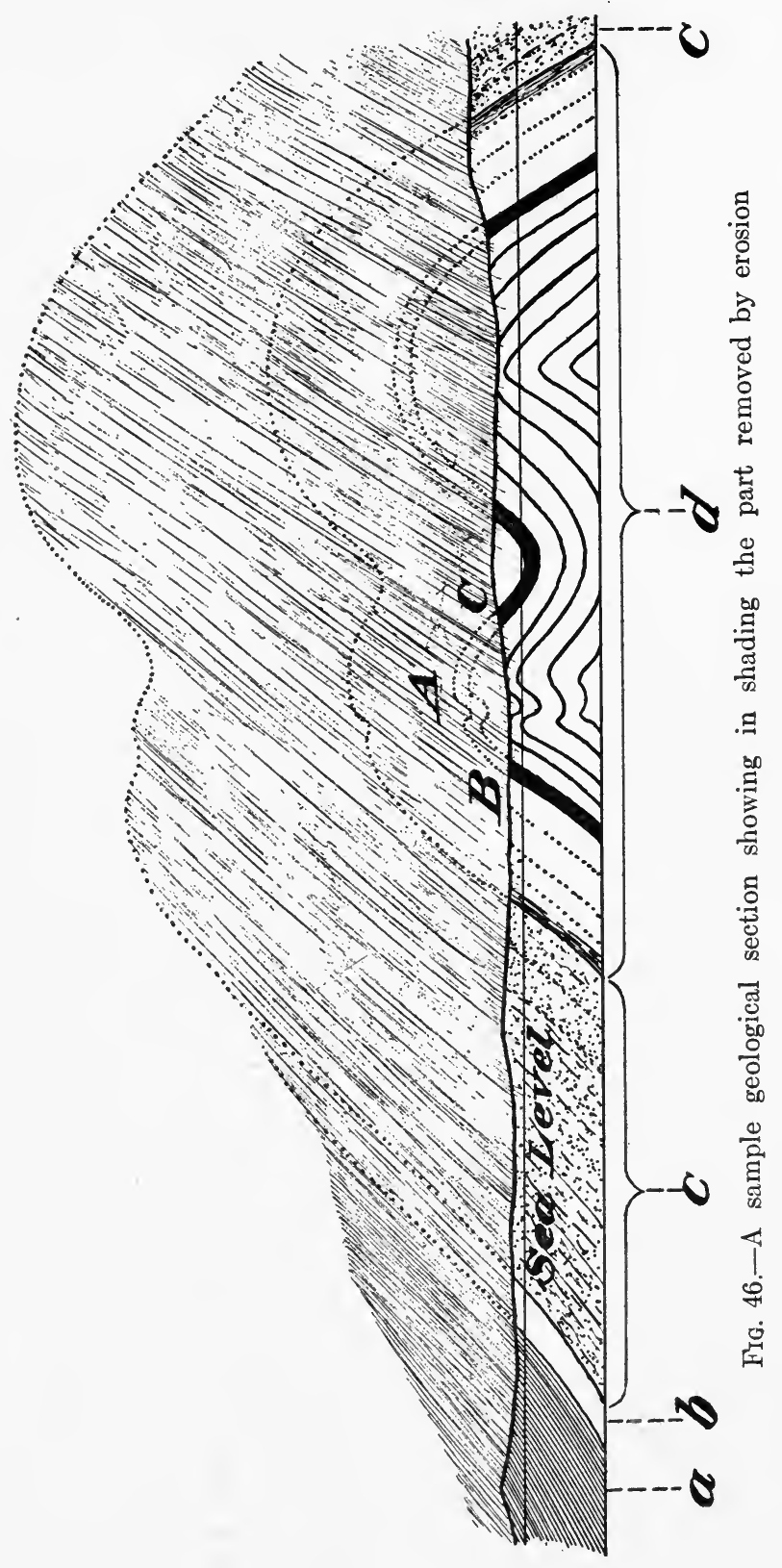


wealth of facts which alone could make broad generalizations of any value.

While geologists were thus assembling the facts, geodesists and military and topographical engineers operating under the direction of national bureaus, were slowly extending the areas of surveyed territory, as they were steadily improving the quality of the maps which they produced. It has been only during the last quarter of the nineteenth century and subsequently that attention has once more been directed toward a study of the broad plan of the earth. This has come about very largely through the influence of Eduard Suess, whose masterful treatise, The Face of the Earth, is comparable in importance with Lyell's Principles.

Suess was the first to realize that the crude geological data which alone had been available a half century before, quite as much as the undeveloped methods of the time, had been responsible for the failures and for the illusions of von Buch, de Beaumont, and their followers. Yet with all his erudition and with a gift for beautiful and forceful presentation which has been seldom equalled, Suess was none the less poorly fitted to deal with the problems of mechanics of earth movements which constituted a vital element in his studies. However, his enormous prestige, like that of Laplace in another field, has carried some of his doubtful conclusions to rather general acceptance, at least in Europe, and without rigid tests having always been applied to them. Many of his large generalizations are destined to stand even when others less securely founded have been given up.

Perhaps the most valuable of all the fundamental conclusions of Suess is his division of the earth's continental areas into two sections, one characterized dominantly by folding structures which appear in the plan of the earth as great sweeping festoon series of mountain ranges, and the other in striking contrast as alternating plateau and plain 
-a mosaic of displaced earth blocks. The first of these is generally characteristic of the continent of Eurasia, and the second of that of Africa (Fig. 47). Though somewhat less clearly contrasted, these broad divisions were extended to the western hemisphere, the outer series of festoons of mountains on the eastern Asiatic coast being connected up through the Aleutian archipelago with the great Cordilleran mountain system which generally borders the Pacific coast of America.

Another generalization of Professor Suess which is of the utmost importance relates to the coast lines on the

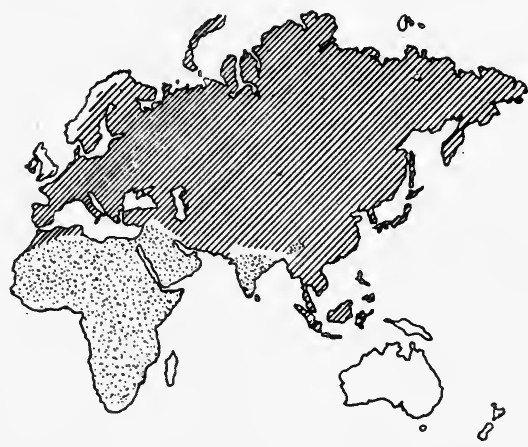

Fig. 47.-Map to show the contrasted aspects of the earth's face within the Eastern Hemisphere (after Suess)

borders of the two great oceans, the Pacific and the Atlantic. On both eastern and western coasts of the former there are mountain ranges markedly festooned in arrangement, and taking their trend parallel to the coast with their convex side always toward the sea. On the borders of the Atlantic, however, few ranges of mountains are to be found, and these instead of trending parallel with the coast, meet it at a large angle and are, in fact, abruptly terminated by it. Such Rias coasts, in the view of Suess, indicate that the adjoining oceanic basin has been dropped down along coastal fractures since the mountain ranges were formed, and their continuations are presumably now removed from 
our view and beneath the waters of the ocean. Professor Suess has given strong grounds for believing that the continuation of the Appalachian mountain system at the close of the long Paleozoic era, instead of being abruptly terminated at the east coast of Newfoundland, as it is today, took its course eastward across a now foundered portion of the continent to be continued in the eroded mountain system of identical age which under the names of Armorican and Variscan arcs may today be found in detached fragments stretching across western and central Europe (Fig. 48).

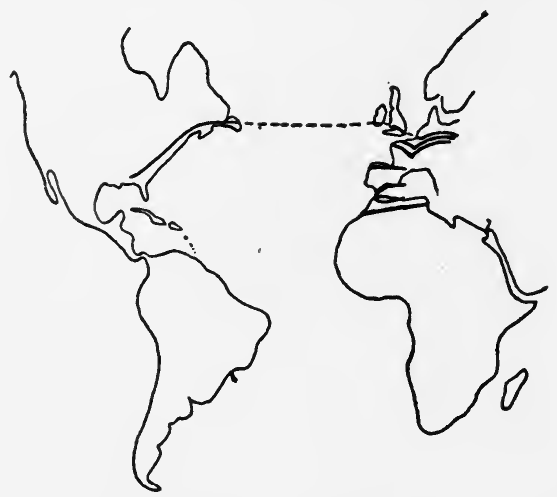

FIg. 48.-Map to show the relation of the Permian mountains of Europe to those of America

The conclusion from all this has been, as already pointed out, that the Atlantic basin was formed by an inbreak during Mesozoic time of the central portion of the former continent of which eastern North America and western Europe are the remnants.

Within the area south of Angara land in eastern Siberia and extending eastward from the continent into the festoons of islands along the coast, as well as southeastward through Malaysia into Oceania so as to mantle toward the east and south the coign of Australia, we encounter a series of great mountain welts which are primarily the result of an intense folding of strata. Faulting has also occurred, but it has 
apparently been to a large extent incidental to the folding process. These Asiatic mountain welts are extended westward into southern Europe and extreme northwestern Africa as the ranges of the Caucasus, Carpathians, Alps, Apennines and Atlas ranges, together with the less definite ranges in the Balkan and Italian peninsulas. Looking eastward from Asia we find that the arcs of folded mountains trail off northward along the borders of the Pacific, first through the Aleutian are and thence down through the long Cordilleran backbone of the western hemisphere to join up with an arcuate hook which projects out from the Antarctic continent to form Palmer Land or West Antarctica.

In northern Europe between the Baltic shield and the southern European arcs extending northwestward to the Atlantic, as in North America between the Laurentian coign and the northern Cordilleran system of the continent, we find areas which are much less easily classified. Within them are the eroded remnants of much earlier mountain arcs which date from periods so much more remote in geological history that their plan is much less easily read. The main lines, however, we can still make out.

The study of ancient geography has revealed clearly the fact that though the ocean basins have not generally been permanent, but have in the course of geological ages been profoundly transformed, the continental shelves with their shelf seas over which marine sediments have been laid down, have persisted throughout long ages as continuous floors of deposition, and that they have subsequently been elevated to form the great folded mountain systems of the earth. Such long marginal bands of marine sediments surrounding the earlier continental areas have been denominated geosynclines, and the best known of them belong to the early and the middle eras of earth history, the Paleozoic and the Mesozoic eras (see Fig. 35).

The Paleozoic geosynclines were elevated into mountains 
at the close of that era and are best known to us in the Appalachian ranges composed of folded beds which involve, as usually. assumed, from 30,000 to 50,000 feet of sediments. The great geosynclines of the next geological era were zones of continuous sedimentation throughout Mesozoic time, at the conclusion of which they were similarly raised to form what are now the greatest mountains of the earth. They include the Himalayas with their associated ranges and extensions to the east and west across Eurasia, and the great Cordilleran system of the western continent. Thus the series of Mesozoic geosynclines marked out the course of the present great mountain systems, and they have undergone less subsequent change than have those mountains which were reared above the Paleozoic geosynclines, and their courses like their structures are so much the more easily followed.

Confirmation of the view that the outermost and most recent welts of the Mesozoic geosynclines are still in process of erection, is supplied by the line of active volcanic vents which parallels the series and almost completely surrounds the ocean as the so-called "fire ring" or "fire girdle" of the Pacific (see frontispiece). It is especially noteworthy in view of what has been said concerning the magma chambers (see Chapter III), that these volcanoes generally lie upon the inner, or back, side of the arcs away from the ocean. Upon the westward border of the Pacific the outermost series of welts, instead of resting upon the continent, rises from the depths of the sea, sometimes with other only less recent island ares at its back, between it and the continent. In front of the outer series of island arcs, the sea bottom generally drops down into long and narrow troughs-foretroughs-running parallel to the arcs. Behind the island arcs are usually other deeps less profound and lacking the characteristically long and narrow trench form, and these we may call "back-deeps" rather than troughs (Fig. 37). Less strikingly trench-like also, somewhat similar deeps lie 
either close in near the Pacific coast of North America or else as an intermontane valley upon the continent between a coast range and a cordillera at its back. Excepting only those Atlantic arcs which lie within the zone of the former twin plane extended in the Sea of Tethys, nothing at all resembling these fore-deeps on the Pacific is to be found near the Atlantic coast or, in fact, within the Atlantic basin.

\section{LITERATURE}

Eduard Suess. Die Entstehung der Alpen, 1875.

EDUARD SUESS. The face of the earth, 1885-1909.

W. M. Davis. The framework of the earth (review of the French edition of "The Face of the Earth"), Am. Jour. Sci. (4), 1919, pp. 195-241.

W. H. HoBBs. Mechanics of formation of arcuate mountains, Jour. Geol., vol. 32,1914 , part 1, pp. 71-79.

Émile Haug. Les géosynclinaux et les aires continentales, Contribution a. l'étude des transgressions et des regressions marines, Bull. de. la Soc. Géol. de France (3) vol. 28, 1900, pp. 617-711, especially fig. 1, opp. p. 632 .

ThEODOR ARLDT. Entwicklung der Kontinent und ihrer Lebewelt, Leipzig, 1907 , especially plate labelled "Gebirgskarte" at end of volume.

Ferdinand von Richtofen. Geomorphologische Studien aus Ostasien, Sitzungsber. d. k. preusz. Akad. d. Wiss., 1900, pp. 888-925; ibid., 1901, pp. 782-808; ibid., 1902, pp. 944-975.

Federico Sacco. Les lois fondamentales de l'orogine de la terre, Turin, 1906 , p. 26, plate.

Frank B. TAYLOR. Bearing of the Tertiary mountain belt on the origin of the earth's plan, Bull. Geol. Soc. Am., vol. 21, 1910, pp. 179-226.

E. C. Abendanon. Die Grossfalten der Erdrinde, Leiden, 1914, p. 183.

$\mathrm{K}$. AndreE. Ueber die Bedingungen der Gebirgsbildung, Berlin, 1914. 


\section{CHAPTER X}

\section{THE MIGRATIONAL MOVEMENTS OF THE SURFACE}

IT has been pointed out in the last chapter that upon the Eurasian continent generally, as well as throughout the zone which extends around the Pacific Ocean, the earth's face is traversed by a wealth of curving creases, whereas the continent of Africa presents a wholly different aspect. In the former region the surface expression of the relief is a result primarily of the process of folding, with faulting playing a generally secondary rôle; whereas in the latter the surface configuration is largely a direct expression of the faulting process, and the result a pattern on first sight resembling perhaps a Chinese puzzle, but on closer examination the more regular design of marquetry.

For the present it is the pattern of the mountain wrinkles within the folded regions which will engage our attention, and it is necessary first of all to rid ourselves of certain preconceived notions derived from our study of geography in the schools. It was long the custom to represent mountain ranges upon small-scale maps where the character rather than the actual positions of the ranges is to be presented, as though they took their courses in a sinuous or serpentine fashion. Most persons who have now reached maturity, and it is not intended to say how many others, think of mountain chains in terms of the appearance which these features made upon the maps of their school atlases, a or b of Fig. 49; whereas for nearly a generation those who have given intimate attention to the problems of mountain structure, know that mountain chains are really nat sinuous, but scalloped, as schematically represented in c of Fig. 49 .

Geologists and geographers are themselves largely to 
blame for this prevalent misconception, for ever since the passing from the stage of von Buch and de Beaumont with their weirdly distorted views of mountain plans, they have as a profession and in a spirit of revolt against the earlier false doctrines, confined their attention largely to the study of vertical sections through the rock strata, rather than to the arrangement of the mountain creases in the plan of the earth.

To prepare sections the local inclinations, the dips, of the strata are studied, whereas to decipher the plan of arrangement of folds, it is the trend or bearing of the strata, their strike, which must be noted wherever they emerge from beneath their cover. It is already apparent that a change

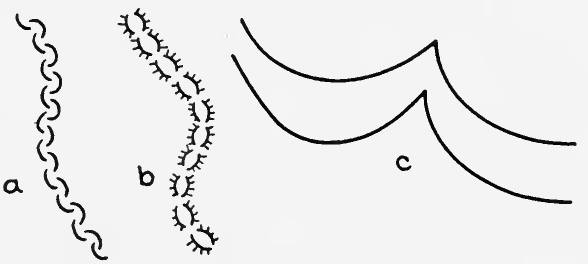

FIG. 49.-Earlier (incorrect) and (correct) methods of representing mountain systems upon maps

in method is coming in the science and it requires no prophet to declare that the present emphasis upon dip geology will in the future in considerable measure be supplanted by attention devoted to strike geology.

It will be remembered that two of the great generalizations of Suess concerning the plan of the curving creases or arcs of mountains were, that their convex side is always presented toward the existing oceans, and that they generally trend parallel with the ocean borders. An additional generalization of equal importance which Suess was the first to discover, is that within these arcs the folds are unsymmetrical with their steeper sides toward the existing oceans. His manner of expressing this has been that the regions "are folded in the direction of the ocean"; a statement involving a theory of arc formation which, it will 
later be pointed out, we believe, to be unsound, notwithstanding the fact that it is generally accepted today by those who have given attention to the subject. We have chosen, therefore, to put his generalization in the form, the steeper side of the old faces the ocean, so as to indicate observed fact quite independent of any theory of origin.

In the last volume of The Face of the Earth, which Professor Suess published in 1885, a full score of years after the foregoing generalization had been first pronounced as a folding of the strata "in the direction of the ocean," Suess felt compelled to modify the statement insofar as concerned

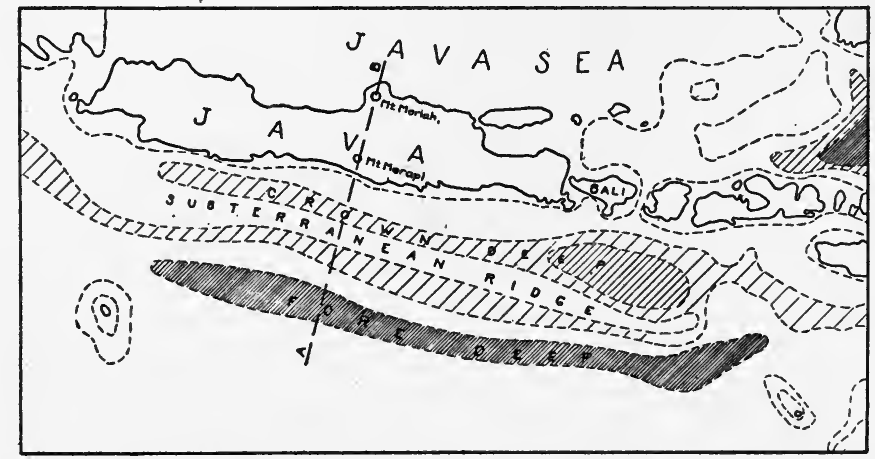

Map of Java with Foredeeps (Brouwer)

FIG. 50

the ares of the western hemisphere to the southward of the 49th parallel of north latitude, and to describe this great exception to his generalization in which the folding was "away from the ocean" instead of toward it, as Andinenbau or Andean structure. It will be shown that if Suess's theory of origin of the arcs be discarded for the view here set forth that mountains have been raised as a result of thrusts going out from areas of subsidence, generally the ocean areas, instead of from the continental regions, the exception of the Andean structure has no reality, since the American Cordillera at the time of its formation faced a sea upon its eastern, and not its western, flank. 
We owe also to Professor Suess the important generalization that in the case of the arcs forming the outer margin of a series, there are fore-deeps along their fronts and fringes of volcanoes at their backs (see Fig. 35). As a case in point we may cite the great sweeping arc of the Malayan archipelago which includes Sumatra, Java and the lesser islands to the eastward, and which fronts the broad expanse of the Indian Ocean to the south and west. In Fig. 50 is represented, mainly after Brouwer, the island of Java with its, in this case, double fore-deep, and in Fig. 51 is shown a geological section across the island with the unsymmetrical folds facing the sea at the front with their steeper limbs.

Suess was led to his pregnant generalizations concerning arcuate mountains from a study of the "Origin of the Alps," which he brought out as early as 1875 and in which the trend that his views were later to take is already clearly foreshadowed. From the outline map of the Alpine region of Fig. 52 it appears that a large area of granite and associated igneous and metamorphic rocks which has become known as the "Bohemian Mass," lies opposite and almost within the reentrant where the strongly marked arcs of the Alps and the Carpathians are united. This Bohemian mass early took on in the mind of Suess the character of a firmly rooted and unyielding obstruction, which by halting and holding in check a generally northwardly directed migration of the area to the southward, permitted those portions toward the flanks to advance northward and in part enclose the obstruction.

When now Suess had extended his studies to include the continent of Asia with its even more perfect examples of arcuate mountain creases, 
he appears to have been no less strongly impressed by the supposed unyielding quality and significant position of a somewhat similar mass of ancient granite and gneiss which he called the "Indian Mass," and

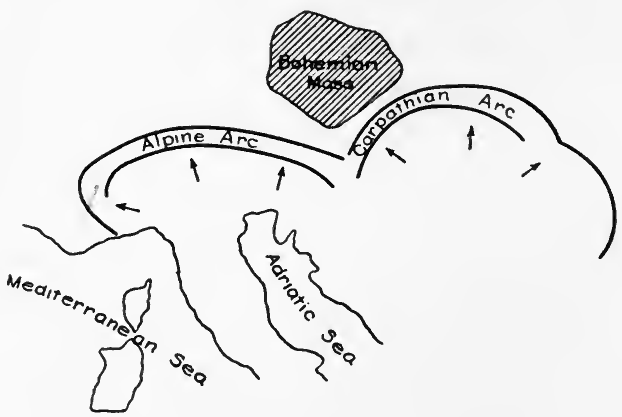

Fig. 52.-Sketch map of southern Europe to show the position of the "Bohemian Mass" with reference to the mountain arcs

which was situated similarly opposite the most striking reentrant of the Asiatic series of ares (Fig. 53). These two masses appear, however, to be each unique within its own region and, like the rings of Saturn in the astronomical field, they appear to have been responsible for the form which a

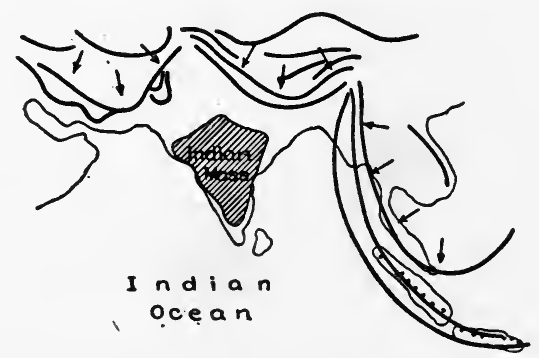

FIG. 53.-Sketch map of southern Asia to show the position of the "Indian Mass" with reference to the mountain arcs

great theory was to assume; for Suess became confirmed in his view that the portions of the land areas lying within the arcs moved forward over the portions in front, and so produced the creases by a process of overturning from the rear toward the front of the arc. The nature of this move- 
ment, as he conceived it, is quite analogous to that which takes place in the surf, where the upper layer of water in a wave advancing toward the shore rides forward over the lower and so results in an overturning of the layers from the back toward the front (a and b, Fig. 54).

Under the conception of Suess it is the land areas of the continents which in their upper portions are migrating seaward and over-riding the layers below, which are therefore conceived to be in a state of relative repose-they offer passive resistance only. It is our belief, as was pointed out in a series of papers published in the Journal of Geology

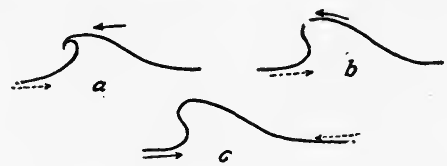

FIG. 54-Diagrams to illustrate the contrasted views of Suess and the author concerning the direction of the active thrust in mountain evolution. a, surf; b, Suess view; c, author's view

as long ago as 1912, that the migration of strata which become involved in the formation of arcuate mountains is exactly in the reverse direction from what Professor Suess believed it to be (c, Fig. 54). The mountain arcs face the sea, not because the land is thrusting itself seaward from within the continental areas behind them, but because the strata beneath these sinking sea bottoms at their front find themselves ever more closely pinched because of their settlement, and in consequence are exerting a thrust outward against the continent.*

Such a formation of arcuate creases by a process of underturning, we demonstrated experimentally as to its mechanics by the simple device shown in plate VI. This is a

* So far as the author is aware, the only geologist who has advanced the view that the thrust in mountain building has been exerted toward the continent from the ocean is Willis, and he in connection only with his later studies in China. The cause is in his opinion the "undertow" resulting from isostatic adjustments. (Bailey Willis, Research in China, vol. II, Systematic Geology, Carnegie Inst. of Washington, 1907, pp. 123-133. 


\section{Plate Vi}
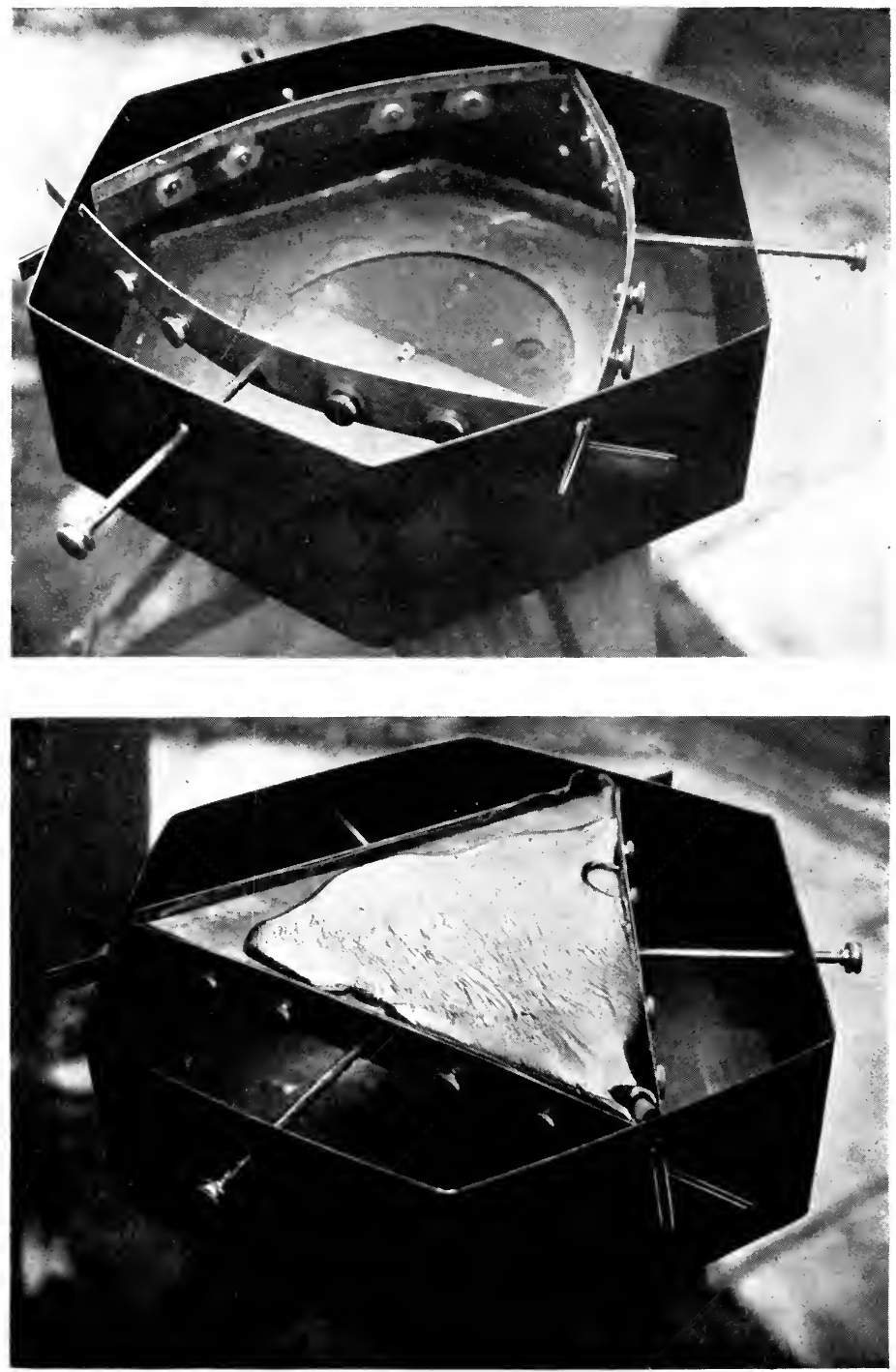

Experiment for producing arcuate wrinkles by underturning of plastic Canada balsam during the contraction of a rubber sheet. 1. The apparatus. 2 . The effect on the balsam. 

rigid triangular frame enclosing elastic adjustable walls which permit of attaching to them an india rubber membrane which can therefore be stretched or released at will. On the surface of the membrane, which is made of the material in common use by dentists for rubber dams, is poured Canada balsam after reducing it to a consistency from which it quickly cools and remains rigid. When this balsam layer has been added as a coating to the membrane and before it has had time to solidify, a mass of cold metal is brought in contact with the membrane from below and a local area cooled and congealed. The membrane is now allowed to contract and the still viscous balsam surrounding the rigified "shield" allowed to crease by underthrust from without, whereupon it quickly congeals in definite arcs as shown in plate VI at the bottom.

The essential contrast of the two views of arc formation is brought out in Fig. 54, in which b represents the view of Suess regarding the positions of the active force and of migrating strata with reference to the passive forces, and c that of the author. In the author's view, we would repeat, it is the layers of strata at the front that are forced under those situated at a higher level near the coasts to produce underturned folds from the front of the arc, and not overturned folds from its top and rear. As we shall see later, the mechanics of the process of arcuate folding permits of local lateral overthrust inward in the case of strongly curving arcs, but not overthrust outward, as was assumed by Suess.

It must further be clear that upon the author's hypothesis, it is a vast region which supplies the compression resulting in a reduction of superficial area so that the "slack" of the strata is taken up within the folds. In the conception of Suess it is, on the contrary, a distinctly circumscribed area within the arc which is involved, and which must therefore actually expand to produce the outward migration of the strata to form the arc (Fig. 55). Such 
an expansion of the strata must certainly require a noteworthy thinning of the strata themselves within the area where they are expanding, and such variation in thickness must appear in the folds themselves as a thinning of the upper limbs in a manner which is brought out in Fig. 55, in which the contrasted views are graphically expressed. The form of fold required, which is shown at the left in the figure, has seldom, we believe, been observed; whereas the other form required by the theory of underturning from in front is the normal type within all areas of intensely folded rocks.

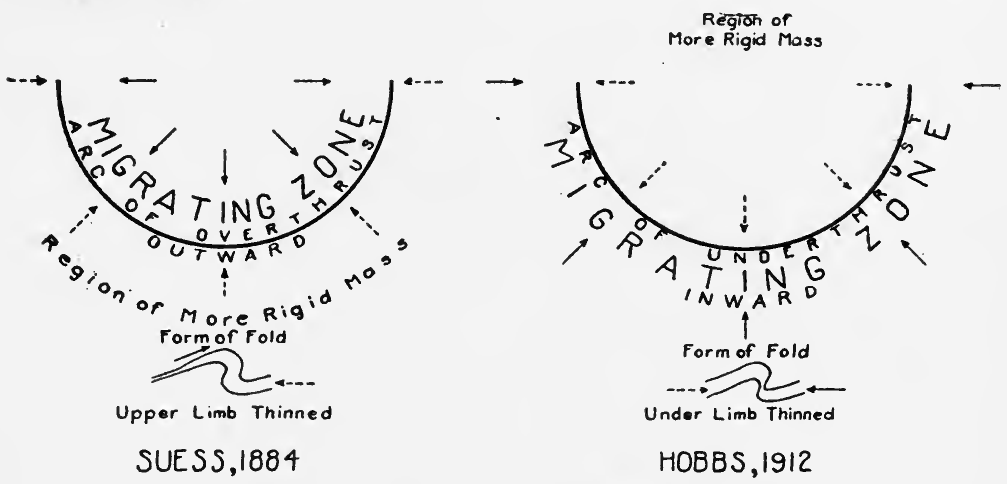

Contrast of opposing views concerning the origin of arcuate mountains

Fig. 55

If the active force which induces folds and yields arcuate mountain creases, is one which goes out from sinking areas of the ocean floor it becomes possible also to study the mechanics of those mountain systems which have been reared in the remote past on the borders of former oceans, since these latter may now be mapped upon the basis of the distribution of their sediments. If, on the other hand, such forces have gone out from the land areas we are prevented from carrying out such studies by the fact that ancient land areas are much more difficultly located, their materials having long since been scattered in many directions and been mingled in the deposits laid down in their time. 
It seems to have been overlooked that Professor Suess nowhere in his great treatise has suggested why the rock of the continental interiors should migrate outward toward the surrounding seas. To invoke the force of gravitation is obviously beside the point.

We may begin now by considering the conditions which marked the close of the long Paleozoic era when the continents stretched in east and west directions, with a northern coast line of Appalachia-Armorica extending across the present Atlantic from Newfoundland to Brittany and facing an ocean to the northward. The mountain ares on this coast line are represented in fig. 56, and ranged behind them we
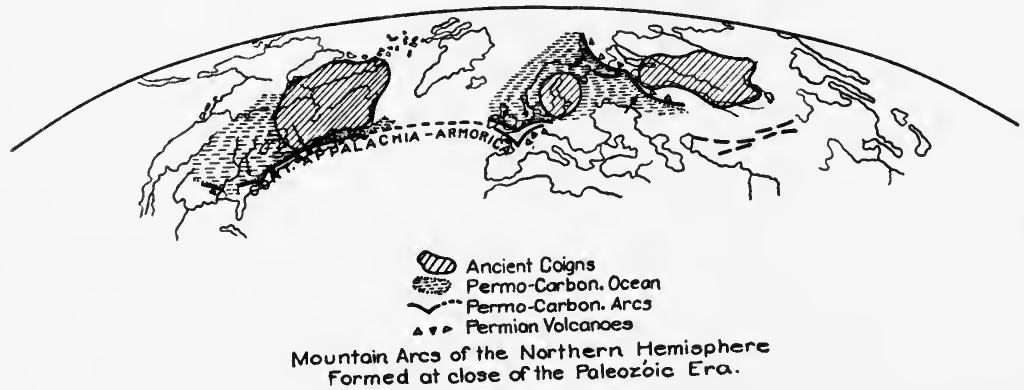

FIG. 56

find the present remains of the igneous materials which took part in the mountain building process. For the eastern United States, these facts are set forth on a larger scale in the map of Fig. 57, the geosyncline of the long preceding era having determined the position of the belt within which the arcs are developed. A few examples of the forms of folds are also supplied to show how they were underturned from the direction of the then ocean lying to the westward. The point of importance to be noted is that here, as apparently in all cases, the steeper limbs of the folds, and the thrusts whenever formed, face the basin in front, by the settlement within which the folding is believed to have been determined. 
The fact has already been alluded to, that Professor Suess felt compelled to modify his earlier generalization that arcs in all cases face the existing oceans with the steeper sides of their folds, by later making exception for that portion of

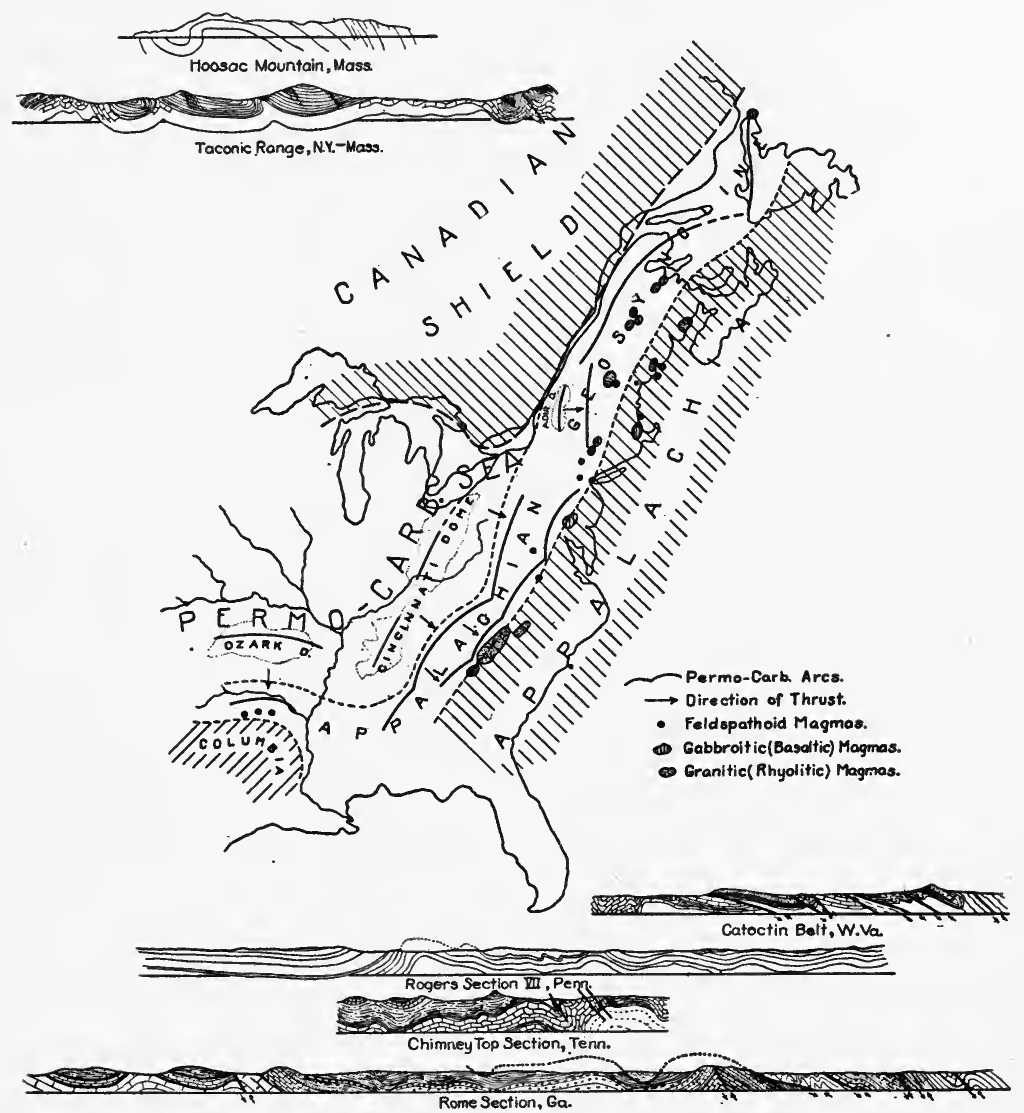

FIG. 57.-Map of the arcs of the eastern United States with geological sections

the great Cordillera of the western hemisphere which lies to the southward of British America. His later reference to his first statement is that this earlier statement "was in accordance with the observations which had been made up to that time." This later modification, printed in the fourth 
volume of his masterpiece, was made after Willis, Daly and others had brought out their sections from near the 49th Parallel of North Latitude and shown that great thrusts have in the Rocky Mountains taken place with folds which faced eastward, or away from the Pacific, instead of westward as had at first been supposed. For the great Andean system of South America the fact that the steeper limbs of the folds face away from the Pacific had been brought out by Steinmann (Fig. 20, p. 58), and to this evidence we may now add a section by Palmer (Fig. 58). Today we may extend the exceptions cited by Suess in the other direction so as to carry them northward to the Arctic Ocean and state that for the entire Cordilleran backbone of the western con-

EASTERN COROLLLRA

PRE-COROILERA

THE. PAMPAS

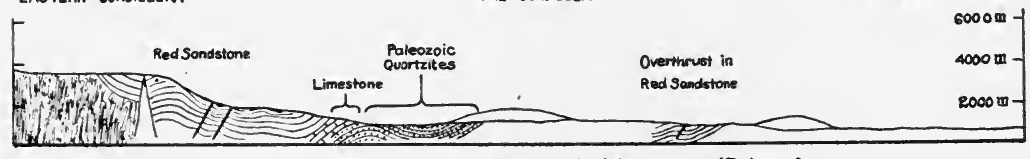

Section at east base of Andes, N.W. Argentina(Palmer)

FIG. 58.-Geological section across the eastern base of the Andes in northwestern Argentina (after Palmer).

tinent the folding is away from the Pacific in the sense of Suess; i.e., the steeper limbs of the folds are on the eastern rather than on the western sides. In order to make this clear for the areas to the northward of Colorado, the sections of Fig. 59 have been assembled.

The difficulties encountered by Suess in bringing the American Cordillera within his scheme, was wholly due to the fact that he was requiring the continents to move outward toward the oceans by overthrust. When now we look upon the fold arcs as raised by thrusts from the seas on whose borders they are being elevated, the American Cordillera conforms absolutely to the law which elsewhere prevails.

As is well known, the Rocky Mountain system began to be elevated in Laramie (late Cretaceous) time when a depression was formed to the eastward, as can be seen by in- 
spection of the map of Fig. 60. The Coast Ranges, which face the Pacific directly, betray no indication of such a direction of movement, and the sections thus far prepared in-
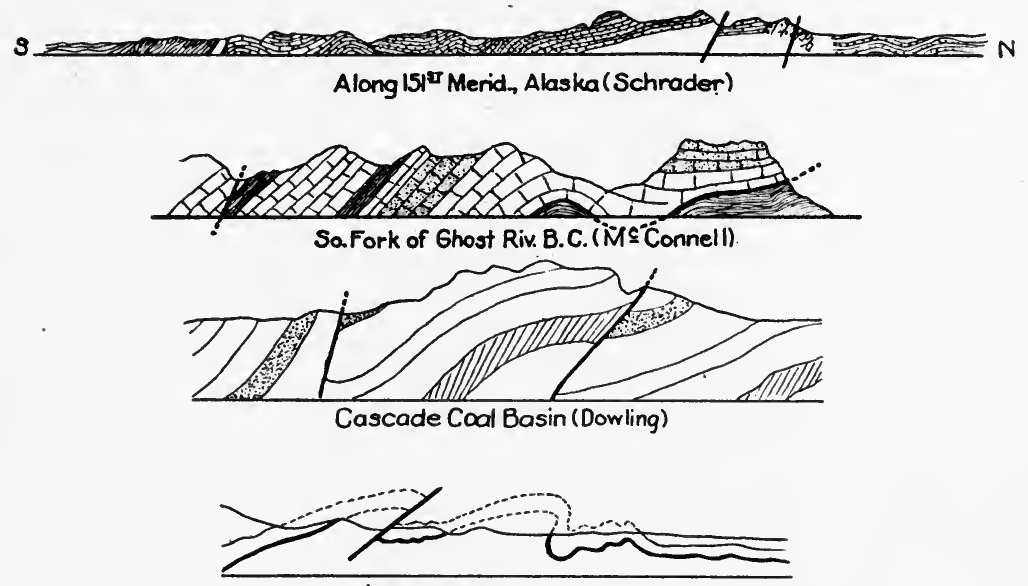

Moose Mt.Region, B.C. (Cairns)

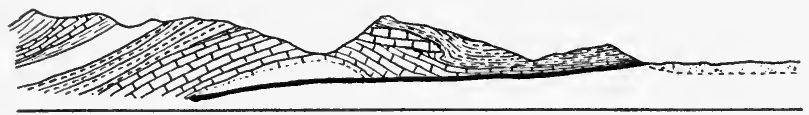

Along 49 ${ }^{\text {w }}$ Parallel (Daly)
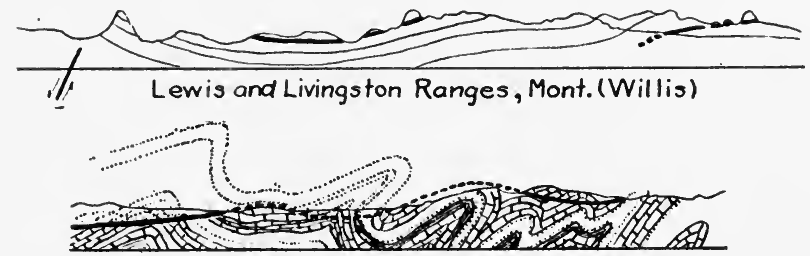

Along $43^{\text {Bs }}$ Parallel (Richards and Mansfield)

Geological Sections of the Rocky Mountains facing the Laramide Sea FIa. 59

dicate for the direction of thrust the exactly opposite quarter, insofar at least as the late Mesozoic and Cenozoic formations are concerned. The trend of the formations also indicates an arcuate structure convex toward the Pacific and 
with vertices or reëntrants at Puget Sound and also near the international boundary with Mexico (Fig. 61).

Subsequent to the formation of the series of ares forming the eastern and western boundaries of the broad area sepa-

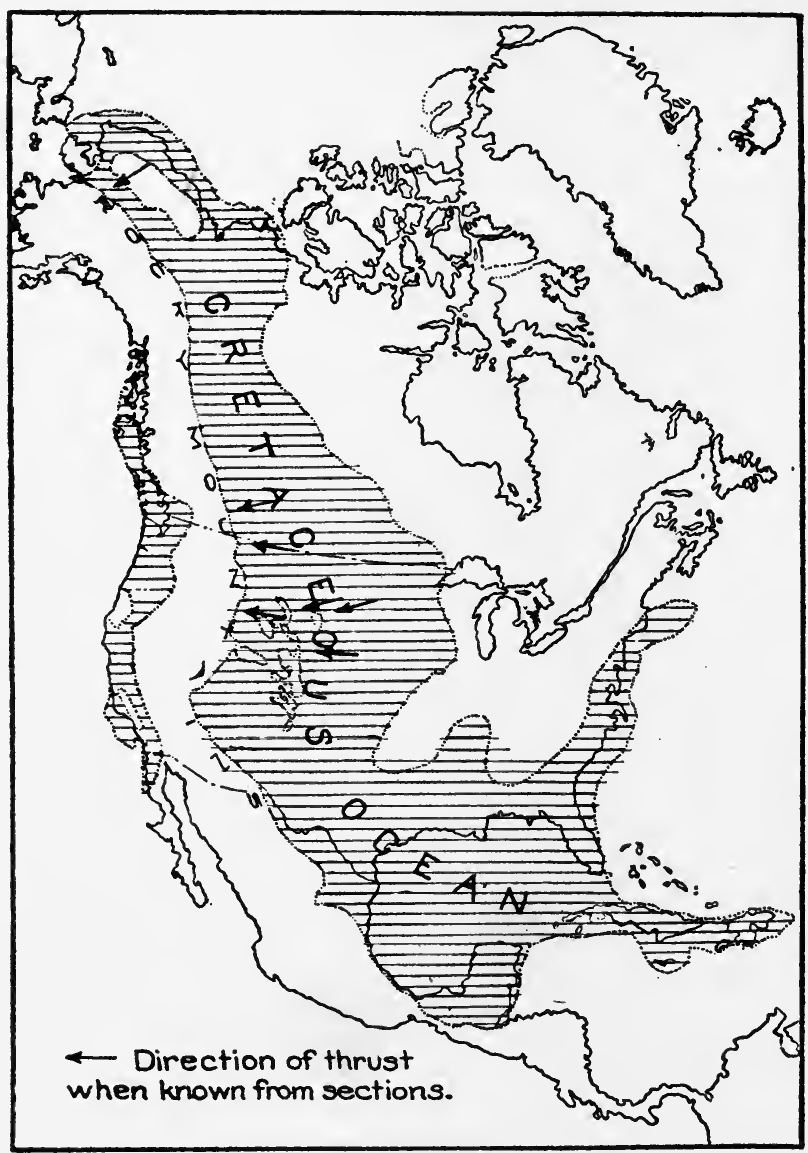

Fig. 60.-Map of the Cretaceous Ocean and the Rocky Mts. which rose on its border

rating the Rocky Mountain Ranges from the Pacific coast, there came the settlement of a vast interior area now represented by the "Great Basin" and its extensions to the northward. This settlement had the effect of introducing new 
thrusts which were directed westward on the west side toward the present Sierra Nevadas, and eastward on the east side toward the Bitter Root, Wasatch, and other ranges which there form the boundary of the basin (Fig. 62). The immense development of contemporaneous or later igneous rocks has been largely responsible for the small number of

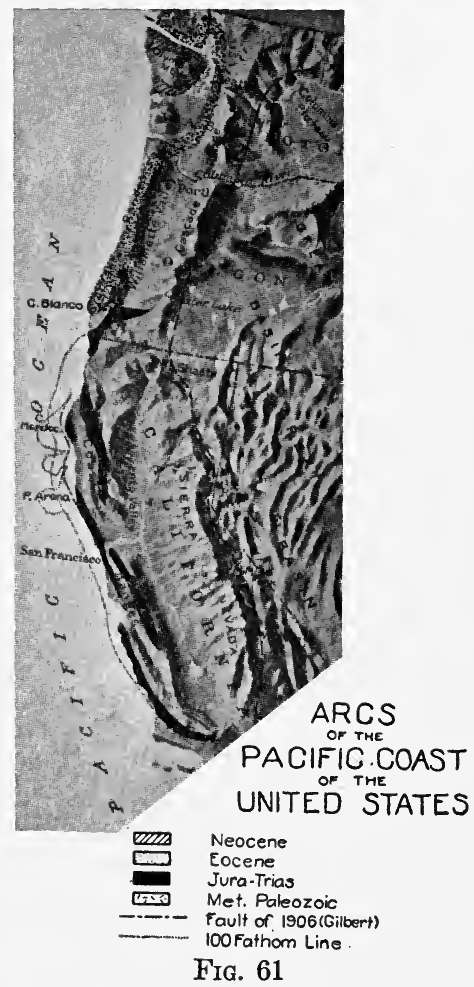

good sections in which the structures of the sedimentary rocks can be clearly made out, but we none the less have one excellent section from the western border, Diller's Taylorville section in California, and also sections through the Wasatch Range on the eastern border.

The contrast between the Suess conception as given in his later modified statement, and the view here set forth by the author, is schematically represented in Fig. 63. 


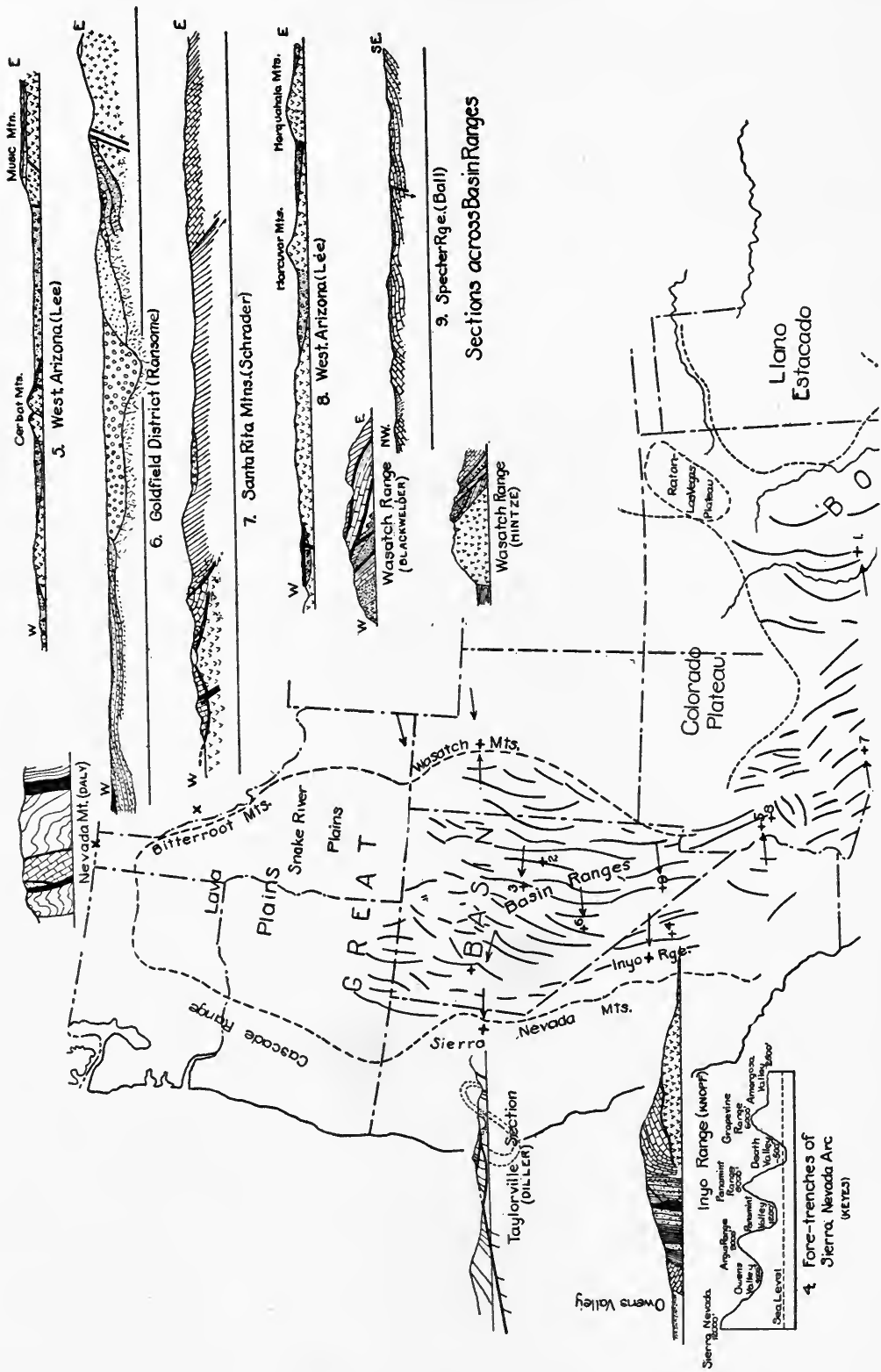

FIg. 62.-Sketch-map of the great depression formed in Pleistocene time, between the Rocky Mts. and the Pacific Coast of the United States, together with sections 

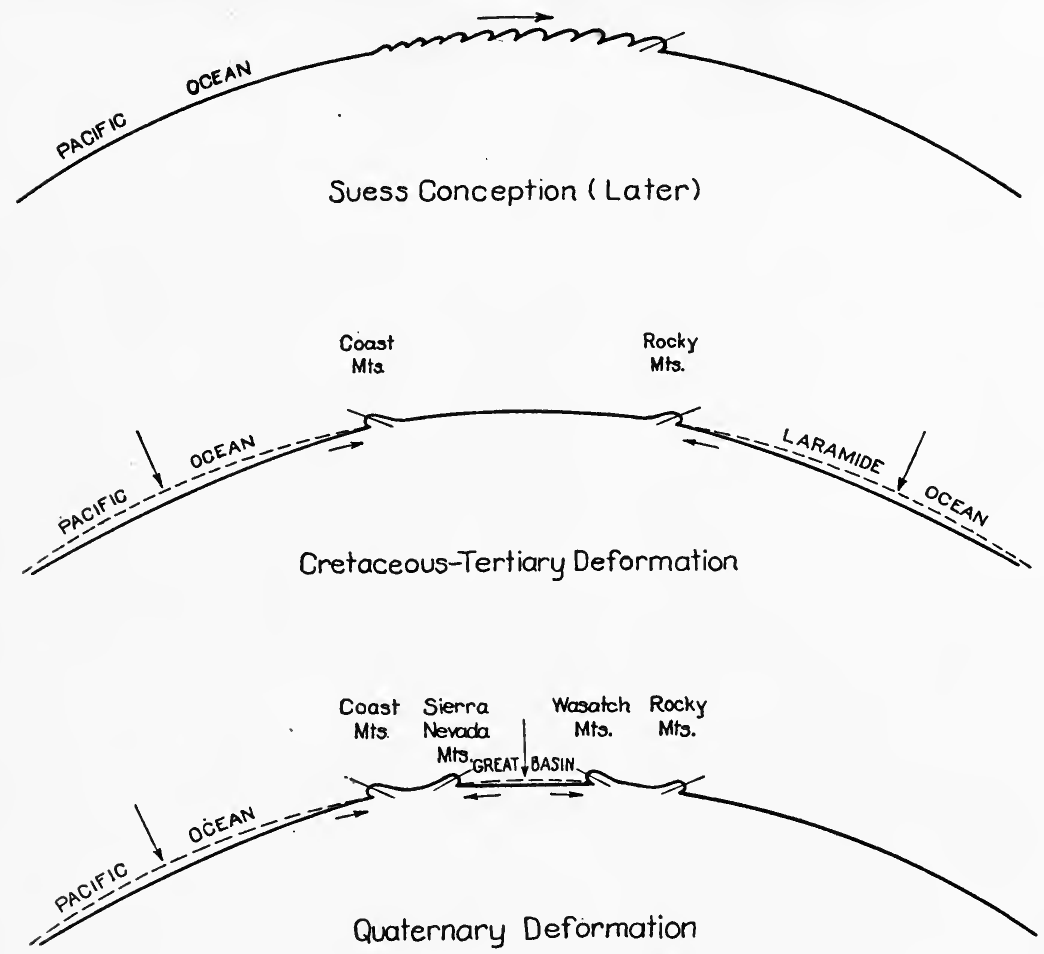

Contrasted views of Suess and Hobbs concerning origin of the mountain arcs of the western United States

Frg. 63

\section{LITERATURE}

K. von Zirtel. History of Geology and Paleontology (translation by Ogilvie-Gordon), London, 1901, pp. 61, 64, 299.

Eduard Suess. Die Entstehung der Alpen, Vienna, 1875.

Eduard Suess. The face of the earth, 5 vols.

Eduard Suess. On the asymmetry of the northern hemisphere, Scot. Geogr. Mag., vol. 14, 1898, pp. 649-654.

WILIIAM H. HoBBS. Mechanics of formation of arcuate mountains, Jour. Geol., vol. 22, 1914, pp. 71-90, 166-188, 193-208.

BAILEY WrLus. Stratigraphy and structure, Lewis and Livingstone Ranges, Montana, Bull. Geol. Soc. Am., vol. 13, 1902, pp. 305-352, pls. 46-53.

BaILEY Wrulis. Research in China, vol. 2, Systematic geology, Carnegie Institute of Washington, 1907, pp. 433, pl. 10. 


\section{CHAPTER XI}

\section{THE PATTERNS OF THE FACIAL WRINKLES AND THEIR MEANING}

Having now shown that the rule of direction of folding within arcs on the earth's face is not subject to an important exception for the western hemisphere, as Suess had supposed, we are in a position to view the general plan of the wrinkles which cross the present earth's face (see frontispiece) and to inquire a little further into the law of their formation.

Our discussions of the folds within the arcs have thus far been centered upon the form of the individual arcs and upon the character of their vertical sections. Let us now consider the problems of mechanics concerned with their development, insofar as these may appear from their design or pattern as a whole with reference to the ancient coigns and to the ocean basins upon their fronts. If, as we have assumed, thrusts proceed outward from the sinking sea-floors toward the neighboring coasts, we are concerned with the way in which the higher coasts acting in the manner of a resisting mass may be assumed to resolve these thrusts in accord with the known laws of mechanics applying to beams or girders, the outer shell of the lithosphere being looked upon as capable of transmitting the stresses to considerable distances under these conditions. Obviously the trend of a coast line must be a prime determining factor, and the results may differ materially for different outlines of coast; as, for example, for a coast reëntrant, for a straight coast line, and for a salient. The case of a salient may further offer some differences according as it is obtuse or acute. 
An attempt has been made in Figs. 64-66 to indicate what are these essential differences. The first case, that of a coast reëntrant (Fig. 64), illustrated by the Eurasian and North American coast lines where they approach at Bering Strait, should develop an anticlinal arc of gentle curvature everywhere underturned toward the front in the normal

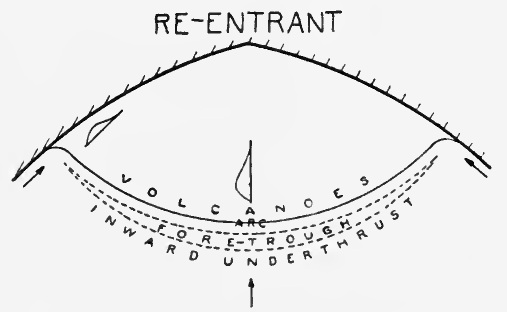

FIG. 64.-Plan of an arc rising in a reëntrant of the coast

fashion. A straight coast line may be assumed to be much the same and perhaps with even simpler curvature and with the anticline developing underthrust and in its later stages underslicing. The southern Andes appear to fairly illustrate this type.

The third type of coast line, which outlines an obtuse salient, is the most common of all and offers no essentially

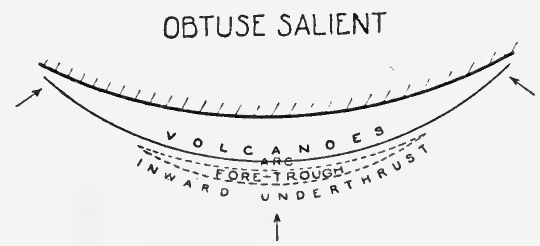

Fig. 65.-Plan of an arc rising off an obtuse salient of the coast

new features (Fig. 65). The greater number of arcs on the eastern border of Eurasia forming the garlands of islands along that coast, fall within this class. In them, so far as evidence is at hand, the anticlines are underthrust from the front and are of the same asymmetrical type, whether viewed from the middle (frontal position), or from nearer the ends-the lateral parts. 
On the other hand, a sharp salient in the coast line, such as is offered by the Malayan peninsula pinched in between the Indian and Pacific oceans, obviously offers a different problem; for the two sides of the salient are each capable of resolving the thrusts from the sea in an individual manner. The attempt to derive the resulting system of arcs for this type of coast line, as has been done in fig. 66, has gone out from the design displayed by the archipelagos about the Malayan peninsula, the one striking example which our planet affords where geosynclines with their lenses of sediments line both flanks of the salient.
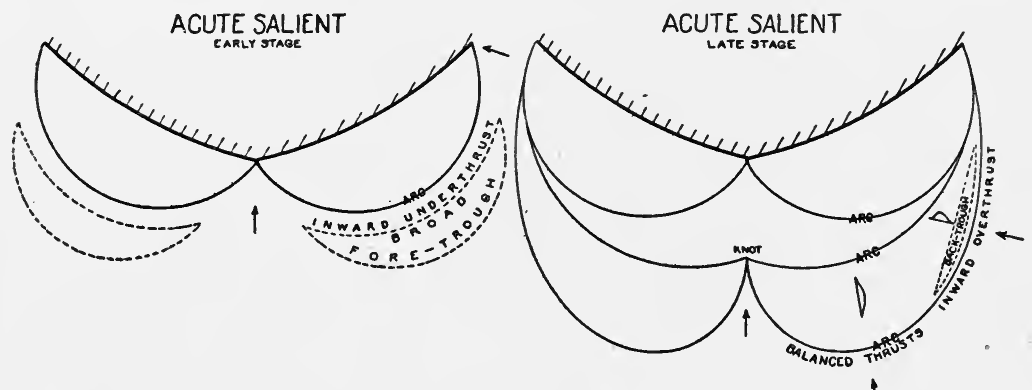

FIG. 66.-Plans of arcs in two successive stages formed off an acute salient of the coast

An attempt to give anything like an adequate discussion of this area must be reserved for another place, but two aspects of the subject may be touched upon here. These are, (A) the intersecting knots, or centers of virgation which have developed, and (B) the back-folding of the anticlines where arcs become strongly curved, with the attendant production of back-troughs instead of fore-troughs. Viewed from a mechanical standpoint this would appear to be a consequence of the enhanced rigidity of the material involved in the arc through pleating (doubling) of the strata. A result is that the thrusts, acting in larger measure upon the lateral portions, overwhelm them at the same time that the frontal portion of the arch is held back in its development. As a consequence the fold continues to retain its 


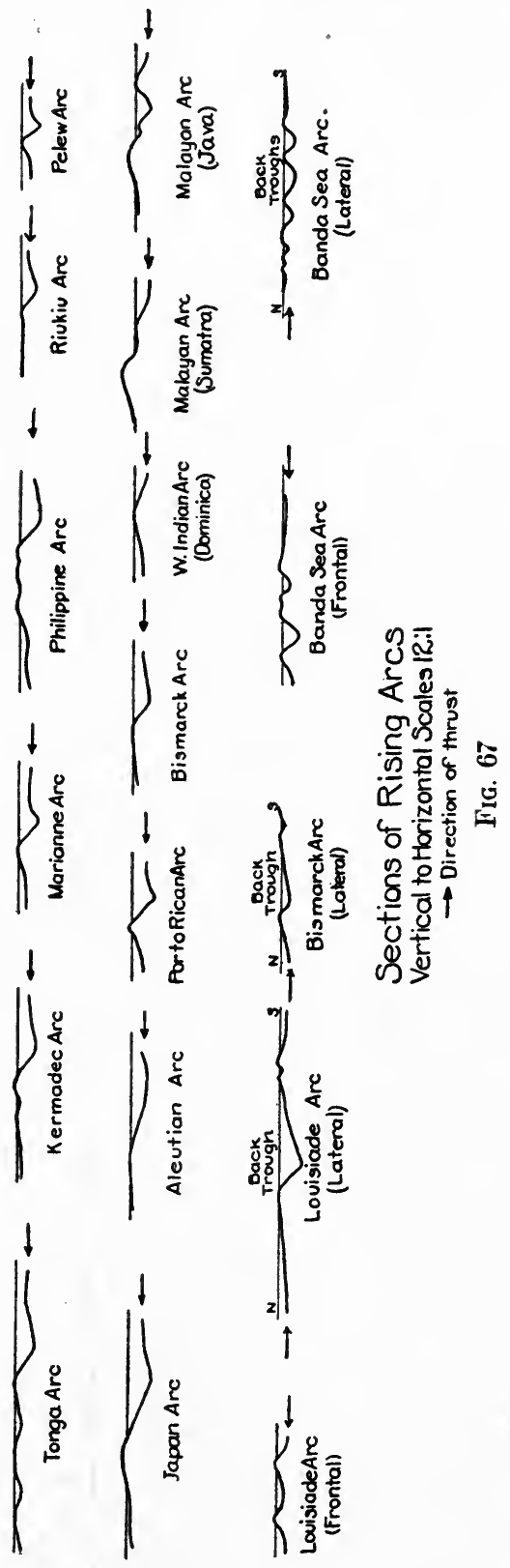


early stage in the frontal portion and no fore-trough develops, whereas at the sides the fold is bent backward, or reversed, and a back-trough is formed behind it-within the arc itself. This condition probably expresses a general law, for it is characteristic of all the more sharply curved arcs of the Pacific archipelagos insofar as soundings are available to permit of their study. Examples are furnished by the Banda, Luisiade and Bismarck ares (Fig. 67). We do not find in this the evidence that tensional stresses are produced in the arc such as have been appealed to in explanation of the straits which separate the islands which compose the Malayan arc. We believe, rather, that the fold or crease does not in its initial stage rise uniformly throughout, but rather as a series of domes with possible laccolite cores beneath, and that these domes only in a later stage unite into a continuous anticlinal arc.

Fortunately we have the opportunity of testing the deformation within arcs which have long been above the sea and in which the folded strata lie open to our inspection. A particularly fortuitous example is supplied by the region in the states of Colorado, Wyoming and Montana, within which strongly curved ares are to be seen in the positions in which they formed off the shore of the former Laramide Ocean to the eastward of the Rocky Mountains. These island arcs rose in late Cretaceous and early Tertiary time as garlands sweeping along the shore at that time and displaying a design surprisingly like that displayed today by the map of the eastern coast of Eurasia (Fig. 68). Similar to the arcs of Japan and the Philippines, there arose in this earlier period those of the Belt Mountains, the Bighorn and the Laramie ranges with others behind them, and with a knot formed at the junction of the Uinta and Wasatch ranges; while out in front other arcs were just rising above the surface of the sea. In these latter, as in the smaller islands which are today strung along the western Pacific boundary as pearls are strung upon a thread, we find 


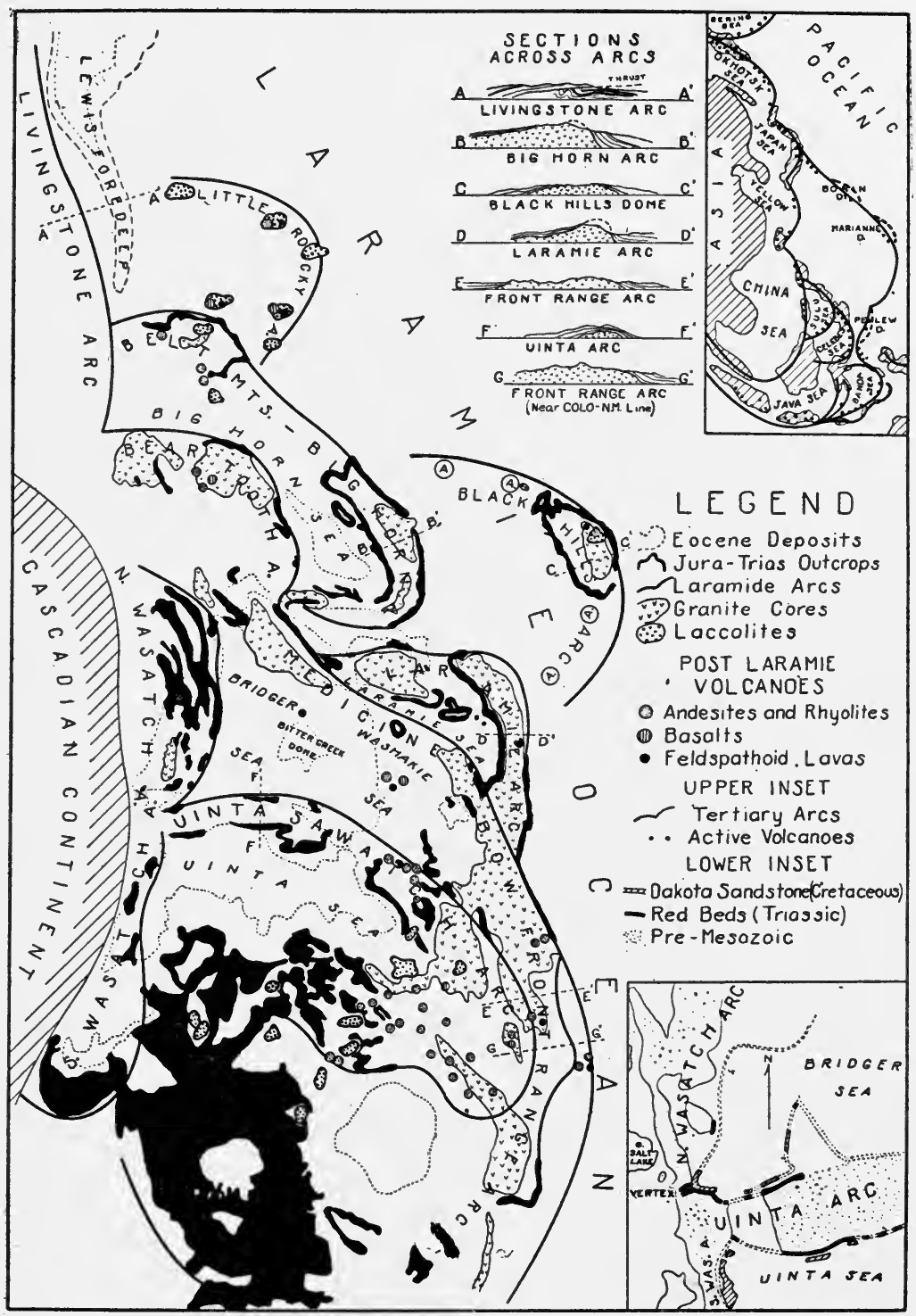

FIG. 68.-Sketch-map of the arcs formed off the eastern front of the Rocky Mts. (based on map by U. S. Geological Survey) 
the chains of laccolites and of domed strata in the Little Rocky Mountains and in the Black Hills with its extension in rising domes.

For each of these two classes, the continuous curving arc and the curved chain of domes, we are fortunate in having at least one elaborate series of geological sections, from which it is possible to compare the frontal with the lateral

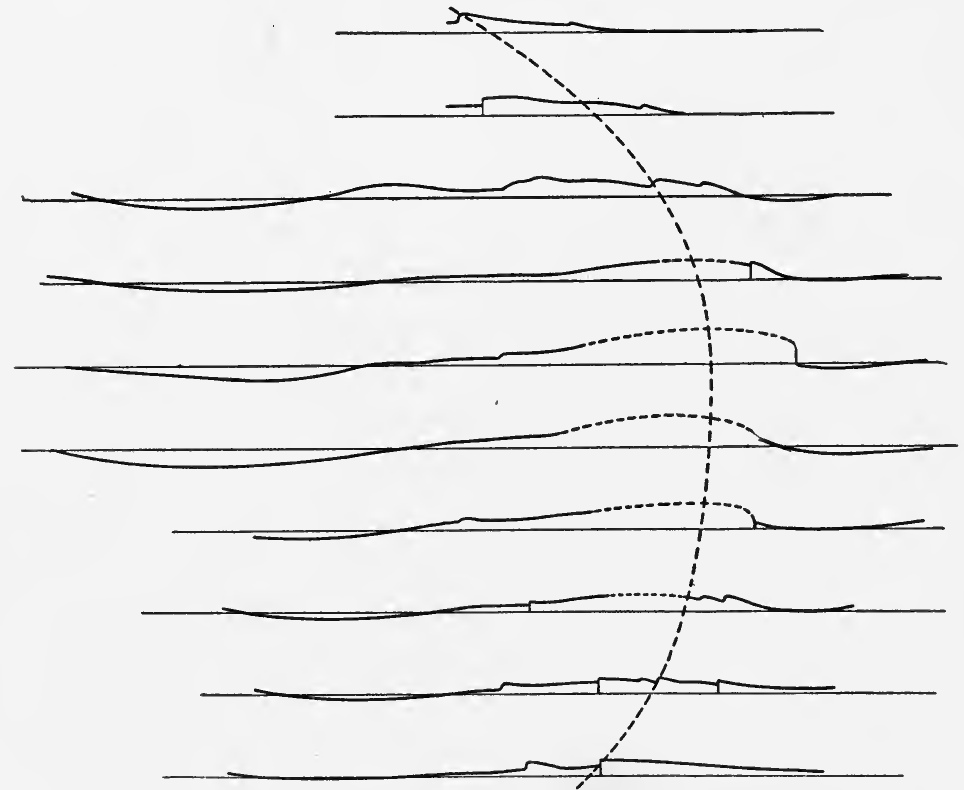

Fig. 69.-Series of sections through the Bighorn Range and showing inward underthrust in the center combined with inward overthrust on the flanks (Darton's sections)

portions in respect to the form of their folds. In Fig. 69 are displayed eleven roughly radial sections through the curving arc of the Bighorn range, within which sections are seen all the gradations from the normal anticline in the frontal position with its steeper limb directed outward, to the strongly back-folded portions in lateral position within which is seen the evidence of an inward overthrust from without.

The Black Hills group of domes is displayed in the sec- 
tions of Fig. 70, and indicates essentially the same conditions-the normal underthrust at the front and the backfolding from inward overthrust within the lateral portions of this strongly curved arc.

From all these examples of the present and the past arc formations, we draw the conclusion that the pleating of competent strata so stiffens this zone in which the crease is made, that if it be too sharply bent in its plan the acquired

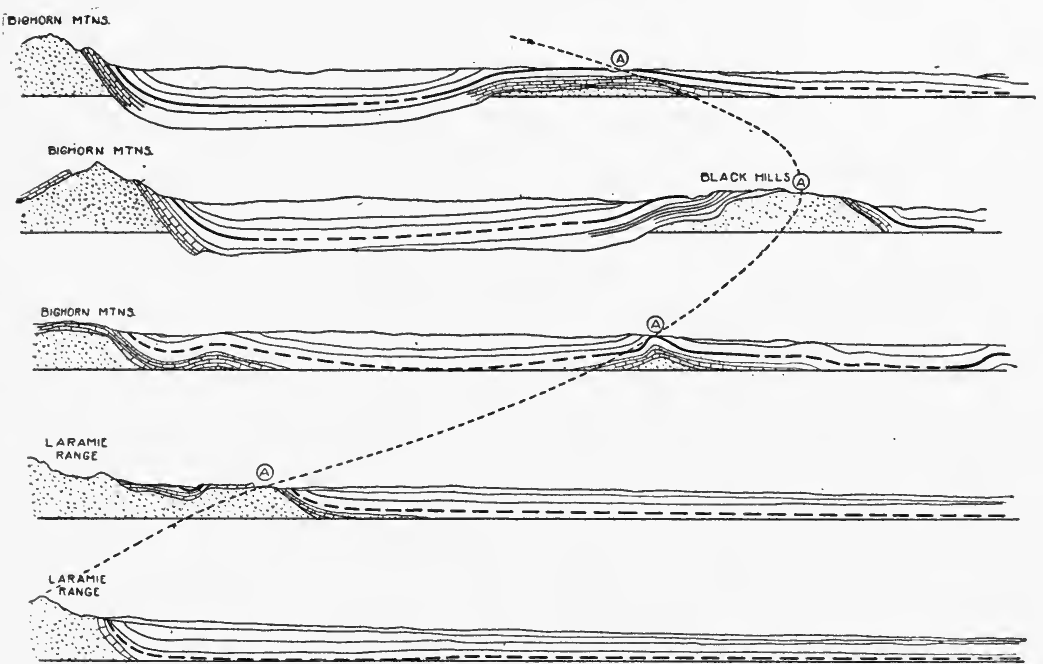

FIG. 70.-Series of sections showing the partly buried arc of the Black Hills with its inward underthrust in the center combined with inward overthrust on the flanks (Darton's sections)

rigidity of the crease asserts itself in mutual reactions of its frontal portion upon its extremities and vice versa.

The Cordilleran system of mountains in North America offers an interesting example of the direct relationship of the competence of the developing anticline to the extravasation of lavas in its vicinity. In that portion of the system which is included in Colorado (see Fig. 68) and has there yielded a series of ares within which the folds are of fairly symmetrical form, the development of laccolitic cores and the extravasation of lava have both taken place upon a 
grand scale; whereas in the zone to the northward, where instead of taking up the slack of the compressed strata by a series of open and therefore competent folds, this adjustment has all been concentrated within a relatively narrow zone of incompetent underthrust and undersliced folds (see sections of Fig. 59, p. 130, neither laccolites nor volcanic extravasations has resulted. This appears to correspond to a rather general rule which applies to underthrust and undersliced folds and must be looked upon as valuable confirmatory evidence in support of the view of the origin of lava from the fusion of shales. This difference in character of the folding Dr. R. T. Chamberlin has recently sought to

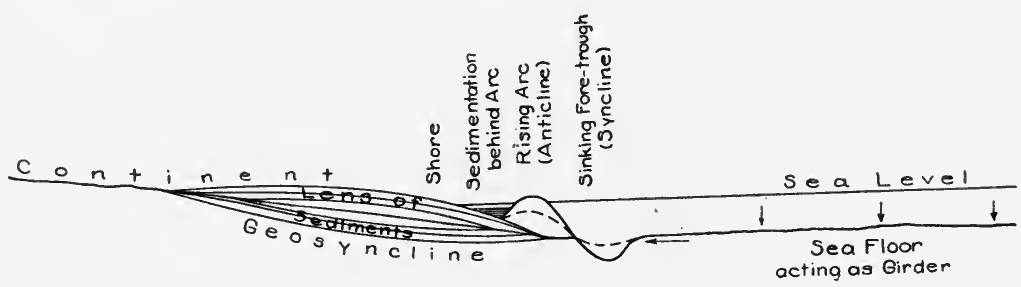

Fig. 71.-Schematic diagram to show plan of formation of rising arc at the front of a lense of sediments

explain through a difference in character of the involved strata.

If we accept the general plan of development of arcs with respect to the form of the coast line as this was set forth in figs. 64-66, there still remains the interesting question concerning the exact places where anticlines will rise and form the individual arcs. Why, for example, does the Aleutian arc rise just where it appears upon the map, rather than either farther out from or nearer to the apex of the reëntrant at Bering Strait? It seems highly probable that the point of initiation of an anticline is to a large degree determined by the initial dip of the lenses of deposits as these bow upward in the zone of the geosyncline toward the margin of the continental shelf (Fig. 71). A stiff rod, otherwise straight, will buckle under compression from its two ends 
at the place where it has an initial bend from its straight axis, however slight in amount this may be.

Behind the arcs, wherever they rise as a festoon of offshore islands, sedimentation will take place and eventually close up the sea which is thus initiated. Such a process of sedimentation is today going on most rapidly in the Yellow Sea behind the Riukiu arc on the China coast, into which sea the Yellow River discharges its great burden of sediment.

In the interesting experiments by Willis which have already been frequently referred to, it was shown that after the first anticline to develop had lost its competence through underturning, a second anticline developed behind it, and in turn a third and perhaps a fourth, but of smaller size as they recede from the original arc. It is evident from the study of anticlines formed in the Malayan archipelago that some such order is characteristic of rock formations, though later subordinate anticlines are probably also formed in front of the initial arch. In the Willis experiments the active thrust was transmitted through a rigid piston which, so far as the experiments were concerned, might be regarded as of infinite rigidity. In the case of anticlines developed in strata, the active thrust is communicated through the competent stratum itself, and the study of fore-troughs in the Pacific region indicates pretty clearly that after an initial and essentially major anticline has been pushed up, at least one smaller anticline is apt to develop along its front and produce what we have called a crown-deep or crown-trough, illustrated particularly well by the sea-floor at the front of Java and Bali (Fig. 50, p. 121).

If we now devote our attention to the general plan of the earth's face (see Frontispiece), we perceive at once the relationship which the later formed arcs bear to the framework of the structure displayed in the ancient coigns. It is about these relatively rigid foundation stones of the lithosphere that the structure is laid. The coigns within the 
southern hemisphere have been relatively less immobile than those of the northern hemisphere, as is indicated by the fact that they have been partially. covered by the Cretaceous deposits. It is only between them, where the thick deposits of the Mesozoic geosyncline stretch out along the twin plane of the earth, that the arcs have been able to develop in long and narrow loops. This girdle of the earth is now represented by the arcuate zone joining the Caribbean Sea in the western hemisphere to the Mediterranean Sea of the western portion of the eastern hemisphere extended to the Malayan zone to the southeast. A somewhat similar belt pushes out eastward within the area between Patagonia and the Antarctic continent in the direction of another portion of the known Mesozoic geosyncline following the East African littoral.

The order of development of these wrinkles in the earth's face is shown both by the geologic age of the formations which have become involved in the folding process, and by the stage of subsequent denudation, to have been from the coigns outward. The outermost arcs of the series are even today in process of rapid elevation, as is attested by the jolting movements manifested to our senses as earthquakes, and by the fusion and exudation of molten rock at the vents of the active volcanoes.

As we go back from these later arcs of the outer series, we pass into arcs of mountains which today rise to the loftiest heights that are anywhere known, but with the quaking renewals of the erecting process now relatively infrequent. The process is thus in this zone nearing its end, and the tearing down agencies are doing their work of levelling out and slowly erasing these wrinkles from the earth's face.

Still farther back toward the ancient and long stabilized Angara shield, the work of levelling down has been already accomplished, and the former ranges have left us little save their roots. These inner arcs we note also have a simpler 
and straighter course, and about them the outer arcs have been laid on in the form of festoons ever more differentiated in character as we pass toward the outer marginal series.

The inner and earlier arcs trending in roughly east-west direction south of the ancient coign of Angara Land, from their age must have been formed when the Sea of Tethys stretched in the same direction to the south of them, so that the underthrust would be to the northward. The later arcs with their more intricate pattern of festoons developed in the deposits of the Tethys Sea and rose with the foundering of the portions of the Gondwana continent which had formed its southern border, and which after the foundering formed the bed of the Indian Ocean.

The strikingly compressed arcs which extend the Himalayan highland southeastward in the direction of the coign of Australia, represent a much widened area of Mesozoic deposits where the two great zones of geosynclines approach and intersect, and where these were caught in the vise between the thrusts of the sinking basin of the Pacific and that of the Indian Ocean, while protection was being furnished at the southern end by the shield of Australia (Fig. 72). To the eastward of Australia the extension of this series seems to have been crowded against the Australian coign by the thrust from the broad sinking area of the Pacific (see frontispiece).

An even more striking instance of compression of arcs is furnished by the Andean system of South America which was compressed both from the east and from the west. This intense compression is reflected in the closely squeezed and nearly vertical isoclinal folds with their flattened laccolitic cores, so well brought out in Steinmann's generalized section (Fig. 20, p. 58). Around the northern end of the Brazilian coign in Peru, this compressed series of arcs opens out in most strikingly schematic fashion as the sheaf of mountain chains which pushes northeastward into the island arcs of the Antilles and northwestward as a long ex- 
tended arc whose course may be faintly followed by the volcanic islands off the west coast of South America (see frontispiece). At the compound Peruvian knot there is found the chief development of volcanic energy, as is well brought out in Karsten's geological map (Fig. 73), to which

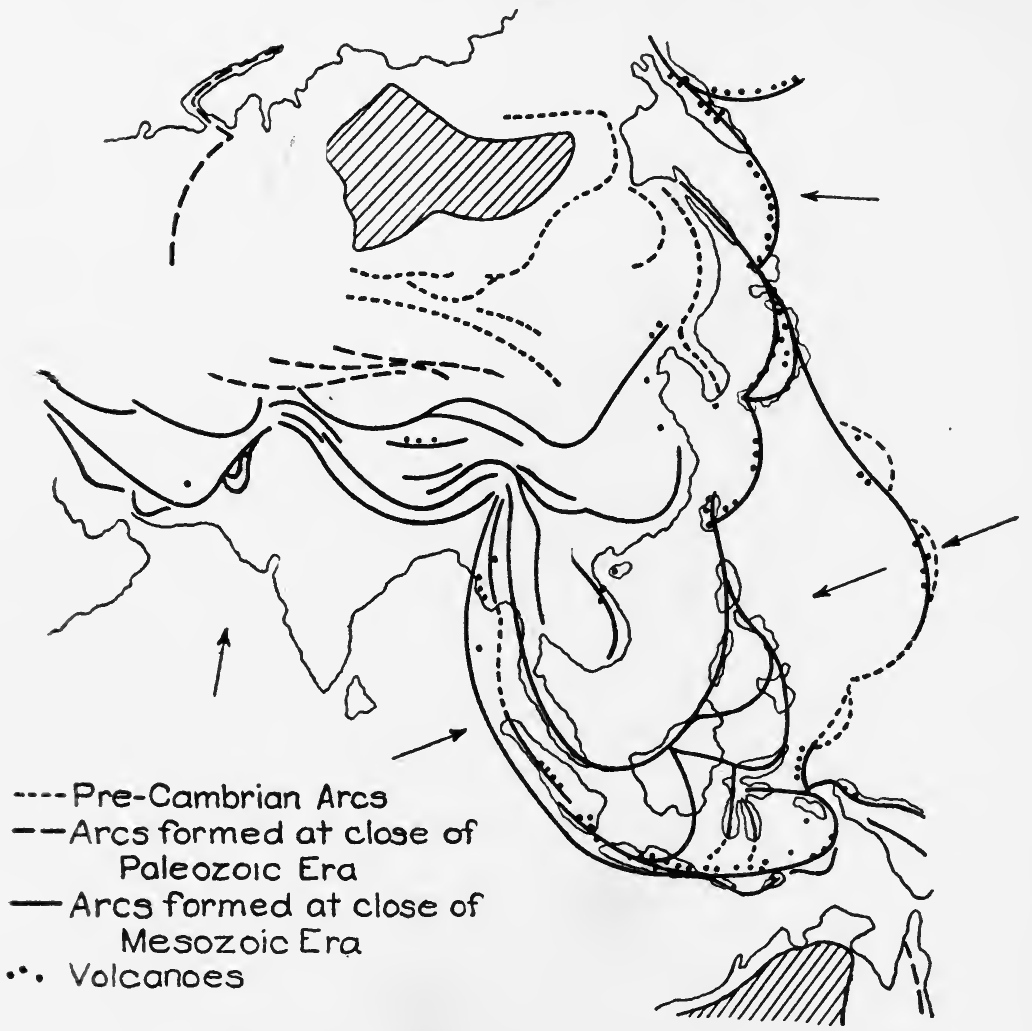

FIG. 72.-Sketch map to show the arcs of southeastern Asia

we have added only the heavy lines to show the approximate courses of the several arcs.

The best indication of the rising arcs upon the floors of the oceans is a curving ridge or curving chain of islands with a definite fore-trough at its front. It is only after these features have developed sharply inclined slopes that the volcanic activity is likely to be observed as an important 


\section{8}

confirming indication that an arc is forming in this position. In the earlier stages of arc formation the indication of its location will naturally be relatively slight. We are therefore in great need of additional soundings from the oceanfloor in significant localities where the possibility of an arc is indicated, and until such soundings have been made no clear statements can be offered for certain sections of the ocean areas. The rich results of the soundings made by

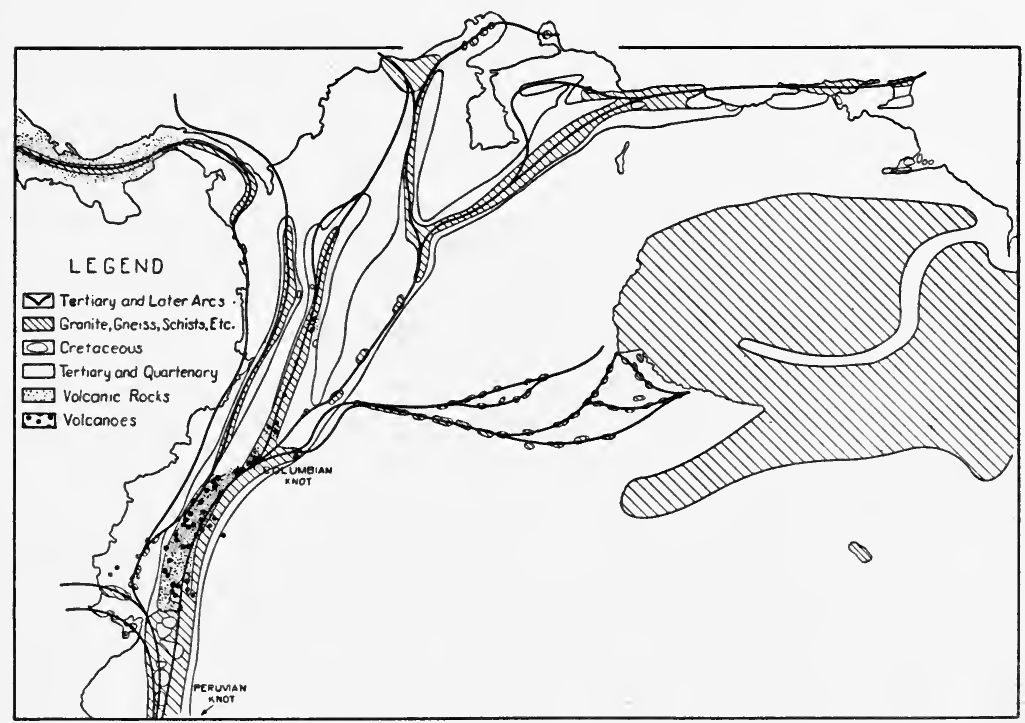

Fig. 73.-Virgation of the ares of the Andes at the Peruvian knots (after Karsten's geological map)

the "Nero," "Planet" and "Siboga" expeditions should leave us in no doubt as to the real importance of continuing such investigations. There is the most urgent need of a new "Challenger" expedition for investigation of the Pacific area, which is to-day a region scientifically almost unknown.

The Central Atlantic area shows upon the basis of the few soundings a long S-shaped ridge which passes through the Azores and Madeira, and which may indicate the beginnings of a zone of arcuate folding. The evidence is, 
however, too scanty to make prediction safe at the present time.

In eastern Africa and in the neighboring portions of the Indian Ocean there is a large area within which arcuate folding would appear to be combined with faulting, but, unlike the Eurasian continent the folding is here subordinate to the faulting process. Within the western portion of this region upon the continent of Africa we find some of the most stupendous fault displacements that are anywhere known, and these are so associated as to outline great trenches or rifts of which the more remarkable are indicated by the position of lakes Tanganika, Albert Nyanza, and Nyassa.

The view of Suess that faulting alone has produced the structures found in the rocks of this portion of the African continent, has been opposed by de Lapparent, who regards the great rifts which outline the western boundary of the area as the broken western limb of a sharp anticline with its steeper side towards the west. This view seems to be supported also by Abendanon.

Gregory, after revisiting the scene of his earlier studies in the Rift Valley region, says in a recent paper, "The first stage in the formation of the Rift Valley was the elevation of the country along it into a low, broad arch, which would have formed a belt of down-like highlands, ranging across British East Africa from north to south. * * * The more active earth movements in late Cretaceous times and the foundering of the floor of the Indian Ocean between East Africa and India, led to volcanic outbreaks in western India on a colossal scale. *** If the formation of the Arabian Sea led to such violent volcanic activity in India it is natural to expect some corresponding events in East Africa, on the other side of the foundered land."

Suess had indeed noted the upswelling of the Rift Valley borders, and Jaeger makes this arching of the strata precede the faulting. 
In the area of the western Indian Ocean adjacent to the East African region under consideration, the courses of the submerged ridges strongly suggest that these are the initial stages in the formation of folded arcs, and in part this view is confirmed by the active volcanoes. Though we must await the results of future soundings to settle this question, the arcs suggested by the submerged ridges have been outlined upon the map in dotted lines.

Perhaps the most interesting, but also the most complex, of all the regions of arcuate mountains, are those which follow the ancient twin plane of the earth and include the American and the European Mediterraneans as well as the Malayan and Australasian regions; but the discussion of these areas must be reserved for another place.

Intermontane valleys along the western base of the Andes and its extensions into North America take the place of the fore-deeps characteristic of the western margin of the Pacific Ocean. They appear to be in part at least fault rifts differing in degree rather than in kind from the African rift valleys.

\section{LITERATURE}

H. A. Brouwer. On the Tectonics of the Eastern Moluccas, Kon. Akad. v. Wetensch., Amsterdam, vol. 19, no. 2, pp. 197-209.

H. A. Brouwer. Fractures and faults near the surface of moving geoanticlines, I, ibid., vol. 23 , no. 4 , pp. 1-7 (reprint).

G. A. F. Molengraaff. Modern Deep-Sea Research in the East Indian Archipelago, Geogr. Jour., vol. 57, 1921, pp. 95-121.

E. C. Abendanon. Die Grossfalten der Erdrinde, Leiden, 1914, pp. 115130.

Alex. Supan. Die Bodenform des Weltmeeres, Pet. Mitt., vol. 45, 1899, pp. 177-188, pl. 12.

Alex. Supan. Die Sunda Gräben, ibid., vol. 53, 1907, pp. 70-71, pl. 6.

E. Horn. Ueber die geologische Bedeutung der Tiefseegräben, Geol. Rundschau., vol. 5, 1914, pp. 422-448.

Hans Stille. Alte und junge Saumtiefen, Nachr. d. K. Gesell. d. Wiss. z. Göttingen, Math.-phys. Kl., 1919, pp. 1-36 (reprint).

GroLL. Tiefenkarten der Ozeane mit Erlaüterungen, Veröff. d. Inst. f. Meereskunde, Berlin, 1912, N. F.

A. DE Lapparent. Soulèvements et affaisements, Revue des Questions Scientifiques, vol. 14, 1898, pp. 22-24.

Hermann Berghaus. Atlas der Geologie, Justus Perthes, Gotha, 1892.

Hermann Karstens. Géologie de l'ancienne Columbie Bolivienne, Venezuela, nouvelle Grenade et Equador, Berlin, 1886, map.

J. B. Woopworth. Geological expedition to Brazil and Chile, 1908-1909, Bull. Mus. Comp. Zool., vol. 16, no. 1, p. 117. 
W. D. Sмiтh. The Philippine Islands, Handb. d. reg. Geol., vol. 6, Abt. 5, p. 23, fig. 5 .

W. H. HoBbS. Earth Features and their Meaning, 1912, pp. 436-439.

W. H. HobBs. Mechunics of Formation of Arcuate Mountains, Jour. Geol., vol. 22, pp. 77-82.

J. W. GREGoRY. The geological history of the Rift Valley, Jour. East. Africa and Uganda Nat. Hist. Soc., vol. 6, 1920, pp. 429-440. See also The African rift valleys, Geogr. Jour., July, 1920, pp. 13-47. 


\section{CHAPTER XII}

\section{THE DESIGN OF THE FRACTURE MARQUETRY}

OF the two contrasted aspects of the earth's face to which attention was first directed by Suess, we have now seen that the one exemplified by the greater part of the continent of Eurasia with its extensions to the southeastward, is characterized by curved wrinklings in the rock strata appearing as great earth welts which rise above the general surface in a pattern of concentric ares festooned about the rigid coigns of the earlier eras. The origin of these arcs is clearly bound up with the folding processes and believed to be due to the continued contraction of the earth's core. Adjustments on planes of fracture play a secondary rather than a primary rôle in the formation of these arcs.

We turn now to the contrasted facial expression of the earth exemplified by the greater portion of the continent of Africa, a large part of the Great Basin of the western United States, and other regions, where displacements by block faulting rather than folding have been mainly responsible for the pattern of the surface configuration. The vast area of Africa has been as yet little developed commercially, if we compare it with other portions of the world, and our knowledge of its geology has been correspondingly meager. In the Great Basin region of the western United States, the early reports by the geological pioneers of the region, King, Powell, Dutton, Gilbert and Russell, all agreed in ascribing the major features of the relief to fault displacements in which north and south fractures were dominant. Suess in his discussion of the great faults of East Central Africa has shown that in that region also the north-south displace- 
ments are much the most prominent. Later studies by Passarge and by Simmer have shown, however, that these African meridional displacements constitute but one series within a fracture pattern composed mainly from four series, and that this fault pattern divides up the entire African continent into a fault mosaic. The four directions of the fault series are approximately north-south, east-west, northwest-southeast and northeast-southwest. Not all these directions are found developed in each part of the region. Thus in the region of the great rifts of the eastcentral portions of the continent, the east-west direction is certainly less prominently brought out than the three others; and, as Suess first pointed out, the direction of the meridian is the one most strikingly manifested, and notably in the course of the Nile (Fig. 74, center map).

A study by Spurr of the basin ranges in the western United States has likewise shown that the same four directions - those of the cardinal points and of their intermediate bisecting directions-have played the major rôle in determining the pattern of the displacements. In the earlier studies of the Great Basin region it was assumed that the structure was entirely due to fault displacements, but Spurr was the first to show that while faults may have determined the pattern, folding has also played an important rôle, and the later studies of the Basin ranges, as these have gained importance in mining operations, have supplied ample confirmation for this view (see Fig. 62, p. 133).

It seems to be no less clear that within the areas where arcuate folding is the dominant structure and has imparted its character to the surface configuration, faulting has by no means been absent or without its effect upon the topography. One could hardly hope to find a district where the fold structures are more strikingly displayed in the relief than in the spider-like outlines of the island of Celebes; yet the fracture pattern is also marked, and the faults are in evidence in a characteristic network of which the mer- 


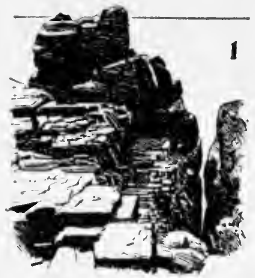

4
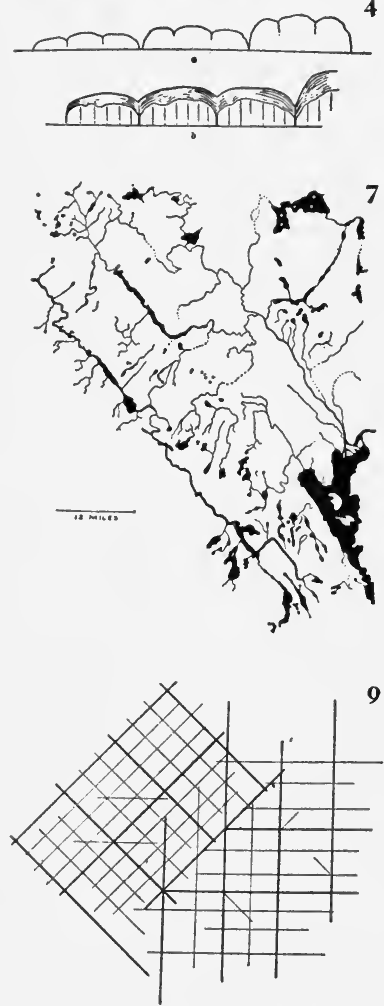

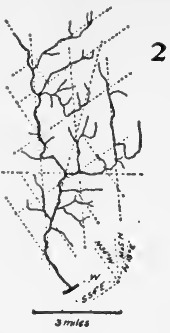

2

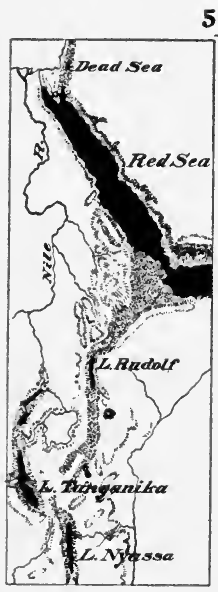

5
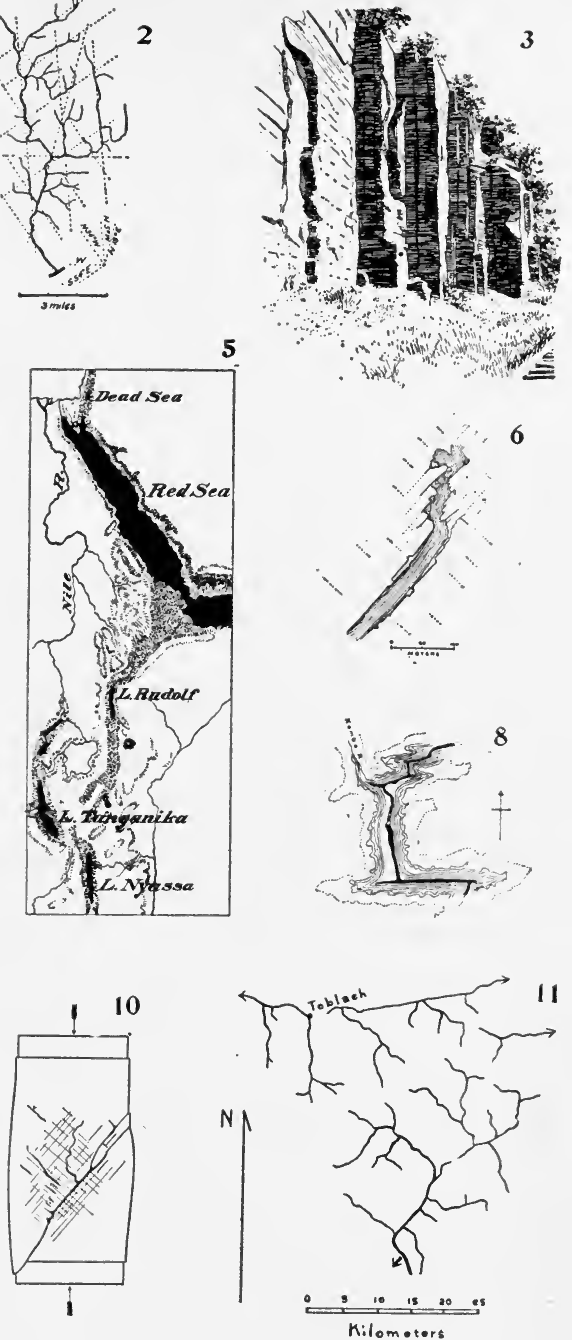

FIG. 74.-Samples of the pattern of the fracture network of the earth. (A), the network itself; 1 , rectangular system of master joints; 3 , escarpement due to master joints in sub-equally spaced series near Cayuga Lake, N. Y.; 4, joint system with composite groups and a patterned fault system evolved from the joint system by displacement, Norwegian coast; 9 , ground plan of the system with pattern changing its position; 10, fractures produced in block of an elastic substance (moulder's wax) by compression from the ends. (B), Imprint of the fracture pattern in the earth's face; 2 , patterned drainage lines of an area in Connecticut; 5, the gigantic fault-rifts of East Central Africa; 6, the fracture controlled course of a canyon in Swedish Lapland; 7, "Checker-board" drainage of Western Ontario; 8, map of the Batoka Gorge below the Victoria Falls, Rhodesia, controlled by the fracture network; 11, drainage of the "dolomites" of the Tyrol controlled by the fracture pattern 
idional and east-west series dominate (Fig. 75). Brouwer, who has done so much to decipher the intricate fold structures within the region of the Dutch East Indies, takes ac-

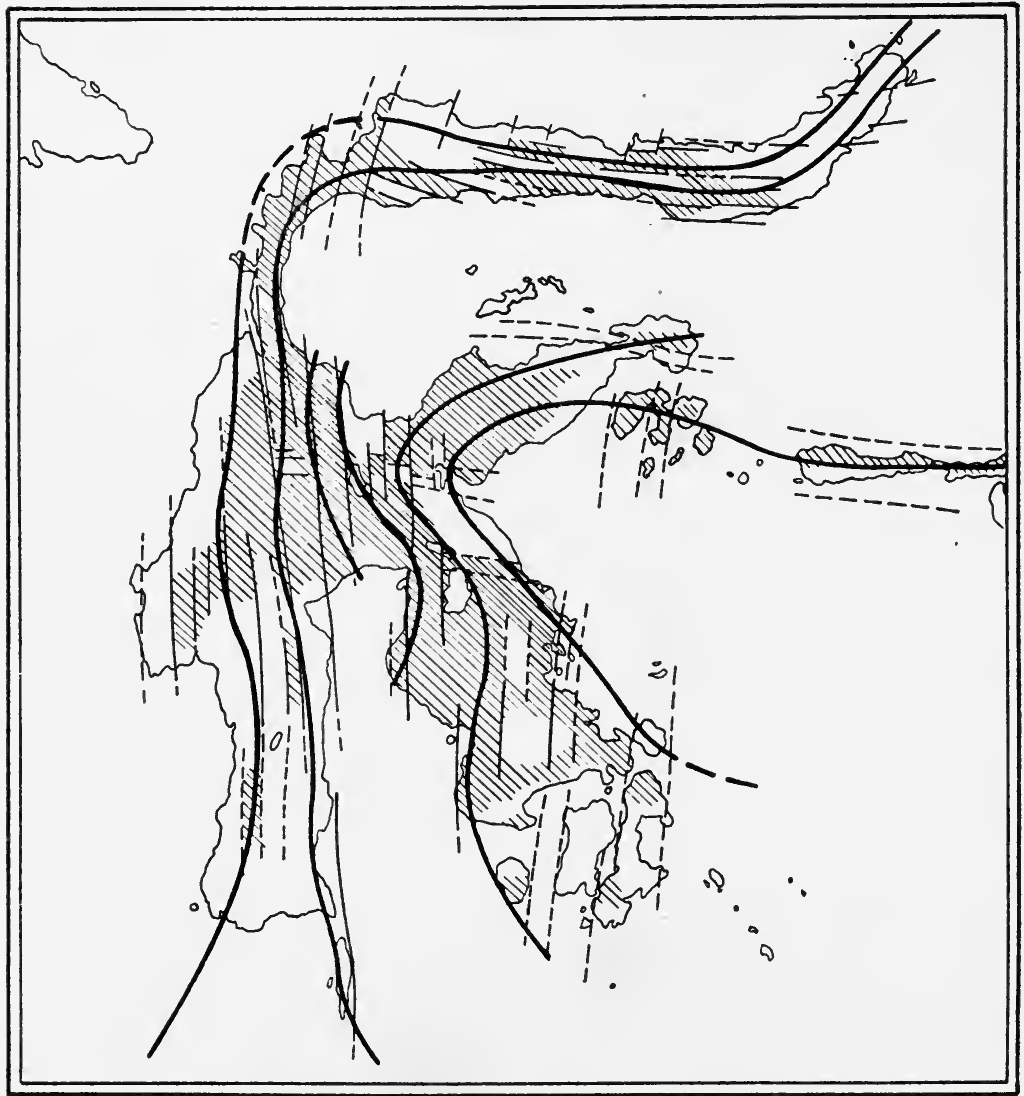

Arcs(heavy lines)and fracture network (light lines) of Celebes(Ahlburg)

FIg. 75.-Map showing the fracture network of the Island of Celebes in its relation to the fold lines (after Ahlberg)

count also of the subordinate fault structures which have contributed their part.

In 1904 and 1905, on the basis of a survey of the field of tectonics, the present writer brought out the fact that there is evidence for a pattern of fractures, made up in part of 
joint fissures and in part of displacements along themfaults; and that this pattern of fractures is at least continental in its extent and probably world-wide. Of this pattern the directions which have determined the mosaic of the African continent-the two cardinal directions and the two intermediate bisecting ones-hold good also through-

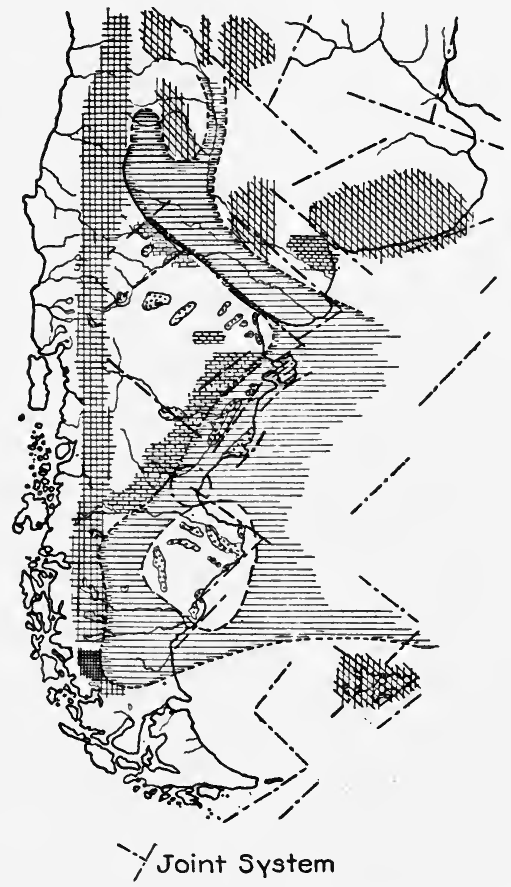

FIG. 76.-Sketch-map showing the prevailing direction of joint fissures in Southern South America (after Windhausen)

out. The results of this study were first published in the Transactions of the Wisconsin Academy of Science, Arts and Letters, and later with greater thoroughness in the Bulletin of the Geological Society of America and in the Comptes Rendus of the International Geological Congress held at St. Louis in 1906.

A few selected examples to illustrate the manner of expression of the fracture pattern in the earth relief are 
brought out by the river networks included in Fig. 74. It was of considerable interest to find that this fracture pattern of the earth largely ignores geological formation boundaries and passes from one district to another apparently little affected in its orientation by the distribution of geological formations. Quite recently this fracture pattern has been found to apply to a considerable portion of the South American continent (Fig. 76).

Inasmuch as in both of the contrasted regions of the globe there is found the evidence of both fault and fold structures within the same strata, it becomes a matter rather of determining which one dominates in the major deformations. Such a result is, moreover, in support of the

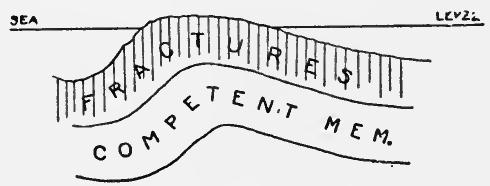

FIG. 77.-Schematic diagram to illustrate the relation of the fractures to the growing anticline

view that the processes of folding and faulting go on simultaneously within the same strata, rather than in separate depth zones, as called for by the theory of the zones of fracture and flow. If, as we have claimed, the element of time is really the vital factor in the problem, there should be greatly subordinated fault structures wherever under pronounced tangential compression the adjustments within the strata go on slowly; but the fault displacements, should, on the other hand, be the dominating ones in those cases where deformation is especially rapid, for in such cases the adjustments may take place within the relaxation time of the strata. At greater depths, and hence under greater loads, the plasticity of the rocks will be correspondingly augmented, and folding is likely to be the dominant type of deformation. Small faults will generally be in evidence at the surface with the measure of the throws on the dis- 
placements of the fracture pattern distributed as required by the developing fold beneath (Fig. 77). The forms of the reefcaps in the islands of the Dutch East Indies, as these have been described by Brouwer, are wholly in accord with this interpretation that the mosaic of blocks within the fracture pattern undergoes adjustments of such a nature as to accomplish a portion of the bending necessary to bring the surface strata into the form of the developing fold.

\section{LITERATURE}

W. H. Hobis. The Newark system of the Pomperaug Valley, Connecticut, 21st. Ann. Rept., U. S. Geol. Surv., part 3, 1901, pp. 162, pls. 17.

W. H. Hobss. The lineaments of the Atlantic border region, Bull. Geol. Soc. Am., vol. 15, 1904, pp. 483-506, pls. 45-47; also Comptes Rendus Congrés Géol. Intern., 1906, pp. 193-203.

W. H. Hosbs. The correlation of fracture systems and the evidences for planetary dislocations within the earth's crust, Trans. Wis. Acad. Sci., vol. $15,1905, \mathrm{pp} .15-29$.

W. H. Hoвss. Repeating patterns in the relief and in the structure of the land, Bull. Geol. Soc. Am., vol. 22, 1911, pp. 123-176, pls. 7-13. See also Earth Features and their Meaning, chap. 17.

J. P. Iddings. A fracture valley system, Jour. Geol., vol. 12, 1904, pp. 94$105, \mathrm{pl}$.

L. V. PIRsson. Crustal warping in the Temagami-Temiskaming district, Ontario, Am. Jour. Sci., vol. 30, 1910, pp. 25-32.

Th. KJerulf. Geologie von Norwegen (authorized German edition by Gurlt of Bonn), 1880, p. 332, fig. 279.

A. Daubrée. Géologie Experimentale, Paris, 1879, pp. 332-375, pls. 3-6.

E. C. HARDER. The joint system in the rocks of southwestern Wisconsin and its relation to the drainage network, Bull. Univ. Wis., Sci. Ser., vol. 3 , no. 5 , 1906 , pp. $207-246$, pls. $1-10$.

A. Windhausen. The problem of the Cretaceous-Tertiary boundary in South America and the statigraphic position of the San-Jorge formation in Patagonia, Am. Jour. Sci., vol. 44, 1918, fig. 3, p. 33.

Siegrried Passarge. Die Kalahari, Berlin, 1904, pp. 79-80 (C. Die Grundlinien im tektonischen Aufbau Südafrikas).

HaNs Simmer. Der aktive Vulkanismus auf dem afrikanischen Festlande und den afrikanischen Inseln, Günther's Münchener Geographischer Studien, no. 18, 1906, p. 24.

J. E. Spurr. Origin and structure of the Basin Ranges, Bull. Geol. Soc. Am., vol. 12, 1901, p. 241.

Johannes Ahrburg. Versuch einer geologische Darstellung der Insel Celebes, Geol. u. Pal. Abh., vol. 16 (N.F., vol. 12), 1913-1914, pp. 172 , pl. 8.

J. G. LIND. Geologische Untersuchung der Beziehung zwischen Gesteinspalten, der Tektonik und dem hydrographischen Netzes des Gebirges zu Heidelberg, Verh. d. naturh. medicin. Vereins z. Heidelberg, N. F., vol. 11, 1910, pp. 7-45, map. 


\section{CHAPTER XIII}

\section{LAVA COMPOSITION IN RELATION TO EARTH PHYSIOGNOMY}

IT is only in comparatively recent times that fruitful attempts have been made in a large way to correlate the distribution of the igneous rock types in respect to geological provinces of the earth. The earlier studies placed all the stress upon supposed fundamental differences being dependent upon the geological age of the magma; while the later ones, made after the age differences had been found to be less important than had been believed, upon the depth below the earth's surface at which the rocks had been consolidated.

The conception of petrographical provinces dates from 1886 , and the rocks within these provinces were recognized as possessing certain family relationships to which the term consanguinity was aptly applied. One of the most striking examples of consanguinity was early discovered in the volcanic rocks of the American Cordillera, and particularly in its southern section, the Andean system of South America. The prevailing type of lava found within this elongated belt is a rock of notably intermediate chemical compositionneither very rich nor very poor in its content of silica, and one characterized by an arrangement of its elongated crystals in waving flow lines, a texture known as andesitic structure.

By Iddings it was pointed out that on the American continent the sub-alkaline group of the andesites in the Cordillera was sharply differentiated from an alkaline group which characterized the areas to the eastward both in the United States and Canada and in Brazil. Harker in 1896 
correlated these separated provinces for the sub-alkaline and the alkaline groups with the Pacific and Atlantic types of coast line as these had been differentiated by Suess, and from this correlation appears to have been derived the use of the terms "Pacific" and "Atlantic" lava types.

In contrast both to the constancy of character and to the near-average rock composition within such a province as that of the Andes, the other type of magmas quite generally represented greater variations both among themselves and in departures from the average magma. As an example we may take the province of the Bohemian Mittelgebirge, and the contrast which it affords with that of the Andes was one of the first to be studied in detail. The types of rock characteristic of these areas are the following:

Bohemian Mittelgebirge
"Atlantic"
Phonolite, Phonolite-
tephrite, Basaltic-
tephrite, Feldspar
basalt, Nephelene
basalt, Leucite basalt,
Essexite, Monchiquite

Andes

"Pacific"

Rhyolite

Dacite

Andesite

Basalt

Essexite, Monchiquite

Just across the arc of the Carpathians from the Bohemian Mittelgebirge is a typical province of the "Pacific" magma, as was pointed out by Judd in the studies which first drew attention to the fact that provinces of special igneous types might be distinguished.

The choice of the terms Atlantic and Pacific as applied to magmas formed within or about the oceans bearing these names, has proved an unfortunate one, as has been pointed out by a number of petrologists. With the earth's surface so divided into two great provinces, examples of both Pacific and Atlantic rocks are to be found in each, while there are others which seem to indicate gradations from one to the other, and these have been termed "Predazzic" after the well known occurrences near Predazzo in the Austrian Tyrol. 
Based on the contrasted groups of rock types represented by the Bohemian Mittelgebirge and the Andes, the chemical characteristics of each group are brought out in the diagrams of Fig. 78, where they may also be compared with the

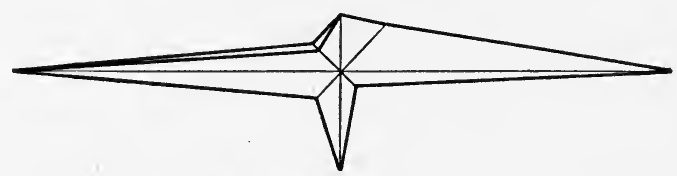

AVERAGE IGNEOUS ROCK

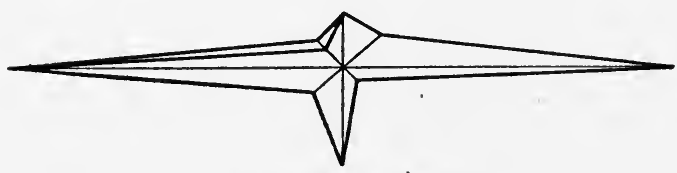

"PACIFIC"IGNEOUS ROCK

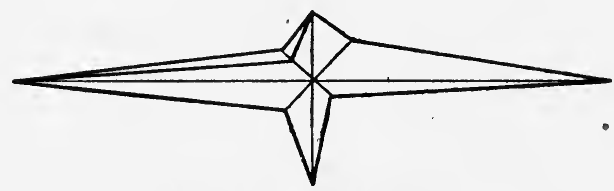

"PredazZic"igneous rock

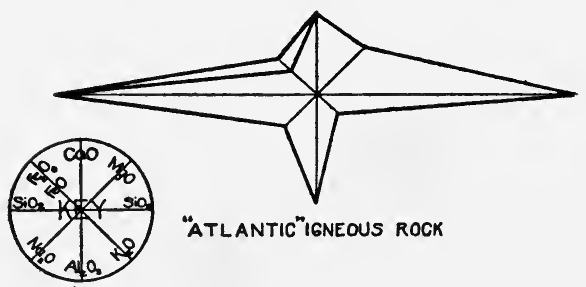

FIG. 78.-Comparison of the average composition of Pacific, Predazzic and Atlantic rock types with the average igneous rock

composition of the average igneous rock. It will be noted that the Pacific type is richer in silica, but poorer in the alkalies and in iron, lime and magnesia than is the corresponding Atlantic type. The Pacific type is obviously of the two much nearer to the composition of the average igneous rock.

It was early pointed out that within many districts where 
there have been successive eruptions of lava, the earliest possessed an intermediate or near-average composition generally corresponding to andesite, that later more siliceous lavas were erupted, and, still later, less siliceous lavas which were either richer in soda or in the constituents iron, lime and magnesia.

We shall here class together under the name of "andesites" the lavas which bear that name and together with them their near relatives, the dacites, trachytes, and rhyolites, and designate them as salic lavas because of their rich-

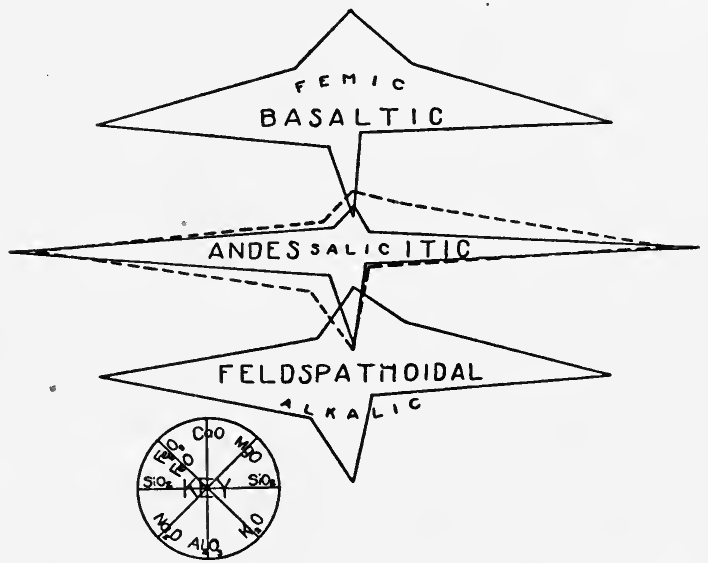

FIG. 79.-Comparative composition of andesitic, basaltic and feldspathoidal lavas

ness in silica and alumina. The later types are by contrast basaltic (femic) or, less commonly, feldspathoidal (alkalic). Composites were prepared from 269 analyses of "andesites" as above broadly defined, 239 basalts and 149 feldspathoidal lavas, the last mentioned usually containing either leucite or nephelene among the mineral constituents. These lava composites have supplied the comparative diagrams of Fig. 79. With them is shown in dashed outlines for purposes of comparison the composition of the average igneous rock. From these diagrams it appears that the earlier eruptions in the sequence so often observed approach closest to the in- 
termediate or average magma, but they are lower in soda and in the femic constituents, iron, lime and magnesia. Had we left out of the composite the dacites and rhyolites which are so generally of somewhat later eruption than the andesites, the resemblance of the "andesite" magma to that of the average igneous rock would have been much closer.

It has been noted also that in a number of districts the low silica lavas of later extrusion, whether these be basalts or feldspathoids, when they have issued in association with mountain arcs have exuded from vents farther back toward

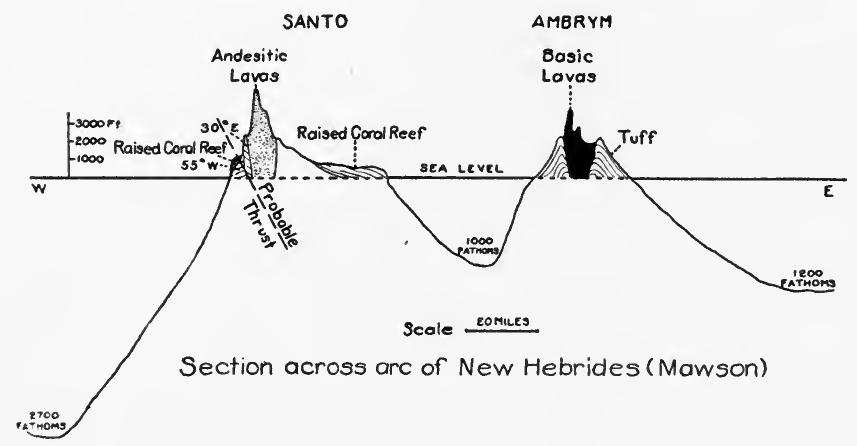

FIG. 80

the rear of the arc than the line of andesite extrusions. This relationship of position has been well established, for example, for the Malayan arc, in which a zone of volcanoes which have extruded leucitic lavas lies to the rear of the great andesite zone of the arc. The same has been shown to be true for the island of Japan, as clearly brought out in the map by Iddings of the distribution of Japanese lavas. Mawson, has added an additional example from the New Hebrides (Fig. 80).

When now we plot upon a map of the world the places of eruption of the andesitic and of the more highly differentiated and generally non-andesitic lava types, most interesting geographical relationships are disclosed. Were we to 
include with the lavas the intrusive igneous rocks and all lavas of whatever age, as has generally been the custom, our map would be hopelessly complex and there would be no means of bringing the nature of the volcanic eruptions into relationship with those movements of the earth's crust which have given it its present facial expression. It is for this reason, we believe, that so much confusion has arisen in the treatment of petrographical provinces. In our general map (fig. 81) we have therefore left out of consideration the intrusive igneous rocks and have included only those lavas which were erupted since the beginning of the elevation of the mountains in late Cretaceous time at or near the close of the long Mesozoic era of geological history. The first observation which is sure to be made from this map is that andesites are associated chiefly with the mountain arcs, and that they do not appear to have been formed to any considerable extent in connection with the contrasted portions of the earth's face, within which the adjustments have been secured largely through block faulting rather than folding. Eruptions of andesitic lava appear, furthermore, to be most general and constant for those arcs which are today rising on the borders of the arcuate mountain regions, and from which in consequence the eruptive history may be assumed to be in its beginnings. This is notably the case for the region of the Dutch East Indies and its extension to the eastward and southward into what has well been called Oceania. In the case of those arcs which have advanced farther in their development we find in addition to the andesites, basaltic and, rarely, felspathoidal lavas also, magma types which have quite generally by petrologists been ascribed to a later differentiation within an originally andesitic magma.

Is there in the process of anticline evolution with attendant fusion of shale beneath the generally competent limestone member, any apparent reason why the lavas should appear in the proportions and in the sequence which has 


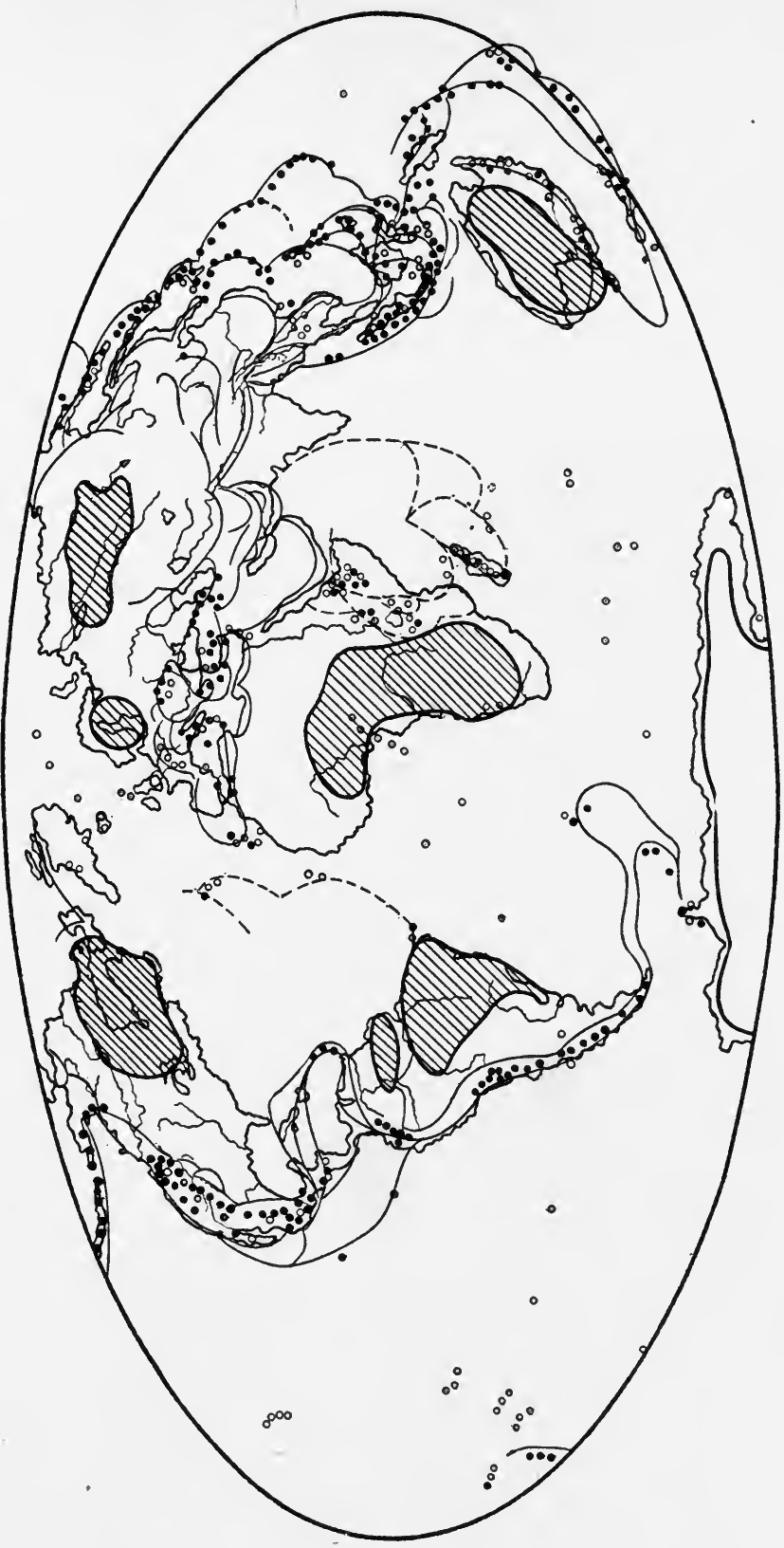

क्ष

坣

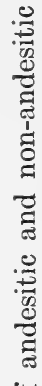

हैं $\overline{0}$

䑸

วัฒ

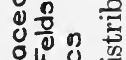

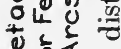

ठ․ำ

产壱)

एक

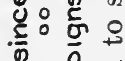

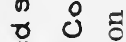

ช 0.0

交镂

ग

कह

乌⿺辶 :

उ०: 
been described-should they in the first instance be largely of intermediate composition, and later develop more sharply differentiated types? The upper section of Fig. 82 has been

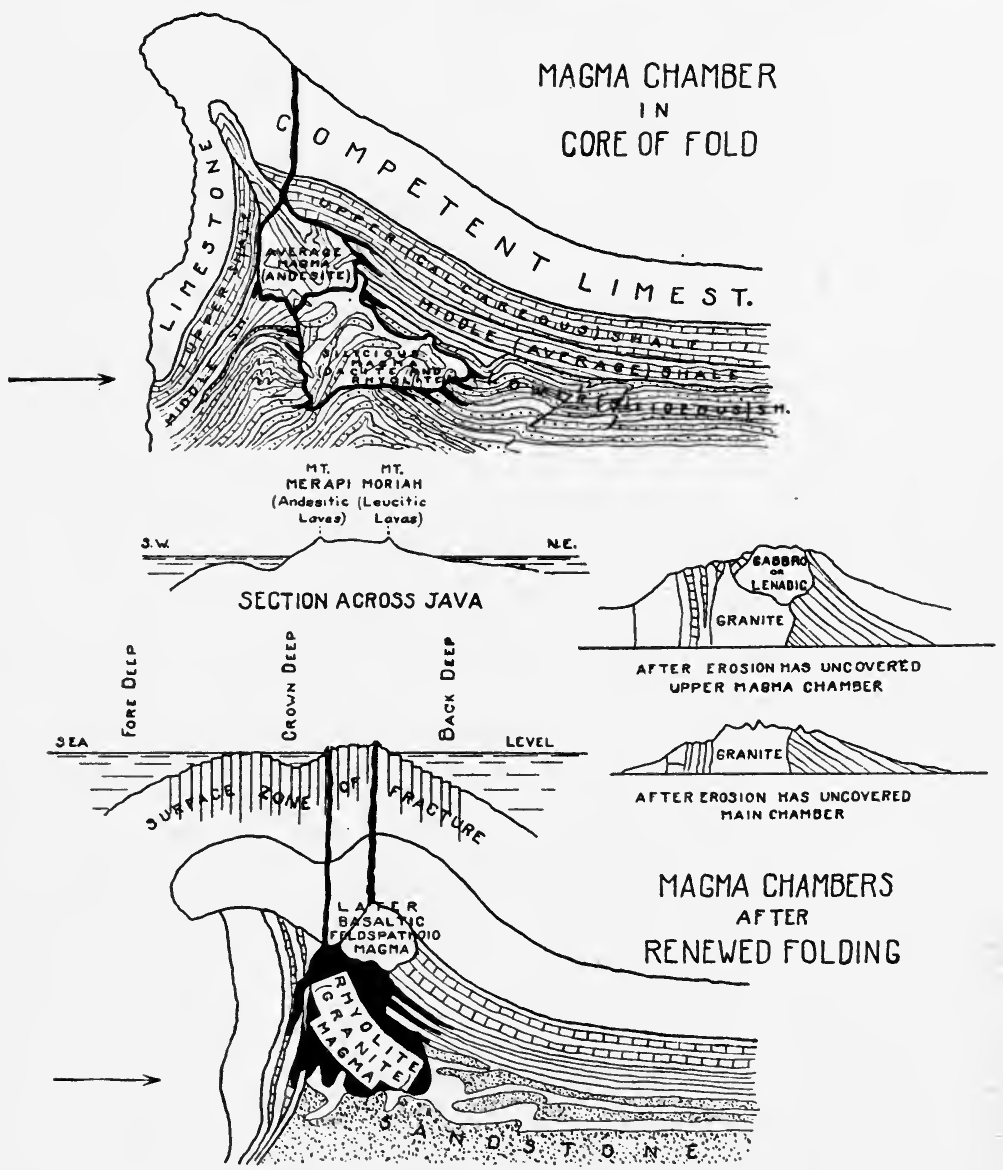

Idealized Successive Sections to Illustrate Splitting of Original Andesitic Volcanic Magmas into Basaltic or Feldspathoid Types

Fig. 82

based upon one of the experiments by Willis where artificial strata were so prepared as to represent shale layers beneath a competent limestone formation and were subjected to 
tangential compression from a direction at the left in the figure. To this experiment we have added the labels to represent the relative positions of the beds within the series on the assumption that the strata were laid down during a transgression of the sea, with the superior limestone separated from the average shale by an intermediate zone of calcareous material having somewhat greater rigidity as well as a higher fusing point than the average shale. Similarly the layers of average shale grade downward into sandstone through a zone of siliceous shale, likewise more difficultly fusible than the normal shale.

In this experiment a partial lifting of the load by the competent layer in the anticline is indicated by the fact that the shale beneath has suffered fracture only within a zone near the axial plane of the fold. Provided temperature and water content are here sufficiently high, a magma chamber may be formed within the space where the shale has been fractured, and of this the superior portion will, as appears from the section, approximate the average composition of the shale formation, which is also that of the average igneous rock. Somewhat later fusion of the fractured portions of the siliceous shale in an inferior position may be accomplished, and this magma being of lower density, should in time through convectional currents either mingle with the andesitic magma above or else rise through it to the upper portion of the chamber. In either case the result will be to bring to the portion of the chamber which can be connected with the earth's surface, a lava more siliceous than that which first occupied this position. If lavas are connected up to the surface through a conduit rising from the magma chamber, the order of eruption would then be andesites followed by the more siliceous dacites or rhyolites.

In the process of folding the initial anticline is first relatively symmetrical and increases in competence up to the stage of underturning, where it quickly loses competence but increases its rigidity in respect to transmitting the 
stresses forward. The consequence is that the deforming compressional stress when the underturning has been accomplished tends to be carried on through the underturned arch and rears a second but generally less pronounced anticline at the back of the first, and still later in succession perhaps a third or even a fourth. This order is amply illustrated by practically all of Willis' experiments, which do not however permit, owing to the rigidity of the piston in the apparatus, that possible anticlines should develop at the front as well as the rear of the original arch, but with the front anticlines the smaller. There is reason to believe that in rock strata both these types of secondary anticlines may develop even though the experiments bring out the mechanical possibility only of those which form at the rear. The effect of such a secondary anticline formed in the later stage of anticlinal development at the rear of the original arch, would by its lifting of the load in the new position tend to extend the original magma chamber upward at the back into the calcareous shale immediately beneath the competent member. Such layers upon fusion should develop lavas lower in silica than the average lava and richer in lime and magnesia and probably in iron as well. These lavas belong in the classes of basaltic and feldspathoidal magmas and are of notably greater density. If gravitational effects in convection currents produce either a mingling of these lavas with the earlier andesitic or rhyolitic lavas, or settle down through them, the effects will be the emission at the surface, first, of basaltic or feldspathoidal lavas, or both, followed by more acid andesitic or rhyolitic extrusions. If the extension of the magma chamber becomes connected with the earth's surface through a newly opened conduit, the later extrusions should reach the surface in a zone behind that of the earlier extrusions of andesites and rhyolites, as they so often have done.

Of volcanoes which are directly associated with the formation of arcuate mountains, the order of extrusion of the 
lavas is a matter of such significance that it seems best to assemble the facts from many districts. This has been done in the following table:

Sierra Nevadas of California, Grizzly Peak.

1 , andesites, 2 , basalts.

Cascade Range, Northern Portion.

1 , rhyolite and basalt, 2 , andesite, 3 , rhyolite, 4 , basalt.

Cascade Range, Lassen's Peak.

1 , andesite, 2 , quartz basalt.

Sierra Madre, Mexico.

1 , andesite, 2 , dacite, 3 , rhyolite, 4 , basalt.

Isthmus of Panama.

1, pyroxene andesites, 2, rhyolites and quartz latites, 3, pyroxene andesites and basalts.

Rocky Mountains, Castle Mountain Dist.

1 , basalt, 2, rhyolite, 3 , basalt.

Rocky Mountains, Black Hills.

1 , andesite and rhyolite, 2, phonolite.

Rocky Mountains, Yellowstone National Park.

1 , dacites and andesites, 2, andesites and basalt, 3, siliceous andesite, 4 , basaltic varieties, 5 , rhyolites and basalts.

Rocky Mountains, Silver City, Colo.

1 , andesite, 2 , dacite, 3 , rhyolite, 4 , andesite, 5 , trachyte, 6 , basalt. Rocky Mountains, West Elk Mts.

1 , andesite, 2 , rhyolite.

High Plateaux of Utah.

1 , andesite, 2 , more siliceous andesites alternating with pyroxene andesites and basalts, 3 , rhyolites, 4 , basalts.

West New Mexico and Eastern Arizona.

1 , rhyolite, 2 , andesite, 3 , basalt, 4 , rhyolite and basalt.

Goldfields, Nevada.

1 , andesite, 2 , rhyolite, 3 , andesite, 4 , dacite, latite and rhyolite, 5 , quartz basalt, 6 , rhyolite, 7 , olivine basalt.

Great Basin (part)

1 , andesite, 2, trachy-andesite, 3 , andesite, trachyte, and rhyolite, 4 , rhyolite, 5 , olivine basalt.

Central Cordillera in Chile.

1 , dacite and rhyolite, 2 , andesite, 3 , hypersthene andesite and basalt.

Graham Land, West Antarctica.

1, dacite and andesite, 2, basalt.

Mitylene, Asia Minor.

1, rhyolitic trachyte, 2, obsidian, 3, various andesites in succession, 4 , basalt.

Siebenbürgen, Hungary.

1 , andesite, 2 , rhyolite, 3 , basalt.

Central Plateau in France.

1 , trachtye and rhyolite, 2 , many varieties from trachyte through Japan. phonolite to basalt, 3 , basalt.

1 , andesite, 2 , basalt.

If now in turn we take into consideration the lava extrusions which have occurred outside the region of arcuate 
mountains, we discover at once not only that andesites are relatively rare and that feldspathoids are noticeably abundant, but also that the sequence of the lava types is in a marked degree different. This will appear from a few examples:

Northern British Isles, Iceland, Hebrides, Faroe Islands and

Portions of Greenland.

1, dolerites and basalts, 2, andesites and dacites.

Bohemian Mittelgebirge.

1, basalt, 2, feldspar basalt, 3, nephelene and leucite bearing lavas, 4, phonolites.

Canary Islands.

1, feldspathoids and pyroxene andesites, 2, basalts.

Gran Canaria, Canary Islands.

1 , basalt, 2, trachyte and phonolite, 3, basalt and phonolite.

Great Rift Valley, Africa.

1 , phonolite, 2 , basalt and phonolite, 3 , feldspathoids and basalt.

Mount Kenia, Africa.

1 , phonolite, 2, basalt.

Spitzbergen.

Feldspathoids throughout.

Iceland.

Very largely basalts but with later soda rhyolites.

Azores and Madeira.

Chiefly basalts and feldspathoids.

Gulf of Guinea.

Chiefly basalts with limburgite and andesite.

Ascension.

Mostly feldspathoids.

St. Helena.

Basalt and phonolite.

Tristan de Cunha.

Feldspar basalt with some hypersthene andesite.

San Francisco Mt., Arizona.

1 , basalt, 2, andesite, 3 , basalt.

South Victoria Land, Antarctica.

1, basalt and rhyolite, 2, feldspathoids, 3, basalt.

In order to compare the Cretaceous and Tertiary volcanic rocks, which have clearly been associated with arcuate mountains, with other lavas of the same general period which are associated with major fault displacements and are outside the zones of arcuate mountains, we have assembled nearly one thousand of the superior analyses derived largely from the tables of Washington and Iddings, ranged them in the two groups, and from these have in each case prepared the composite or average. In this work the author has been assisted by Miss Ellen Stevenson. The results which are 
set forth in the following table and in Fig. 83, while they show a general resemblance of the two classes to the socalled Atlantic and Pacific types of lava, yet reveal even more clearly that the average lava of the zones of arcuate mountains is very closely in correspondence with the average igneous rock, and that the typical fault-block lava differs widely from this, chiefly because it is lower in its

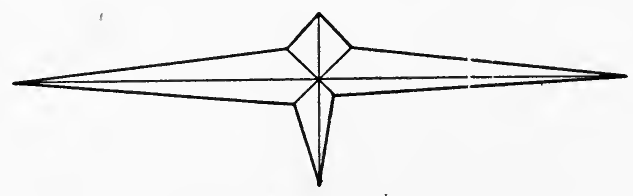

Arcuate Młn.(Fold) Lava

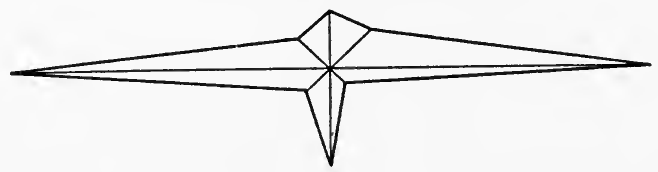

Average Lava

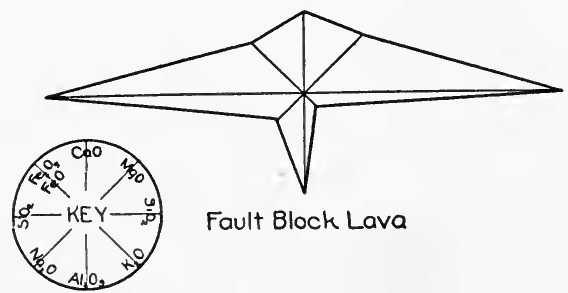

FIG. 83.-Diagrams to illustrate the average composition of arcuate mountain (fold) lava and fault-block lava in comparison with the average magma

content of silica and notably higher in its content in lime, magnesia and iron.

The lava analysis found to represent the zone of arcuate mountains is a composite of 776 separate analyses of rocks from the Pacific belt and its extensions in the Malayan region. Europe has not been included, because of the vast number of analyses which would have to be handled. In these analyses the rarer constituents, which are not taken 
into account, are somewhat more abundant in the faultblock type of lava.

\begin{tabular}{|c|c|c|c|}
\hline & $\begin{array}{l}\text { Arcuate Mtn. } \\
\text { (Fold) Lava } \\
\text { (Composite of } \\
776 \text { analyses) }\end{array}$ & $\begin{array}{c}\text { Average } \\
\text { Magma } \\
\text { (Composite of } \\
5602 \text { analyses) }\end{array}$ & $\begin{array}{c}\text { Fault Block } \\
\text { Lava } \\
\text { (Composite of } \\
188 \text { analyses) }\end{array}$ \\
\hline $\begin{array}{l}\mathrm{SiO}_{2} \\
\mathrm{Al}_{2} \mathrm{O}_{3}\end{array}$ & $\begin{array}{l}58.29 \\
16.97\end{array}$ & $\begin{array}{l}59.09 \\
15.35\end{array}$ & $\begin{array}{l}49.52 \\
15.89\end{array}$ \\
\hline $\begin{array}{l}\mathrm{Fe}_{2} \mathrm{O}_{3} \\
\mathrm{FeO}\end{array} \ldots$. & 6.94 & 6.88 & 11.50 \\
\hline 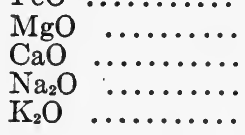 & $\begin{array}{l}2.83 \\
6.06 \\
3.55 \\
3.20\end{array}$ & $\begin{array}{l}3.49 \\
5.08 \\
3.84 \\
3.13\end{array}$ & $\begin{array}{l}5.04 \\
7.27 \\
4.03 \\
2.18\end{array}$ \\
\hline & 97.84 & 96.86 & 95.43 \\
\hline
\end{tabular}

If now we endeavor to find in the theory at which we have arrived to account for the origin of the magmas associated with block faulting, a reason for the generally basaltic or
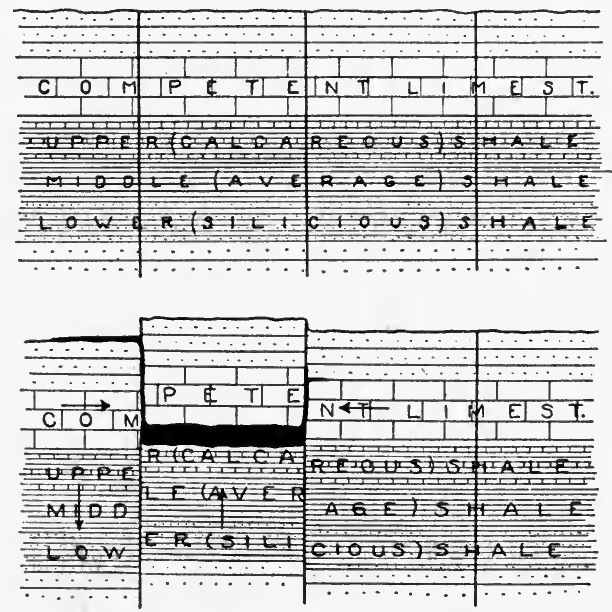

DIAGRAM TO ILLUSTRATE A MANNER OF FORMATION OF MAGMA CHAMBERS BY BLOCK FAULTING

FIG. 84

feldspathoidal magma types characteristic of such regions; the solution would appear to lie in the special zones of the shale formation in which fracture occurs beneath the heavier formation when this is thrown upward in the proc- 
ess of block faulting (see ante Fig. 10 and Fig. 84). If this fracturing occurs within the calcareous portions of the shale formation in the position closer to the heavier overlying limestone, the result will be to yield basaltic or feldspathoidal lavas rather than the intermediate andesitic lavas. The field observations would incline us to this assumption if the fundamental premise is not at fault, and if later the zone of fusion is extended downward toward the average shale near the middle of the formation, the later extrusions would tend to show more of the andesitic phases. : The order of extrusion would thus be the reverse from that which is characteristic of the contrasted type of volcanoes associated with arcuate mountains.

\section{LITERATURE}

JoHN W. JudD. On the ancient volcano of the district of Schemnitz, Hungary, Quart. Jour. Geol. Soc., 1876, p. 292.

JoHs W. JudD. On the gabbros, dolerites, and basalts of Tertiary age in Scotland and Ireland, ibid., 1886.

F. BECKER. Die Eruptivgebiete des böhmischen Mittelgebirges und der amerikanischen Andes, Min. Pet. Mitt., vol. 22, p. 209.

A. HARKER. The natural history of igneous rocks, London, 1909.

J. P. IDDings. Igneous rocks, vol. 2, 1913, part 2, Occurrence of igneous rocks, pp. 343-685.

H. S. Washington. Chemical analyses of igneous rocks, Prof. Paper 99, U. S. Geol. Surv., 1917, p. 1201.

M. Stark. Petrographische Provinzen, Fortschritte d. Min. Krist. u. Pet. edited by G. Linck), vol. 4, 1914, pp. 251-336 (valuable for literature also).

P. Marshall. Oceania, Handb. Reg. Geol., vol. 7, abt. 2, 1911, pp. 28-32.

J. P. IDdings. The problem of volcanism, New Haven, 1914, p. 273, map at end. 


\section{CHAPTER XIV}

\section{EARTH THEORIES IN RETROSPECT}

Anyone who has examined into the history of the theories of earth evolution must have been astounded to observe the manner in which the unique and the difficultly explainable has been made to take the place of the common and the natural in deriving the framework of these theories. The part of the accidental and fortuitous has been by no means a small one in guiding the thoughts and the speculations of those who have dealt with the fundamental theories of the universe.

The unique rings of Saturn gave shape to the nebular hypothesis. The almost unique properties of water near its temperature of congelation was largely responsible for the idea of a molten earth core, long the orthodox doctrine of geological science. The unique rigid mass of Bohemia near the arcs of Europe and that of India near those of Asia, largely determined the form of the Suess conception of arcuate mountains. The centrum theory of earthquakes, which assumed a shock to go out from a subterranean chamber, grew out of the peculiar experience of Robert Mallet in the designing of heavy artillery for the Crimean War.

Those theories which have come to receive general support and so have been able to supplant earlier ones, have quite generally owed their success to the unusual prestige of their promulgators by reason of some outstanding piece of investigation, though this may have been in a different field from that of the theory that has been added to the body of orthodox doctrine. This was notably true of Laplace and 
his great work, the Mechanique Celeste, in which the famous nebular hypothesis is contained as an apparently little considered afterthought appearing as an appendix. There seems to be a rather general opinion that a large and meticulously precise piece of research involving the assembly of a great body of data, necessarily fits a worker to reach correct judgments; though it may well be that his ability to handle detail militates against the forming of broad correct generalizations based upon an ability to evaluate the mutual relationships of the facts and principles involved.

Once accepted by the leaders of thought, the position of a new theory is one peculiarly immune from attack. If its rise to prominence is in any way sensational, the theory becomes as it were, in a measure canonized and clothed with a quality of sanctity. Attacks upon it are welcomed as little by the scientific profession as they are by the promulgator of the theory. The Einstein theory of relativity, which is just now in the saddle, receives extravagant praise, and the voices of those who point out its fallacies are lost in the thunder of applause. A great scientific weekly offers a prize for the best essay upon the theory, but with the proviso that this essay be in support of the doctrine. Unfavorable criticism is taboo.

It is this sacrosanct attribute of an accepted theory in science which alone can explain the persistence of a false doctrine, even when its errors can be easily detected by the application of rigid tests. How else could the nebular hypothesis have endured, though so glaringly in error when examined with regard to the distribution of velocities of rotation, of total energy, and of moments of momentum?

No less remarkable is the reluctance after a theory has been proven to be untenable, to abandon the auxiliary theories which have been founded upon the discredited one, and which are now found to be out of harmony with the corrected viewpoint. This has been especially true of the theories which have been based upon the nebular hy- 
pothesis. Though the conception of a molten earth interior has perforce been abandoned, there has been a noteworthy unwillingness to accept the consequences and to take up de novo the related and dependent problems. Thus we find an impelling urge to assume in the place of a liquid earth interior, at least a continuous substratum of lava between a rigid core below and a solid crust above. It is clear that if such a stratum is assumed those theories which have grown out of the nebular hypothesis can survive unchanged.

The theory of the permanence of the ocean basins when found to be hopelessly in opposition to the later discoveries in faunal geography, instead of being abandoned by those who had supported it, was adjusted to the later knowledge by throwing narrow "bridges" across the oceans, bridges sufficiently wide at least for the animals to advance over them two by two in the decorous fashion in which they are supposed to have entered the Noachian ark. The abandonment of the centrum theory of earthquakes caused but little change in the then orthodox method of preparing seismic maps, which still continued to be brought out with their "epicenters," "isoseismals," and "coseismals," though these could have no existence unless there be a unique focus from which the shocks have emanated.

It is this quite natural reluctance to repudiate long cherished doctrines which has made the real transition from one fundamental viewpoint to another that is to supplant it, cover periods measured in decades rather than in years.

In the foregoing pages we have gone out from the assumption that several theories occupying a fundamental position in the science of geology must now be abandoned as untenable. The nebular hypothesis with its natural offspring, the doctrine of a molten earth interior, we believe the consensus of scientific opinion now places in the category of theories which under the application of rigid tests have been found wanting. Upon the other hand, the 
dactrine of the subterranean zone of flow and the view of Suess concerning the direction of thrust in the evolution of mountain arcs, are theories rather generally accepted by the geologists who have studied the questions. None the less we believe that neither of these theories is tenable, and at some length we have set forth the basis for our belief.

The arcuate island groups in the Pacific with their attendant ocean deeps are believed to outline the positions of developing folds within the near-surface strata. A universal subjacent reservoir of magma beneath the earth's outer shell being, as we believe, no longer available to account for the source of lava and its attendant gases and vapors; we have sought for an available source and believe that one is found in the fusion of shaly sediments beneath rising anticlines and beneath upthrown blocks of the fault mosaic. Both the lavas themselves and their attendant emanations find an explanation in this theory of origin. For the first time an explanation is found for the strictly limited range in chemical composition of volcanic lavas.

Certain facts which have hitherto appeared as paradoxical because their causes were obscure, have been given a relatively simple explanation. The long established fact of the occurrence of block mountains within growing mountain belts has required that these belts should be characterized by tensional stress conditions, although the evidence for such a system was notably wanting. It has here been shown that the conditions are in fact the reverse of those that had been supposed, and that the system of stresses within the zone of rising mountains is not tensional but compressional, and that the sea-floor is pushed up onto the seaward slopes of the rising mountains by an amount more than sufficient to compensate for the expansion of the surface. Thus, moreover, is found a cause for the erection of mountains upon the borders of the sinking ocean basins.

Again, the more recent developments of seismology have been drawn upon to account for the great outflows of lava 
within block-faulted regions. Lastly, a comparison of the lavas which have been forced up to the surface in connection with the growth of arcuate mountains, with those erupted in connection with major fault-block adjustments, has brought out the fact that these lavas are essentially in contrast; and that the former approach in composition to the average igneous rock, whereas the latter type is of different composition and to a notable degree more differentiated and variable.

A general conclusion which has been drawn from these studies is that it has been customary greatly to overestimate the span of geological time, and this largely because of the accident of location of those who have studied geological processes. Had the early universities been located within the Pacific area, rather than about the Atlantic; had geologists made their investigations within those belts of the earth which are undergoing rapid change; the orthodox view concerning the time which has been necessary for the accomplishment of the past geological changes would have been found to be a fraction only of that which it is now supposed to be. 


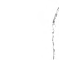






\section{DAY USE}

RETURN TO DESK FROM WHICH BORROWED

\section{LOAN DEPT.}

This book is due on the last date stamped below, or on the date to which renewed.

Renewed books are subject to immediate recall.

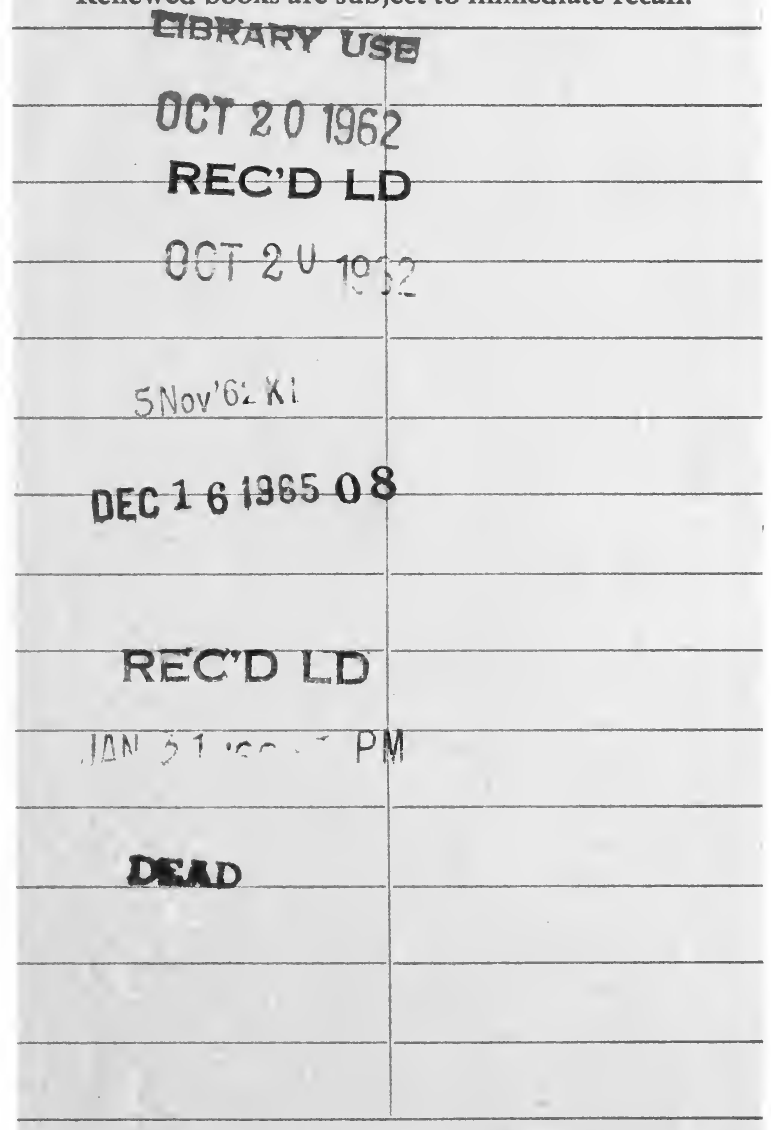

LD 21A-50m-3,'62

(C7097s10) 476B

General Library

University of California Berkeley 

W

(W)

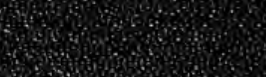

2.

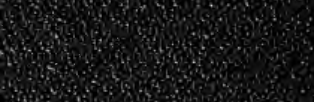

W.7.

W.7.

W.

(9.

H.

H.

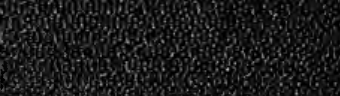

2.

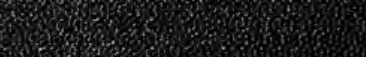

7.

H.

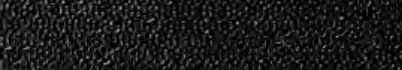

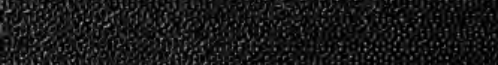

H.

D.

H.

7.

H.t.

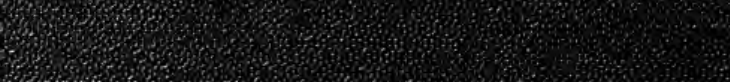

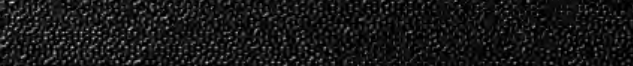

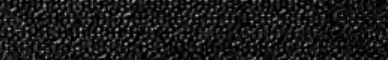

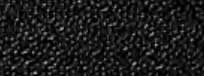

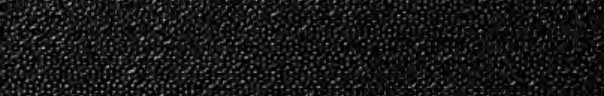

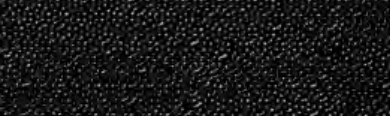

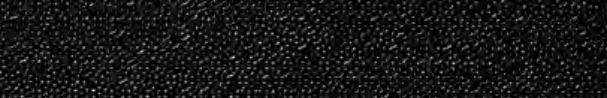

